\title{
Agile-Stage-Gate Approach: Exploratory Research on the Structure, Roles, and Responsibilities
}

\author{
By Ali Eljayar ${ }^{*}$ \& Jeff S Busch ${ }^{ \pm}$
}

\begin{abstract}
One of the most prominent methodologies gaining recognition in recent years is the Agile-Stage-Gate approach. The relatively new hybrid model is a combination of the Stage-Gate and the Agile-Scrum models. Several companies already using the StageGate process have recently adopted the Agile-Stage-Gate approach to improve product development and project management. However, each of these companies has added their adjustments and modifications to the new approach in order to accommodate their specialized needs and to achieve the goals that are unique to their company. Therefore, no fixed structure or standardized features have been explicitly assigned to this hybrid approach. Instead, each company has added on different features and manipulated the new approach to fit whatever needs arise from moment to moment. This ambiguity leads to the question of whether the structure, roles, and responsibilities of this new approach can be defined and if so, how these clear and consistent definitions can improve productivity, efficiency, communication and market response time. The purpose of this study is to explore the structure, roles, and responsibilities within this new approach and to identify patterns that emerge during the product development and project management processes. The research questions presented were administered and examined through a qualitative survey. Fifty-two complete responses were collected from experienced individuals who have varying degrees of experience with the AgileStage-Gate approach. These findings revealed many similarities and differences between the structure, roles, and responsibilities of this approach, which were also dependent on the product and project type being considered. The most apparent similarities between roles and responsibilities were found in the case of software products and new product development projects. The Agile-Stage-Gate approach has also had a significant and undeniable impact on team communication and performance and was shown to improve overall quality and productivity.
\end{abstract}

Keywords: agile, stage-gate, customer, scrum, sprint, hybrid, ideation, combination products, backlog, retrospective

\section{Introduction}

\section{Background of the Agile-Stage-Gate Approach Research}

The nature of new product development is characterized by complexity and uncertainty in most cases. Companies are racing to be the most innovative and to react quickly to market changes. The unpredictable nature of this process places manufacturers under highly-competitive pressure. Organizations are required to keep their product development systems up to date and maintain a level of innovation in order to retain high customer satisfaction. Each organization must

* Graduate Student, Portland State University, USA.

${ }^{ \pm}$Senior Consultant and Adjunct Professor, Portland State University, USA. 
also determine how to introduce their new product to the market in a relatively short time while staying within their predetermined budget and scope. The complexity and uncertainty associated with product development make it difficult for companies to deliver the product on schedule and within budget, all while maintaining high levels of quality. Therefore, companies must prioritize creativity in order to continuously adapt to the rapidly changing industry environment by both modifying and transforming their way of thinking and doing things. This openness to transformation will allow companies to remain adaptive, instead of solely predictive.

One of the most noticeable methodologies that has gained recognition in recent years is the Agile-Stage-Gate hybrid approach. Some companies have adopted this hybrid approach to reduce time-to-market and to respond to changing customer requirements more quickly. The Agile-Stage-Gate approach is a combination of the Stage-Gate model and the Agile-Scrum model, which will be discussed in detail later. The framework of the Stage-Gate model is used to manage New Product Development by following a sequence process and a plandriven focus, whereas agile models (such as Scrum, used widely in the software industry) focus more on customer feedback and short-term outcomes that require immediate attention.

\section{Statement of the Problem}

Several companies that already use the Stage-Gate process have recently adopted the Agile-Stage-Gate approach for new product development. However, each of these companies has also added adjustments and modifications to the hybrid model in order to accommodate their system needs and to achieve their ultimate goals. Therefore, there are no fixed structures or standardized features explicitly assigned to this hybrid approach. Instead, each company adds on different features and manipulates the hybrid model to fit their immediate needs. This research therefore focuses on defining the structures and features of this new approach as well as identifying the roles and responsibilities associated with it in order to discover consistent definitions that lead to improved productivity, efficiency, communication and market response time.

\section{Purpose of the Study}

Many authors have already discussed different aspects of the Agile-StageGate approach. However, few have outlined the fluid changes in roles, responsibilities, and structure associated with the hybrid model and the patterns that emerge when applied to different products and projects. This paper aims to explore the current version of the Agile-Stage-Gate approach when developing different products (such as software, hardware, and combination products), as well as different project types (such as New Product Development, R\&D, and projects that provide a service to customers). This study will focus on companies that implement Stage-Gate first and then adopt the new approach. This research will also identify the recurring structures, roles, and responsibilities that define this hybrid approach. 


\section{Research Questions}

This project will address five research questions (listed below) to outline exactly what will be covered in the research and how the purpose of this study will be fulfilled.

RQ1: What is the structure of the Agile-Stage-Gate approach when applied to the different products (software, hardware, and a combination of both) and within different projects (New Product Development, R\&D, and a project that provide a service to customers)?

RQ2: What team roles are instituted by companies that use the Agile-StageGate approach?

RQ3: What are the responsibilities of each team role when the Agile-StageGate approach is in use?

RQ4: What effect does the Agile-Stage-Gate model have on project team quality, specifically pertaining to 1) communication and 2) coordination?

RQ5: What is the long-term strategy and vision of each company that applies the Agile-Stage-Gate approach?

\section{Assumptions and Limitations}

Although this paper will provide a brief overview of both Agile and StageGate models separately (including the structure, roles, and responsibilities of each), the main focus will remain on the structure, roles, and responsibilities associated with the Agile-Stage-Gate hybrid approach. In addition, the associated benefits and improvements produced by adopting the hybrid model will remain a focal point. The aim is not to focus on the details of each separate model, nor how each stage or sprint is functioning individually. Instead, the organization and communication of team dynamics will be examined, along with how each different type of team operates within the project team as a whole and within the rest of the organization.

\section{Literature Review}

In this section, established information from current and previous research will be presented regarding the Stage-Gate, Agile-Scrum and Agile-Stage-Gate project management methods, which is the main focus of this paper. This section also will provide extensive information from different industry papers about what has already been examined regarding the Agile-Stage-Gate approach in terms of the structures, roles, and responsibilities of this approach, along with project team organization and resources for each implemented method.

\section{Stage-Gate Models}

The Structure and Principle of Stage-Gate Models

The Stage-Gate approach was adopted by industries world-wide around 1990. Since then, it has become a well-known model used to manage New Product 
Development. The model is designed to move a new product from idea to launch (Cooper 1990). It aims to drive new product projects to the market, both quickly and effectively. The model's structure is made up of stages and gates, with each stage composed of a set of prescribed cross-functional and parallel activities (following a typical 5-stage/5-gate process, as shown in Figure 1).

In each stage, the project team members execute tasks and take action to move the project forward. The necessary pieces of information related to each stage are compiled and monitored closely in order to reduce risk and uncertainty (Cooper 2006). A gate follows each stage, at which time a Go/Kill decision is made. Each of these gates also serves as a checkpoint and a function of quality control to ensure that the project is executed correctly. Over the past few decades, Stage-Gate models have evolved from a simple linear process to a more dynamic and integrated process that can quickly respond to market changes and customer needs (White 2008).

Figure 1. Flow of a Typical Stage-Gate Model

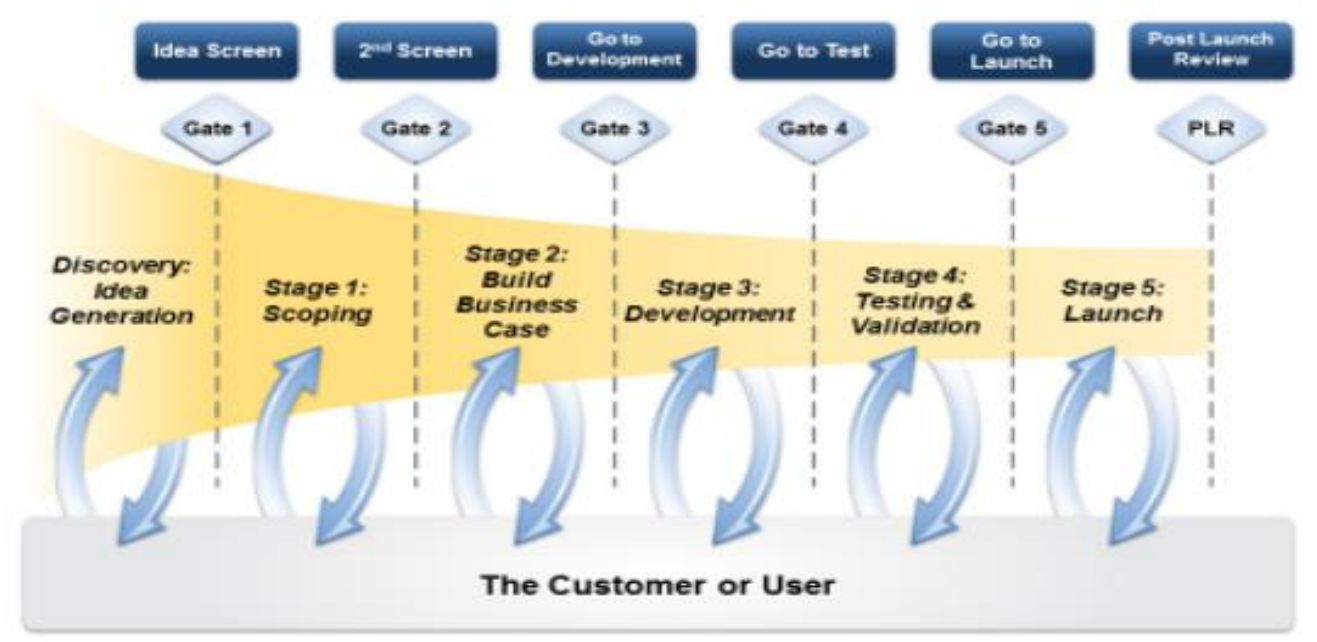

Source: Cooper 2010.

The phase of Discovery is designed to discover business opportunities and provide new ideas.

1. Scoping: The primary purpose of this stage is to build a robust understanding of the project and define the general scope of the product (Cooper 2015, 2010).

2. Building a business case: The selected ideas are tested and developed in regards to technical, financial, market and operational aspects. This phase aims to ensure that the product is feasible and corresponds to the market requirements. A more detailed and in-depth investigation takes place, justifying the project and planning a robust business case (Cooper 2015, 2010).

3. Development: At this point, a specific criterion for the new product must be met in order to move into this stage. The project team develops a 
detailed design of the new product and the result of this stage is a labtested product (Cooper 2015, 2010).

4. Testing and validating: A complete paradigm is tested and validated in this phase to determine if there are any required changes before moving on to the last stage. Marketing and branding validation is also checked and tested (Cooper 2015, 2010).

5. Launch: In this stage, the commercialization process begins with a full operation of production. The market and distribution plans are executed and the project team is now ready to launch the product (Cooper 2015, 2010).

6. Gates: Before each stage, there is a gate where a Go/Kill and prioritization decision is made. These gates serve as quality control checkpoints to ensure that the product has successfully met the six proven criteria, which include 1) Strategic Fit, 2) Product and Competitive advantage, 3) Market Attractiveness, 4) Technical Feasibility, 5) Synergies/Core Competencies and 6) Financial Reward. By applying these criteria, any mediocre projects are culled out at each gate. These gates are usually monitored and controlled by senior managers from different functions. They are called the gatekeepers and they own the resources required by the project leader and team for the next stage (Cooper 2015, 2010).

\section{Stage-Gate Roles and Responsibilities}

Project team members in all organizations and projects need to thoroughly understand their roles and responsibilities in order to complete their specific tasks and participate effectively in the project development. Roles and responsibilities are an imperative component of the Stage-Gate model and are considered to be one of the five primary artifacts of the Stage-Gate approach. In his book "Winning at new products", Dr. Cooper, who introduced the Stage-Gate model for the first time in 1986, outlines the specific roles that are vital to the success of the StageGate model. These include Project Team Members, a Project Leader, a Project Manager (optional), Gatekeepers, a Process Manager, and an Executive Sponsor (Cooper 2011).

Project Team is made of members from different departments (such as technical, marketing, operations, and sales) who come together to create a cross-functional team. Usually, the team starts the project and is accountable for accomplishing their individual tasks, and the project deliverables within the designated time frame.

Project Leader is a member of the Project Team and plays a critical part in terms of leading by promoting the project, managing resources, and handling the external interfaces of the project with senior management.

Project Manager is an optional role for the smaller project because the Project Leader is also able to act as Manager. The responsibility of the Project Manager is to ensure that the project functions well, and the project team utilizes the project management tools and methods appropriately. 
Gatekeepers form a cross-functional group that is usually made up of senior management. This group owns the resources for the project and makes the $\mathrm{Go} /$ Kill and prioritization decisions.

Process Manager is assigned by $72.2 \%$ of manufacturing companies to supervise the gating system and to ensure that the Project Teams understand and maintain the process and its practices (Cooper 2011). The Process Manager may also facilitate gate meetings, coach teams, and provide training. Executive Sponsor role is activated for large projects and is usually a member of the senior management. This role serves to mentor and guide the Project Team and advise the Project Leader. The Executive Sponsor can also overlap roles by simultaneously acting as a Gatekeeper.

\section{Project Team Organization and Resources}

Providing the Project Team with sufficient resources and the right organizational structure will strongly influence project outcomes. Having dedicated resources that are available for full-time use is one of the most critical factors for producing practical product innovation, as seen in Figure 2, 58.6\% of the best innovators have dedicated resources for product development, while 48.3\% have a focused cross-functional group (made up of marketing, operations, and R\&D departments). Overall, a focused Project Team that makes use of available resources has been proven to have a strong positive impact on performance (Cooper 2011).

Figure 2. Impact of Project Team Focus and Dedicated Resources on Performance

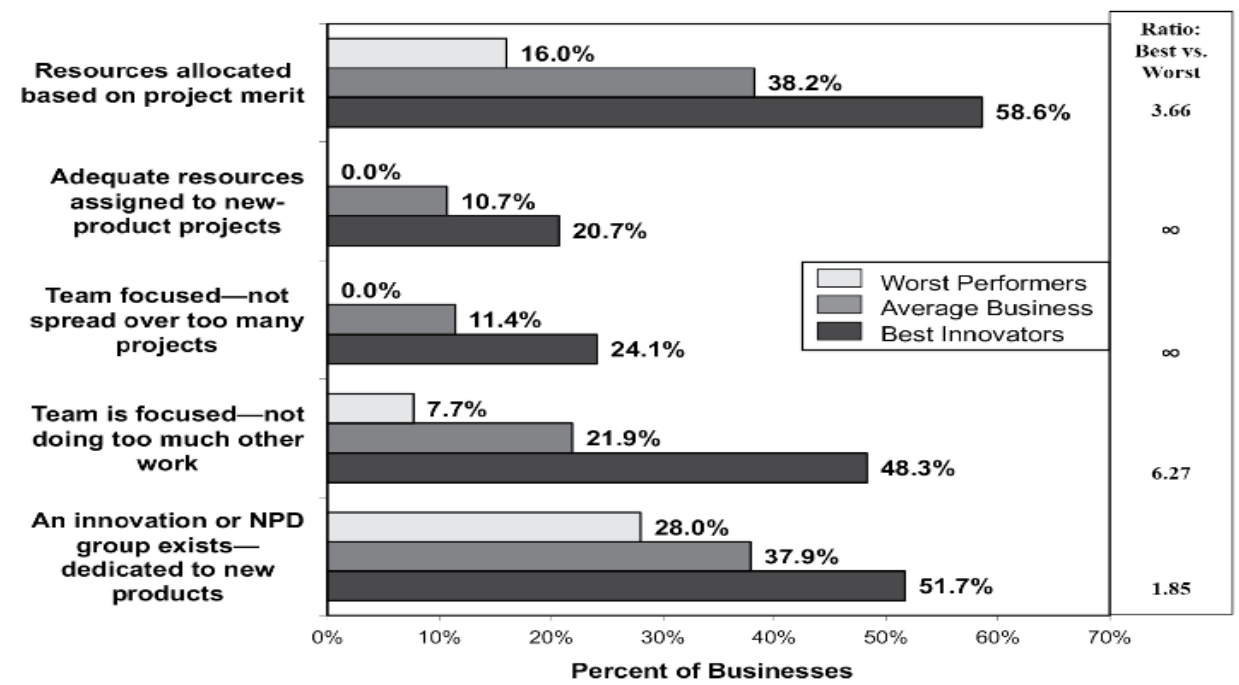

Source: Cooper 2011.

The organizational structure and composition of the Project Team dramatically determine the success of product innovation, which includes the identification of roles, responsibilities, and assigned tasks. The product innovation process is not the mission of only one division; it is multidisciplinary, cross-functional work. As shown in Figure 3, more than $79 \%$ of the best innovators have a cross-functional 
team with clearly assigned individuals and an identifiable Project Leader (Cooper 2011).

Figure 3. Impact of New Product Development on Innovation and Performance in Project Teams

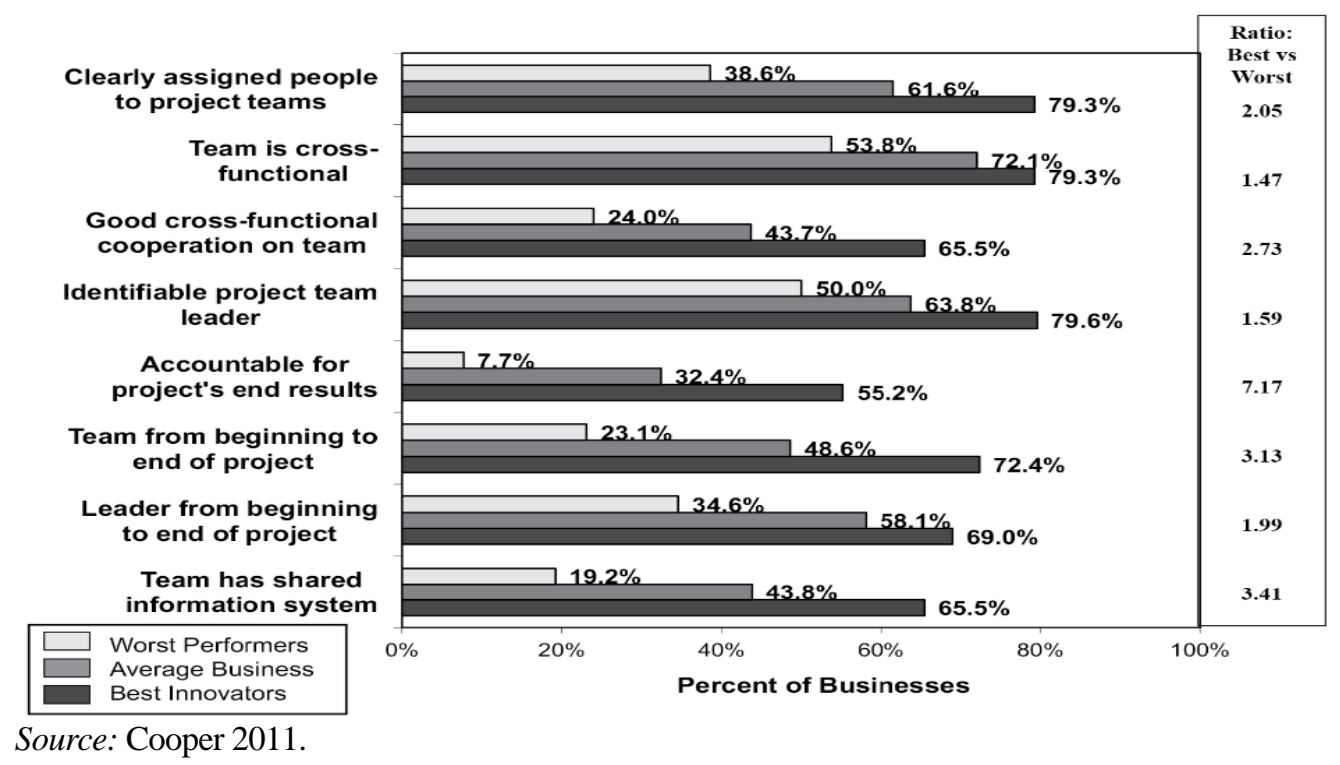

Agile Project Management

New management techniques have emerged in the latter part of the $20^{\text {th }}$ century as a response to the internet revolution and its associated technologies. This evolution raised the criteria for successful projects. Companies are now required to not only produce high-quality products but to produce them rapidly. This evolving global economy is characterized by 1) a high degree of uncertainty in business projects, 2) an increase in customer desire for speed, and 3) a quick response to market changes (White 2008).

Organizations and project managers must be equipped with persuasive techniques (such as Agile project management) in order to have the ability to adjust quickly and respond to business needs. Agile project management is based on the twelve principles from The Agile Manifesto that was first introduced in 2001. Agile project development relies heavily on the concept of self-organized teams, who work closely with customers and collaborate between multiple functions throughout many iterations. The focus is on the adaption of changes as the project progresses (Sliger 2011). Agile project management aims to help companies maneuver the reality of continuous change by allowing the project team to work closely with customers, define their requirements, and incorporate changes throughout the project life cycle (Sliger 2011). Agile project management is also considered to be a better way to oversee the older problems associated with traditional project management techniques (such as Waterfall) when managing large IT projects (Cooper and Sommer 2016a). 
Applying Agile Methods through Scrum

In 1981, Ikujiro Nonaka and Hirotaka Takeuchi first identified the Scrum approach in the Harvard Business Review in a piece titled, "The New New Product Development Game" (Cooper and Sommer 2016a). The authors utilized the sport of rugby as a metaphor to show the effectiveness of self-organized teams in innovative product development and delivery. Jeff Sutherland, Ken Schwaber, and Mike Beedle applied this method to their field of software development at Easel Corporation in 1993, which became the Scrum framework (Sliger 2011).

Scrum is a dominant agile methodology and is intended to guide teams in the form of iterative and incremental delivery of a product. $42 \%$ of organizations use Scrum, while another $54 \%$ of companies combine it with other techniques (Scrum Alliance 2015). The Scrum approach focuses on the use of an experimental process that allows the team to respond rapidly, effectively, and efficiently to market changes and customer needs. The Scrum framework is based on the idea that fixed timeframes and costs will best control project requirements. In contrast, traditional project management methods use fixed requirements to control time and cost. The Scrum framework consists of Sprints, Product backlog, Sprint Backlog, Sprint Planning meeting, Backlog Tasks, and Daily Scrum Meeting, as shown in Figure 4 (Vedsmand et al. 2016).

Figure 4. Important Elements of the Agile-Scrum Method for IT Projects

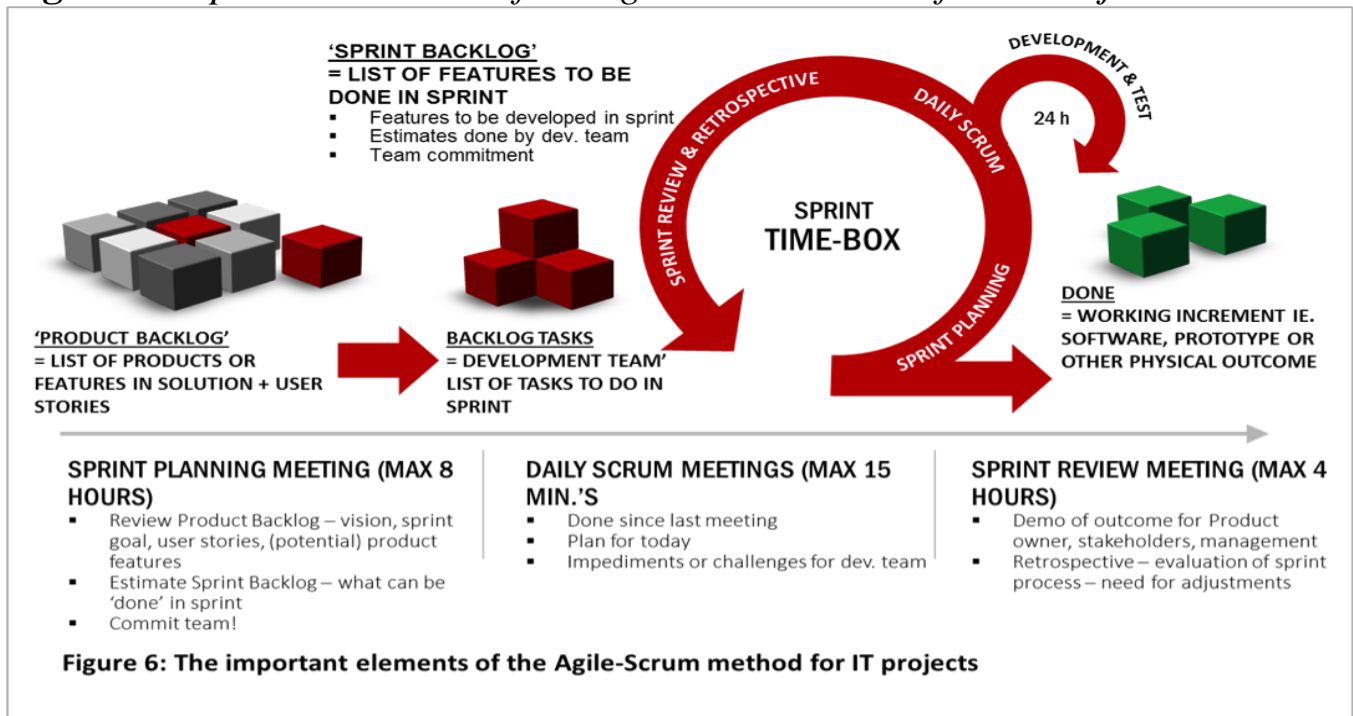

Source: Vedsmand et al. 2016.

Sprints are the basic units of Scrum methodology. Each is a time-box of continuous development and test iteration, usually lasting 1-4 weeks. The Sprint can be seen as a container for other Scrum activities, such as the Daily Scrum daily meeting, Sprint Review, Sprint Planning, and Sprint Retrospective. In the case of a big project and a larger team, many sprints can be run simultaneously or consecutively (Schwaber and Sutherland 2017, Sliger 2011, Schwaber 2004).

Product Backlog acts as the overall vision and map for product production. The Product Backlog lists all the product features, functions, and requirements 
necessary to create a finished product. It is managed by the product owner and continuously updated based on product progress and customer needs. The Product Backlog is prioritized based on the development strategy with the essential items listed first (Schwaber and Sutherland 2017, Sliger 2011, Schwaber 2004).

Sprint Backlog is a list of chosen items from the Product Backlog that are developed in each Sprint. The development team agrees on how they will deliver the requirements for the current Sprint during the Sprint Planning Meeting. The Sprint Backlog provides a thorough overview of the work that has been done, along with the remaining work required for completion (Schwaber and Sutherland 2017, Sliger 2011, Schwaber 2004).

Sprint Planning Meeting is an event where the Scrum team determines how the team will accomplish the Sprint Backlog tasks. In this meeting, the Scrum team selects items from the Product Backlog that will be achieved in the subsequent Sprint. The team will also agree upon the definition of "done" and define the Sprint goal (Schwaber and Sutherland 2017, Sliger 2011, Cooper and Sommer 2016a).

Daily Scrum Meeting is a daily 15-minute meeting facilitated by the Scrum Master. At this meeting, the development team discusses what they accomplished in the last 24 hours, what they will do today, and what challenges they are facing. The daily Scrum meeting is meant to improve communication, remove obstacles, share knowledge, and make sound decisions (Schwaber and Sutherland 2017, Sliger 2011, Cooper and Sommer 2016a).

Sprint Review is conducted at the end of every Sprint when the delivered product increment is presented to management and customers. The outcome of the Sprint Review is a working increment, such as a prototype or a piece of functioning software. The Product Backlog is also revised, and the team provides their input for the following Sprint (Schwaber and Sutherland 2017, Sliger 2011, Cooper and Sommer 2016a).

Sprint Retrospective is often a three-hour meeting for a one-month Sprint. The goal of the Sprint Retrospective is to evaluate the process and implement the lessons learned into the next Sprint. The Scrum Master is responsible for facilitating the meeting and ensures that the Sprint process is adequately adhered to (Schwaber and Sutherland 2017, Sliger 2011, Cooper and Sommer 2016a).

Roles and Responsibilities of the Agile-Scrum Method

The Scrum team is a multi-functional and self-organized team. The team should have all the competencies needed to achieve all tasks for the product increment. The Agile-Scrum framework has only three roles: Scrum Master, Product Owner, and Development Team (Sliger 2011, Schwaber and Sutherland 2017).

Product Owner owns the Product Backlog and is responsible for communicating the project vision to the team. The Owner focuses on 
maximizing the product value and ensures everything is completed during the Sprint. The Product Owner is also responsible for prioritizing and managing the Product Backlog (Sliger 2011, Schwaber and Sutherland 2017).

Scrum Master is the keeper of the Scrum's rules and process. The Scrum Master usually facilitates team communication and ensures that the team operates according to the Scrum rules. The Scrum Master also assists the team in removing any external obstacles and negotiates with stakeholders who are external to the team (Sliger 2011, Schwaber and Sutherland 2017).

Development Team typically consists of 3-9 people who are responsible for delivering the product requirements that were agreed upon beforehand at the end of each Sprint. The team is self-organized and co-located, meaning that they work in the same physical environment. The whole team is accountable for the Sprint, meaning that they collaborate and help each other to solve problems (Sliger 2011, Schwaber and Sutherland 2017).

\section{Integration of the Agile Method into the Stage-Gate Process}

\section{The Drive to Adopt the Agile-Stage-Gate Model}

As a result of the internal and external challenges faced by the manufacturers in new product development, the Agile-Stage-Gate has become a practical solution to overcome these challenges. The high demand from the customers to shorten the time-to-market, respond faster, and increase the flexibility during product development also revealed the need for this new approach. Manufacturers have recognized that the traditional methods are no longer feasible to deal with challenges evolving from new complexity. Thus, a new approach and mindset are needed to overcome these challenges (Cooper and Sommer 2016a, Sommer et al. 2015). In recent years, various manufacturing companies (especially Business-ToBusiness organizations) have adopted the Agile-Stage-Gate hybrid method in order to respond to market changes in the industry quickly (Cooper and Sommer 2016a, Sommer et al. 2015).

\section{Combining the Agile-Scrum Approach with Traditional Gating Processes}

The discussion on whether or not the Stage-Gate and Agile methods can be successfully combined has already begun. Since identifying successful examples of this combination is imperative for the future of the hybrid model, a few IT companies have begun to implement the agile methods into their existing StageGate process. For example, Karlström and Runeson (2005, 2006) studied three large scale European technology companies, namely Vodafone, Ericsson, and ABB (Karlström and Runeson 2005, 2006). These three firms each integrated the Agile approach into the Stage-Gate process for their IT projects. The results of this study revealed that the two approaches integrated seamlessly. Also, the new approach improved the internal team communication, planning, and customer feedback on the early stages, thus proving that the two models were compatible (Karlström and Runeson 2005, 2006). 
Applying the Agile-Stage-Gate Approach to Physical Products

Although there is a shortage of research that examines the application of the Agile-Stage-Gate approach for the development of physical products, one Danish study chose to focus on five manufacturing companies that integrated Agile into their Stage-Gate system (Cooper and Sommer 2016a, 2016b, Sommer et al. 2015). The results of this study positively indicated that the Agile-Stage-Gate method could be successfully implemented for physical products from an operational standpoint. The study specifically revealed that the hybrid approach improved efficiency, and reduced work effort by $25 \%$ per project and reduced rework by nearly 20\% (Cooper and Sommer 2016b). These five firms also reported that the new approach increases the visibility of the processes overall, improves team ownership, and increases motivation. In addition, they noted a significant improvement in the communication within the team and in the coordination across the entire organization (Cooper and Sommer 2016b).

Previous Instances of Main Research Questions Addressed by Other Researchers

This section examines what research has been conducted previously regarding the five main research questions outlined in this paper. The previous research available is somewhat limited, hence the purpose of the in-depth analysis presented in this project. However, all available information found in the literature has been gathered and outlined below.

RQ1 - What is the structure of the Agile-Stage-Gate approach when managing different products (e.g., software, hardware, or a combination of both) and different projects (e.g., new product development, R\&D, or customer service)?

Combining Agile and Stage-Gate methods does not necessarily mean abandoning the individualized nature of the Stage-Gate approach. Instead, the Agile-Scrum features can be integrated into the Stage-Gate model to maximize the benefits of both (Sommer et al. 2015). The Agile-Stage-Gate is most often implemented during the Development and Testing stages. However, it has been found that Agile-Stage-Gate functions effectively in all stages of the project, as shown in Figure 5 (Vedsmand et al. 2016).

For instance, one case study conducted by Dr. Robert Cooper on a global company called Thermo-Valves (a disguised name) revealed that the Agile-StageGate approach should be applied across every stage in order to achieve the maximum benefit (Cooper and Sommer 2016a). Another example comes from a GEMBA Innovation company in Denmark that applied the Agile-Stage-Gate approach to their version of the ideation and concept stages to great success (Cooper and Sommer 2016a). Other early adopters of the Agile-Stage-Gate approach reported that it could be used in the early stages, but that some adjustment and modification is still needed (Cooper and Sommer 2016a). Figure 6 outlines the structure required to effectively integrate the Agile-Scrum model into the earlier stages of development (Vedsmand et al. 2016). 
Figure 5. Flow of an Integrated Agile-Stage-Gate Hybrid Model

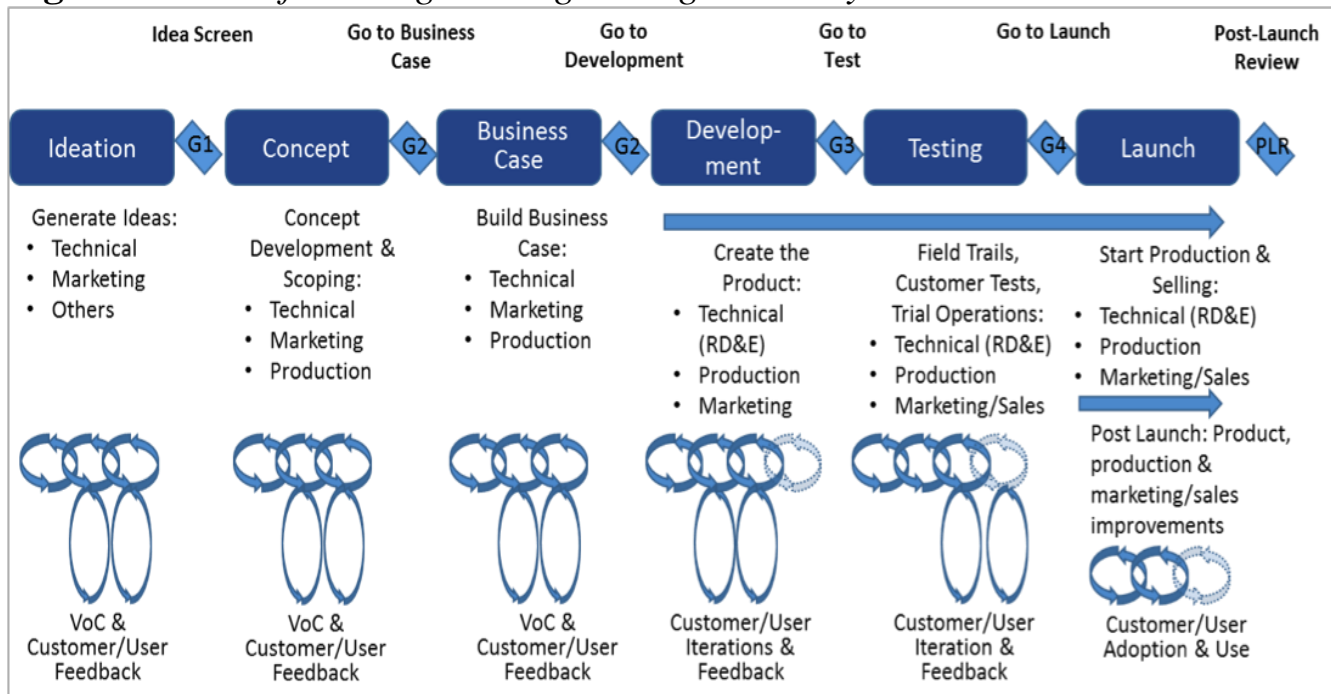

Figure 3:The integrated Agile-Stage-Gate hybrid model - a typical 5-stage, 5-gate Stage-Gate idea-tolaunch system, with Agile built into each of the stages (Source: Cooper \& Sommer, IMM, 2016; footnote 6)

Source: https://innovationmanagement.se/2016/08/09/integrating-agile-with-stage-gate/.

Figure 6. Example of the Agile-Stage-Gate Approach using Scrum (Including Early-Stage Sprints)

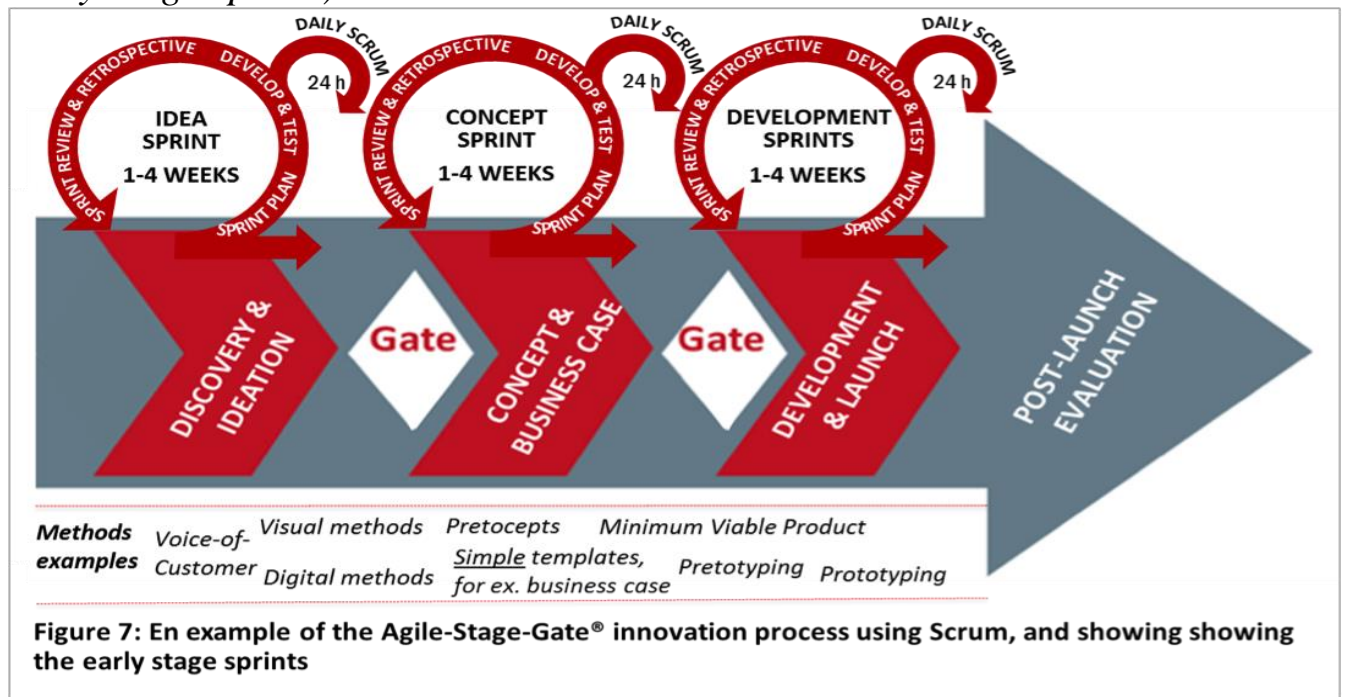

Source: https://innovationmanagement.se/2016/08/09/integrating-agile-with-stage-gate/.

Although manufacturing companies still tend to modify the Agile-Stage-Gate hybrid to fit their needs and maximize their values, most of the Agile-Scrum features that are used in the IT industry (such as the Sprint, Product Backlog, Sprint Review and Daily Scrum meeting) are still applied when using the AgileStage-Gate model. The Agile-Stage-Gate approach introduces a brand new way of thinking and planning for manufacturing organizations. For instance, when using the hybrid model, the project team can implement a plan-on-the-fly approach so 
that they only need to expend energy on what is mandatory in the current Sprint or Stage (Cooper and Sommer 2016a).

Unlike the planning process involved in traditional project management methods, the Agile-Stage-Gate approach allows the Project Team to plan on the fly for each Sprint in real-time and respond more dynamically to product improvement. The hybrid model also enables the team to work more closely with the customer and receive their feedback on the incremental release of the designs and prototypes. This increased access to the customer is crucial since the customer's voice acts as the primary driver for improvement, allowing the team to move product development in the right direction. In the Agile-Stage-Gate model, time-boxed Sprints are still applied and last from 2 to 4 weeks, although they may last longer for big or more complex projects. The Project Team is still required to produce something physical for the customer and stakeholders at the end of each Sprint. The Sprint Review occurs at the end of each Sprint with the aim to present the Sprint result to the customer and management. As a result of this Sprint, the Scrum team presents a concept, prototype, or even a Voice of Customer study "something tangible" (Cooper and Sommer 2016a).

The Daily Scrum Meeting is one of the Agile-Scrum tools that quickly integrated into the Agile-Stage-Gate approach. This is a short meeting, where the project team meets every day for 10-15 minutes to review the work progress. The Scrum Master gives every member of the team the opportunity to provide the status of what they achieved yesterday, what they expect to do today and to discuss any future problems they may foresee. During this meeting, the team collaborates and shares their collective knowledge in order to solve the problem of the day.

The purpose of the Retrospect Meeting is to improve the standard way of doing things. The team members discuss their successes and failures from the previous Sprint and try to solve the key issues that prevented them from reaching peak performance. In this meeting, each team member shares their concerns and suggestions on how to self-improve for the next Sprint.

The Agile-Stage-Gate approach adopts most of the Agile-Scrum tools. The Product Backlog is an agile tool that has also been adopted by Agile-Stage-Gate. The Product Backlog is equivalent to the product definition (or requirements specification) in traditional project management. Unlike standard product definition, however, the Product Backlog does not contain a detailed specification of the product but rather highlights the customers' needs and requirements. The Product Backlog is a dynamic document in which items are prioritized, and the most crucial obstacle is tackled first.

The Sprint Planning Meeting occurs at the beginning of each Sprint. The Project Team takes the top priority items from the Product Backlog (which is maintained by the Product Owner) and creates the Sprint Backlog, a list of the most critical items to be implemented in the current Sprint. The Product Owner decides what moves to the top of the list, while the team translates these items into clearly defined actions and estimates the time needed to accomplish each task.

Gates and Stages are still applied in the Agile-Stage-Gate hybrid approach. Each Gate acts as a door where the Go/Kill decision is made, which allows a 
project to either move on to the next stage, or be rejected and thus discontinued. The Stages provide a high-level overview of the main phases of the project. Stages and Gates provide the senior management with the ability to micromanage the process and also obtain any necessary information about the actions being implemented and the expected deliverables for each Stage.

The use of Gates is critical in the Agile-Stage-Gate approach, but the question of whether or not separate Gates should be used for products with hardware components versus products with software components still remains. Most AgileStage-Gate users find that having multiple Gates for different deliverables within the same project is troublesome and not beneficial. It is more efficient to have one Gate and one Gatekeeper to control each Stage and make the Kill/Go decisions. Because of the high level of uncertainty in the early Stages, Gates in the AgileStage-Gate approach are more flexible and focus more on what is delivered, not on the Kill/Go decision structure.

RQ2/RQ3 - Roles and responsibilities instituted by companies using the AgileStage-Gate model

In 2016, Cooper and Sommer presented the results of their Agile-Stage-Gate hybrid model case study, which examined two global manufacturing companies (Cooper and Sommer 2016a). The case study highlighted how these companies did not adopt all Agile-Scrum roles but continued to use one or more of the familiar roles and traditional responsibilities (including Project Leader, Project Manager, and Team Members). For instance, the companies used the title "Project Leader" instead of "Product Owner" for the individual who was responsible for leading the project. In the case of more complex, large scale projects, the companies sometimes had a "Process Manager", whose role is similar to that of the traditional "Project Manager". Although the responsibilities associated with the roles' terms were similar to those in the Agile-Stage-Gate approach, the titles used were markedly different (Cooper and Sommer 2016a).

In the Agile-Stage-Gate model, the Project Leader is one of the project team members and is responsible for pushing the project forward to its ultimate goal. The Leader is responsible for managing the resources and handling the external interfaces of the project with senior management, as well as generating a clear value proposition and ensuring stakeholder commitment.

The Product Owner owns the Product Backlog and is responsible for communicating the project vision to the team. The aim of this role is to focus on maximizing the product value and ensure that all necessary steps are completed within the Sprint. The Product Owner is also responsible for prioritizing and managing the Product Backlog and works closely with the development team to ensure they are moving in the right direction. The Product Owner shares some of the same responsibilities as the Project Leader in traditional product development. Some companies prefer to label the role of Project Leader as Product Owner in order to avoid confusion. In contrast, the responsibility of the Project Manager is to verify that the project is functioning well and that all project management tools and methods are being employed. 
Many Agile-Stage-Gate users implement the Gatekeeper Role at the leadership level, which stems from the Stage-Gate system. This role allows senior management to review the project periodically, kill weak projects, and make resource commitment decisions so that the project team can secure the funding and personnel needed to accomplish the project. The resource commitment is imperative in terms of accelerating the work and reducing the time-to-market (Cooper and Sommer 2016a). In addition, the Gatekeeper Role allows senior management to track the project's progress and performance in each Gate.

The Project/Process Manager and the Project Leader are highly valuable and essential roles in the Agile-Stage-Gate approach. The roles are best split between two different people, preferably a Product Owner or Project Leader and a Scrum Master. The Project Manager or Scrum Master can often support multiple projects at once, depending on the size and complexity of each project. When managing smaller projects, the team leader will sometimes take on each role and act as both a leader and project manager (Cooper and Sommer 2016a). Based on the research results outlined in this paper, the roles and responsibilities in the Agile-Stage-Gate approach are noticeably different from company to company and depend primarily on the size and complexity of each project. Since each company tailors this new hybrid approach to fit their specific needs, the terminology for these roles and responsibilities are inconsistently applied from company to company and project to project, leaving room for ambiguity and miscommunication.

RQ4 - What effect does the Agile-Stage-Gate model have on project team quality, including 1) communication and 2) coordination?

Team communication, coordination, and performance are essential components to measure when operating under the Agile-Stage-Gate approach. The project team is co-located and dedicated to one project with designated project rooms. The team uses visual, physical scrum boards to produce efficient developments and better communication. Scrum meetings are conducted daily within the teams at their Scrum boards and are facilitated by the Scrum Master. When operating from the Agile-Stage-Gate approach, the project team remains intact for the lifespan of the project to ensure ownership and accountability. Isolation from other parts of the organization is the main challenge that arises from having a dedicated team.

In the Agile-Stage-Gate approach, the Sprint board is still used to outline the Sprint Backlog, which lists all the activities and tasks that must be completed during the Sprint. There are many ways to utilize the Sprint board, but the most common format is to use three columns: "To-do", "Doing", and "Done". The Sprint board is a useful tool to track Sprint tasks and to monitor team activities (Cooper and Sommer 2016a).

The Danish study revealed that employing the Agile-Stage-Gate approach reduced work effort by $25 \%$ per project, reduced repeated work by nearly $20 \%$ and improved efficiency overall (Cooper and Sommer 2016b). The five organizations that were studied also observed an increase in the visibility of processes, improved 
team ownership, and overall motivation. Additionally, the manufacturing firms noticed a significant improvement in the communication within the team and in the coordination across the whole organization.

In order to measure performance, the Danish researchers created their own consistent metrics across all five of these companies. These metrics, as presented in Figure 7, outlines the results of the Danish study and reveal significant improvements, including faster response time to product changes and customer requirements. The results also reveal an improvement in team communication, ownership and project productivity.

Figure 7. Benefits from Implementing the Agile-Stage-Gate Approach (Mean Scores of 10 Respondents across 5 Firms)

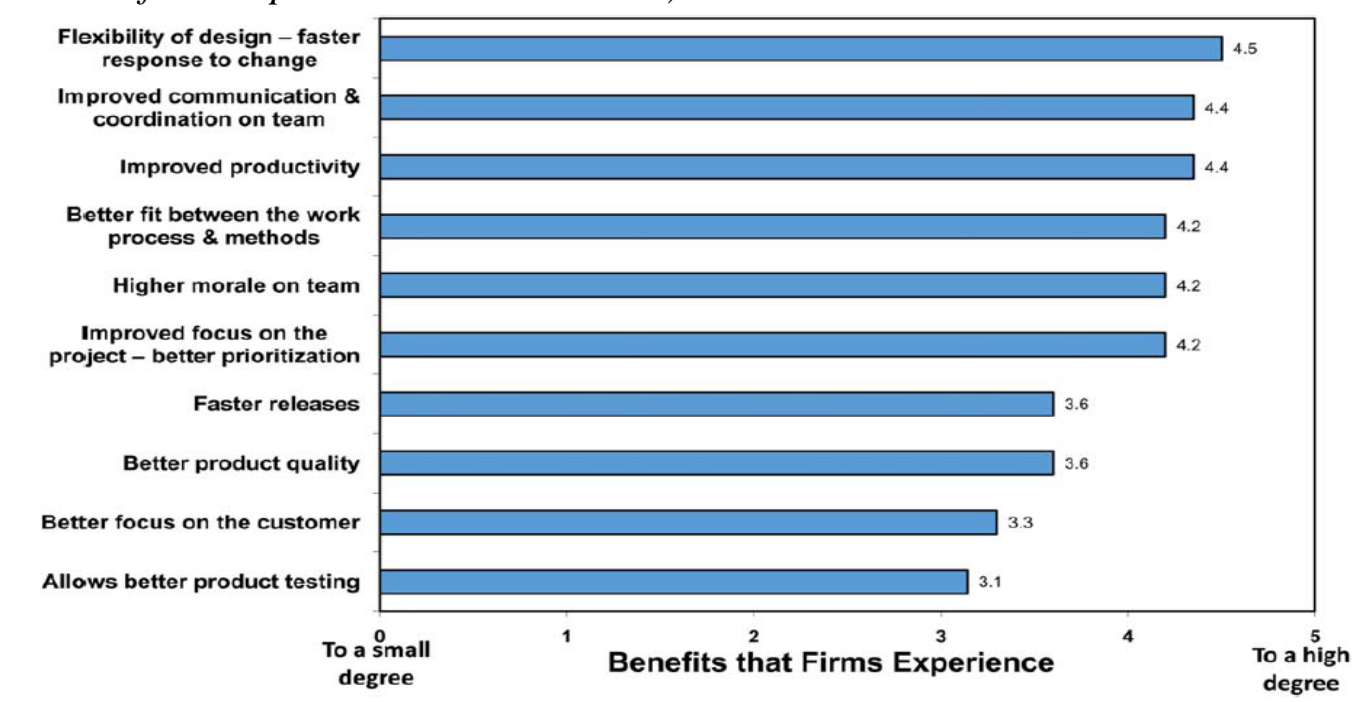

Source: Cooper and Sommer 2016.

The results from the Danish study also align with the Agile-Stage-Gate case studies that Dr. Robert Cooper conducted in the United States in 2016. The American companies Dr. Cooper studied were early adopters of the Agile-StageGate hybrid approach. Each of the five organizations reported an improvement in product requirement modifications, better team communication and a reduction in time-to-market response. Although Dr. Cooper's studies are somewhat limited in scope, when his results are combined with the previous results of the Danish study, the research strongly suggests that the Agile-Scrum method can be seamlessly integrated into the Stage-Gate system and that the two methods are remarkably compatible (Cooper and Sommer 2016a).

Several manufacturing firms have adapted the Agile-Scrum approach at the operational level (Sommer et al. 2015). Applying Agile-Scrum at this level allows the project team to benefit from the broad range of communication paths provided by the Agile-Scrum model versus the limited communication styles found in traditional models, as seen in Figure 8. 
Figure 8. Communication Paths Provided by the Agile-Scrum Model vs. Traditional Communication Styles

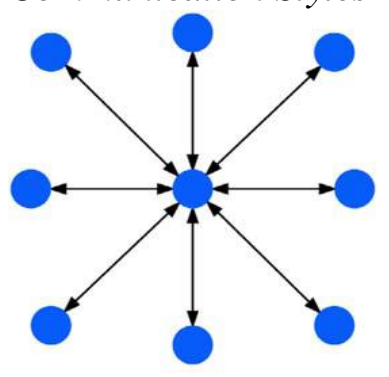

Traditional Teams: Spider Communication Flow

Source: Cooper and Sommer 2016b.

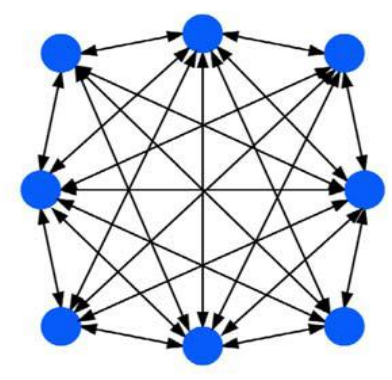

Agile Teams: Diamond

Communication

As seen in Figure 8, a spider communication flow is used in the traditional methods where the Project Manager remains the focal point for all communications. This structure strictly limits the amount of communication that takes place between project members. In contrast, adapting the Agile-Scrum method within the hybrid approach opens up more communication pathways between team members, which increases the sharing of knowledge and collaboration within the project team (Cooper and Sommer 2016b).

RQ5 - What is the long-term company strategy and vision when applying the Agile-Stage-Gate model?

Most Agile-Stage-Gate users keep the Stage-Gage unchanged at the management level and implement Agile-Scrum at the operational level (Cooper and Sommer 2016a, Sommer et al. 2015). This strategy allows the organization to manage its portfolio and allows the Portfolio Manager to clearly see the progress of the project and status of the product backlog (Cooper and Sommer 2016a). Using a virtual software tool that creates visual boards further enables companies to not only manage individual projects but to monitor and control the full project portfolio in real-time. In addition, these visual boards allow managers to run analytics across the portfolio of all projects in order to see the actions and types of tasks being implemented by specific people and departments. Managers are also able to monitor and control the resource capacity in order to improve project planning within the portfolio.

In traditional methods, the Portfolio Manager receives periodical reports on the project's status, which may delay the necessary intervention by weeks at a time. In contrast, the enhanced capability inherent in the Agile-Stage-Gate model allows potential problems to be immediately identified so that the required actions can take place without delay (Cooper and Sommer 2016a). Although there is still a limited amount of research that focuses on the performance results achieved when implementing the Agile-Stage-Gate approach for physical products, the available research still provides positive evidence that this new hybrid approach reduces time-to-market and increases the success rate of projects (Cooper and Sommer 2016b). 
Learning how to maneuver the uncertainty involved in new product development is crucial to the ultimate success of a product. For innovative products that use new technology and are new to the market, staying attuned to the voice of the customer and performing technical assessments or market analyses does not reduce all risk when dealing with the uncertainties that exist prior to the development stage. Understanding customer needs and values on a deeper level can technically only be learned through experimentation. The sprint-iterations process in the Agile-Stage-Gate model provides an excellent environment in which to experiment and test the prototype. The Project Team can begin by first understanding the product requirements and then envision a technical solution during the Development and Testing stages of the project. The Agile-Stage-Gate approach also allows the Project Team and the customer to learn more about the product during the Development and Testing stages, especially for more innovative products.

Ever-changing product requirements pose a significant challenge when it comes to new product development. Traditional gating models often struggle to respond and adapt to these changing requirements, especially by the time they enter the late stages. In contrast, the Agile-Stage-Gate approach rapidly builds a prototype via the Sprints, which allows the customer and the Project Team to implement any necessary modifications in the product design during the development stage at a much lower cost.

\section{Methodology}

\section{Research Method}

Since the Agile-Stage-Gate model is a relatively new approach that has only recently been adopted by the manufacturing industry, the structure, roles, and responsibilities have not been clearly defined or standardized. Instead, each firm adopts and modifies its own version of this hybrid approach. In order to examine the similarities and differences among companies who have adopted this model in more depth, a survey was created and conducted in order to investigate the recurring patterns that emerge when the Agile-Stage-Gate approach is implemented.

\section{Survey Design}

The survey questions were developed by first reviewing the available literature on the Stage-Gate method, Agile-Scrum, and the Agile-Stage-Gate approach, along with a round table discussion with Subject Matter Experts (SME). to establish result expectations. As a result, the survey covers seven main categories of research questions. This specific survey approach was selected because obtaining data from participants who have varied experience with multiple projects and products helped to define the structure of the Agile-Stage- 
Gate model, as well as the roles and responsibilities involved. The survey has 71 questions divided into seven groups:

1. Participant experience and knowledge

2. Structure and features in the Agile-Stage-Gate approach

3. Project team roles in the Agile-Stage-Gate approach

4. Responsibilities in the Agile-Stage-Gate approach

5. Communication and teamwork performance in the Agile-Stage-Gate approach

6. Company strategy for adapting the Agile-Stage-Gate approach

7. Agile-Stage-Gate approach performance rate

Respondents were asked to answer each question by selecting an agree/ disagree statement that ranged from 1 to 5 (1-Strongly disagree, 2-Disagree, 3Neutral, 4-Agree, 5-Strongly agree). For each research question, multiple answers were presented based on different Product and Project Types to understand the similarities and differences that exist within the Agile-Stage-Gate approach.

\section{Data Collection and Visualization}

The survey was launched online using the Qualtrics tool and distributed on multiple social media platforms and on several Project Management websites and was redistributed every three days for one month. The target population was experts who already had experience with the Agile-Stage-Gate approach in the manufacturing industry. Following a one month posting, 144 responses were collected with incomplete responses not considered for the research process. Using Tableau Desktop Software multiple factors were applied to create specific charts, such as product and project type. The application of these factors and variables helped to clearly highlight the elements that affect the implementation of the Agile-Stage-Gate approach within different products and projects.

\section{Respondents}

A final 52 qualified respondents became the final pool from which the research results were based upon. Overall, $97 \%$ of the respondents were in strong agreement with all the survey questions as shown in Figure 9. 
Figure 9. Total Percentage of Responses

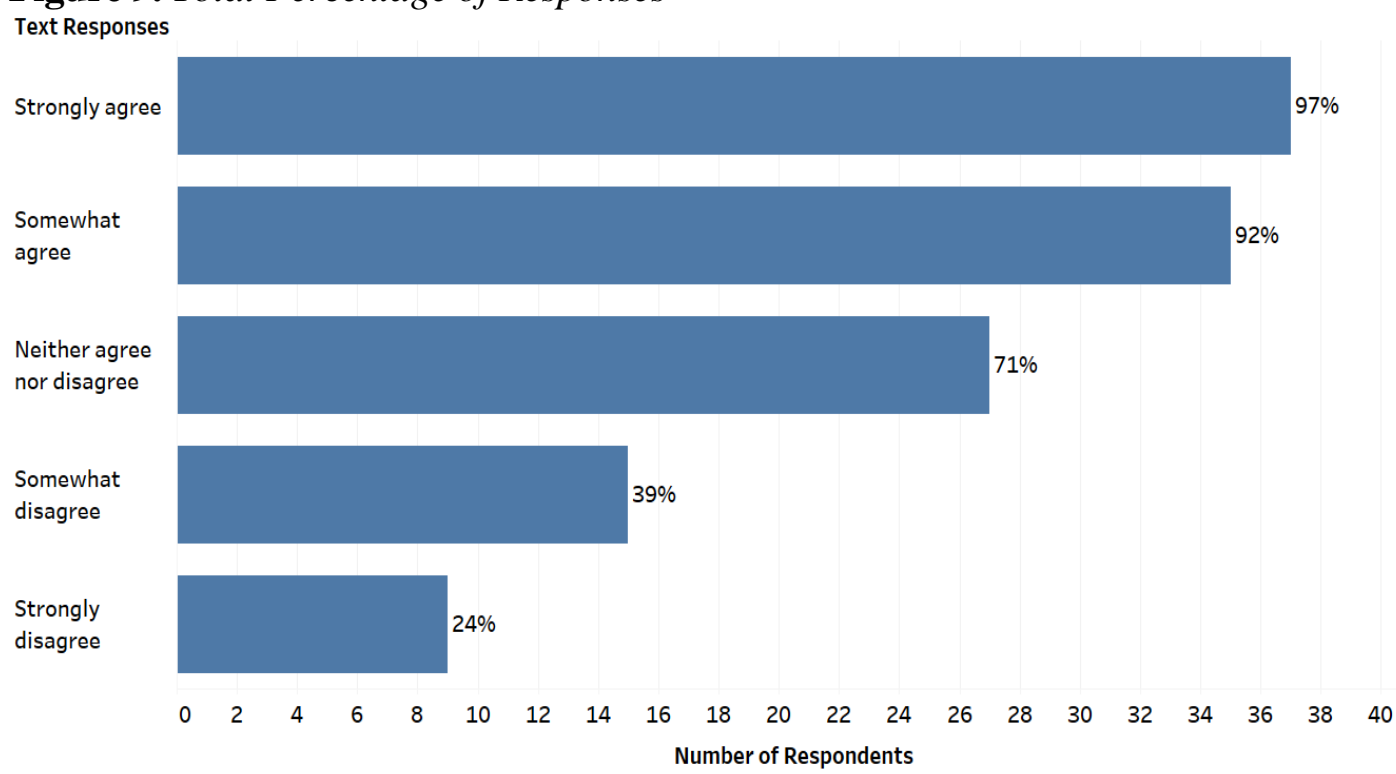

The demographics reflecting the respondents' experience, educational background, participant's organization, project types, geographic location, and those that are using a form of Agile-Stage Gate have been removed to conserve publishing print space (Figures 10-15 were removed).

\section{Results and Analysis}

Figure 16. Percentage of Companies that Implemented the Stage-Gate Model First

Q9- Did your company implement Stage-Gate first before applying Agile?

Q9
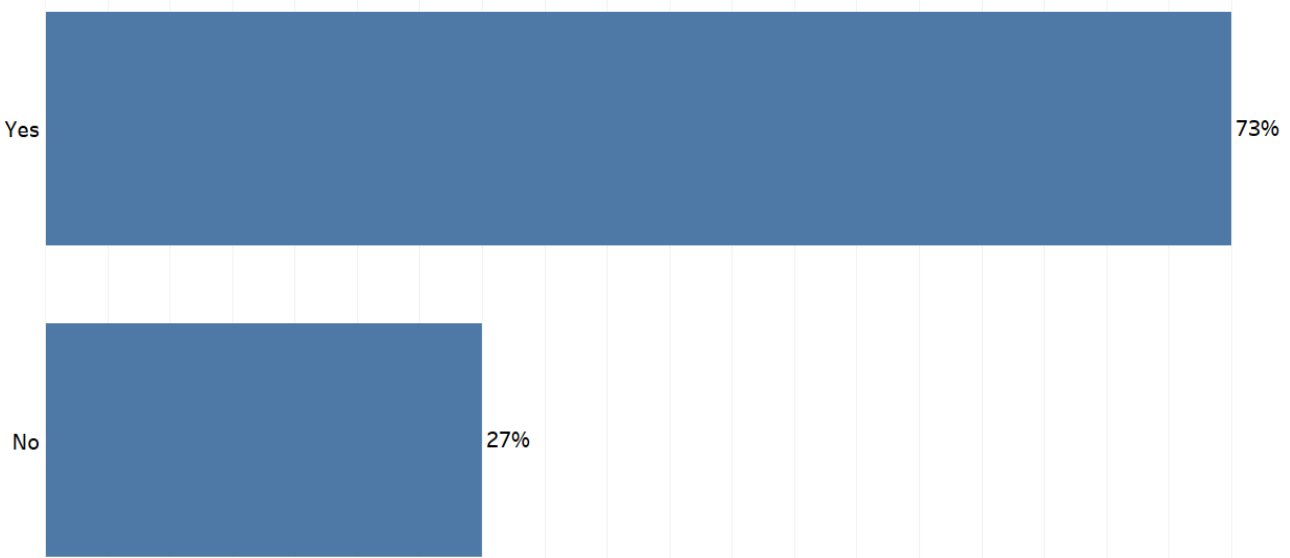

$\begin{array}{llllllllllllllllllllll}0 & 2 & 4 & 6 & 8 & 10 & 12 & 14 & 16 & \begin{array}{c}18 \\ \text { Number of Respondents }\end{array} & 20 & 22 & 24 & 26 & 28 & 30 & 32 & 34 & 36 & 38 & 40 & 42\end{array}$

To analyze the results of the six groups of survey questions, specific filters were applied firstly to respondents who selected "Strongly Agree" to the survey 
questions (see Figure 9), followed by specific factors pertaining the differences between the structures, roles, and responsibilities and additionally to each group based on the product and project type that companies manage. A third filter was applied to the type of project such as New Product Development (NPD), Research $\&$ Development (R\&D), and Services. Figure 16 indicates the Percentage of companies that implemented the Stage-Gate model first, prior to the application of Agile. All of the figures referenced below are provided in the Appendix.

\section{Common Structures and Features in the Agile-Stage-Gate Approach}

The results (Figure 17) show that the integration of the Agile-Scrum model is not limited to a specific stage. Instead, manufacturing firms apply this model throughout different stages of the Stage-Gate model. This finding reveals that the integrated approach can be implemented throughout every stage. Dr. Robert Cooper obtained the same results from his Agile-Stage-Gate case studies, which revealed there is not only a possibility of using the Agile-Stage-Gate model during Development and Testing but during the earlier stages as well (Vedsmand et al. 2016).

Common Structures and Features of the Agile-Stage-Gate based on Product Type

The results related to this section were filtered based on the product and project types (Software, Hardware and Combination) in order to learn more about the Agile-Stage-Gate structure. The survey's findings revealed that the structure of the Agile-Stage-Gate approach varies slightly depending on the participant's opinion. For example, in the case of software products (Figure 18) respondents strongly agreed that companies integrate all the features of AgileScrum into the Stage-Gate model. This means that the Agile-Stage-Gate approach combines all Agile-Scrum and Stage-Gate structures and features under one model.

In contrast, the results that were in agreement for hardware and combination products have a lower percentage overall than for software products (Figures 19 and 20). It would appear that companies are still determining how to best combine both models when working with hardware and combination products. Regarding the implementation of the Agile-Scrum into different stages, the results based on the product type show that the implementation of the Agile-Scrum model is not limited to the Development and Testing stages and can effectively be applied to all stages.

\section{Common Structures and Features based on Project Type}

Results filtered by project type, (NPD, R\&D, and Services) all the established structures and features are still applied in the hybrid model, but with different levels of agreement (Figures 21 and 22). Participants 33\% of the time indicated more familiarity integrating the Agile-Stage-Gate model when managing NPD projects.

Regarding service projects, none of the respondents (Figure 23) strongly agreed that the Agile-Scrum model is implemented throughout all the stages of the project. Overall, the results in this section indicate that the early adopters are still 
attempting to find the best combination of both the Stage-Gate and Agile-Scrum models. This result also highlights the room for improvement when it comes to companies adjusting and modifying the hybrid approach during implementation.

\section{Project Team Composition and Roles within the Agile-Stage-Gate Approach}

Figure 24 showed that the Project Team consists of a Product Owner, Scrum Master and the Development team according to $47 \%$ of respondents. $50 \%$ of participants reported that there is also a steering committee and that the project team is co-located and dedicated to one project.

The project team's roles, indicated in Figure 25 show that the titles of Product Manager, Product Owner, Project Manager, Scrum Master and Business Analyst are all recurring roles within the Agile-Stage-Gate approach.

\section{Project Team Roles in the Agile-Stage-Gate Approach based on Product Type}

$100 \%$ of the respondents strongly agreed (Figure 26) that there is always a Gatekeeper, Product Manager, Product Owner, Project Manager and a Scrum Master during software development and $50 \%$ of the strongly agreed on the team roles associated with Hardware products, (Figure 27).

For products that have a combination of software and hardware components, $71 \%$ strongly agreed that there is always a Product Manager role (Figure 28) and 64\% introduced the Business Analyst as a hybrid role, who takes on the role of the Project Manager and/or the Product Owner.

Based on the results of the survey, companies appear to adjust the project team roles based on different product types. Therefore, an extensive analysis of the survey's results was conducted based solely on the product type being considered. By comparing the results through the filter of product type, it was found that all the roles have been integrated into the Agile-Stage-Gate approach for software and combination products. The only exception is the Business Analysis role, which does not get a high level of agreement as seen in Figures 26 and 28. Although the participants strongly agreed that all these roles existed in the case of software products, this could potentially create future conflict if the responsibilities are not identified clearly, leading to impeded efficiency and productivity.

\section{Project Team Roles in the Agile-Stage-Gate Approach based on Project Type}

In New Product Development Projects (Figure 29), 71\% of respondents strongly agreed that there are always Product Owner and Scrum Master roles, while 57\% strongly agreed that there are always Project Manager and Business Analyst roles. For R\&D Projects, only $17 \%$ of respondents strongly agreed that there are always Gatekeeper, Product Owner, Scrum Master and Business Analyst roles in the Agile-Stage-Gate approach (Figure 30). In contrast, 0\% of the respondents strongly agreed that these roles exist for projects that provide services to customers (Figure 31 ).

It was found that the Agile-Stage-Gate approach integrates the team roles based on the project type normally associated with NPD projects, while in contrast, roles associated with $R \& D$ projects received a very low percentage of agreement 
and there was no agreement at all in the case of service projects. Thus it would appear that the normal roles do not transfer over into services projects and R\&D projects.

Adjusted Project Team Roles after Adopting the Agile-Stage-Gate Approach (based on Product Type)

Findings indicate that implementing the Agile-Stage-Gate hybrid model requires organizations to modify aspects of roles and responsibilities to ensure that individuals achieve their tasks and maximize all the benefits available within this combination of models. Even more important, organizations must remove any conflict between roles and ensure there is no interference between the responsibilities of the project team. Findings indicate (Figure 32) that some of the roles have been adjusted when companies adopted the Agile-Stage-Gate approach. For example, $100 \%$ of participants strongly agree that the Project Manager takes on most of the Scrum Master role for Software product development while in contrast (Figure 33) shows that only 25\% strongly agree that the Project Manager takes on most of the Product Owner role for Hardware products.

Adjustments are made to the existing roles in the team roles when adopting the new approach developing combination products. For example (Figure 34) 43\% strongly agreed that the Product Manager takes on most of the Product Owner role, 29\% strongly agreed that the Project Manager takes on most of the Product Owner role and 36\% agreed the Project Manager takes on most of the Scrum Master role, indicating that the roles in the hybrid approach can be slotted into existing roles.

Adjusted Project Team Roles after Adopting the Agile-Stage-Gate Approach (based on Project Type)

For NPD projects, 57\% strongly agreed (Figure 35) that the Product Manager takes on most of the Product Owner role. 50\% strongly agreed that the Project Manager takes on most of the Product Owner role. In the case of $\mathbf{R} \& \mathbf{D}$ projects, Figure 36 shows that $17 \%$ strongly agreed that the Product Manager both takes on most of the Product Owner role, and that the Project Manager takes on most of the Scrum Master role. For projects providing Services, again 0\% strongly agreed on the adjusted roles (Figure 37).

Results of this section show that most of the roles can be easily adjusted for NPD, which differ from the roles applied to R\&D and Services projects, indicating that defining roles is often dependent on the type of project.

\section{Project Team Responsibilities in the Agile-Stage-Gate Approach}

Respondents $63 \%$ of the time (Figure 38) strongly agreed that the responsibilities of the Project Manager are to manage the project in terms of scope, cost and time using a project plan with defined deliverables, detailed budgets and a milestone plan and 53\% strongly agreed that the Product Manager is responsible for providing a clear, prioritized Product Backlog, keeping track of feedback and incorporating it as needed into the Product Backlog. Meanwhile, 
55\% strongly agreed that the Scrum Master is responsible for facilitating the Scrum process and communication, as well as tracking team performance.

Project Team Responsibilities in the Agile-Stage-Gate Approach (based on Product Type)

Participants strongly agreed that all responsibilities of the project team were identifiable in the Agile-Stage Gate approach and understanding the similarities and differences of these responsibilities was important. $100 \%$ of respondents (Figure 39) strongly agreed that the responsibilities of the Project Manager include managing the project in terms of scope, cost, and time using a project plan with defined deliverables, detailed budgets and milestones and that $100 \%$ strongly agreed that the Product Owner is responsible for providing a clear, prioritized Product Backlog, keeping track of feedback and incorporating the feedback as needed into the Product Backlog.

The distribution of responsibilities for Hardware products produced different results as only $25 \%$ (Figure 40) strongly agreed that the responsibilities of the Project Manager include managing the project in terms of scope, cost and time using a project plan with defined deliverables, detailed budgets, and milestones. However, $100 \%$ strongly agreed that the Scrum Master is responsible for facilitating the Scrum process and communication, as well as tracking team performance.

For combination products (Figure 41) $57 \%$ strongly agreed that the responsibilities of the Project Manager include managing the project in terms of scope, cost and time using a project plan and $50 \%$ of participants strongly agreed that the Product Owner is responsible for providing a clear, prioritized Product Backlog, keeping track of feedback. There were $43 \%$ that strongly agreed that the Scrum Master is responsible for facilitating the Scrum process and communication, as well as tracking team performance.

The hardware product questions had less overall agreement regarding these responsibilities. However, the participants were in $100 \%$ strong agreement on most responsibilities applied to software products. This leads to the conclusion that project teams working on software products specifically have more defined and clear responsibilities when operating within the Agile-Stage-Gate approach.

\section{Project Team Responsibilities in the Agile-Stage-Gate Approach (based on Project} Type)

For NPD projects, 64\% of respondents strongly agreed that the responsibilities of the Project Manager are to manage the project in terms of scope, cost and time using a project plan with defined deliverables, detailed budgets and milestones (Figure 42), while 57\% strongly agreed that the Product Manager is responsible for providing a clear, prioritized Product Backlog, keeping track of feedback, and incorporating it as needed into the Product Backlog and 50\% strongly agreed that the Product Owner is responsible for the same tasks as the Product Manager.

For R\&D projects, (Figure 43) 33\% of respondents strongly agreed that the responsibilities of the Project Manager include managing the project in terms of 
scope, cost and time with defined deliverables, detailed budgets and scheduled milestones, while 50\% strongly agreed that the Product Owner is responsible for the same tasks as the Product Manager, and 50\% strongly agreed that the Scrum Master is responsible for facilitating the Scrum process and communication, as well as tracking team performance.

When analyzing designated responsibilities for Service projects, $100 \%$ of respondents strongly agreed that the Scrum Master is responsible for facilitating the Scrum process and communication, as well as tracking team performance (Figure 44). The results relating to responsibilities in regards to NPD and R\&D projects are robust and it is clear that the responsibilities are well-defined and decisively assigned.

\section{Communication and Coordination in the Agile-Stage-Gate Approach}

Regarding project team communication, shared values and team coordination when implementing the Agile-Stage-Gate approach, 55\% of respondents (Figure 45) strongly agreed that the approach allows the team to share their values and lessons with the rest of the organization and $61 \%$ were in strong agreement that the approach creates effective communication among project team members.

\section{Project Team Communication and Coordination (based on Product Type)}

Overall, there was a substantial level of agreement in regards to communication and coordination. In the case of software products, $100 \%$ of respondents (Figure 46) strongly agreed that the Agile-Stage-Gate approach encourages the team to share their values and lessons with the rest of the organization and $100 \%$ of participants were in strong agreement that the approach creates and improves more effective communication and coordination and improves team ownership and motivation. In contrast, only $25 \%$ strongly agreed that the approach allows the team to better share their values and lessons with the rest of the organization during hardware product development (Figure 47).

When developing a product that has a combination of components $57 \%$ (Figure 48) strongly agreed that the Agile-Stage-Gate approach encourages the team to share their values and lessons with the rest of the organization, while $64 \%$ were in strong agreement that the approach creates more effective communication.

Findings indicate that adopting the Agile-Stage-Gate approach has different results based on how the model is applied, whether in software, hardware, or combination products. It would appear that the approach has a positive impact on communication, coordination and ownership for software products and improves each of these areas respectively. In contrast, the approach has less impact when it comes to improving communication, coordination and ownership for combination products.

\section{Project Team Communication and Coordination (based on Project Type)}

In the case of NPD, 50\% of respondents (Figure 49) strongly agreed that the Agile-Stage-Gate approach encourages the team to share their values and lessons with the rest of the organization, while only $57 \%$ were in strong agreement that the 
approach creates effective communication within the project team. For R\&D projects, only $17 \%$ of respondents (Figure 50) strongly agreed that the AgileStage-Gate approach encourages the team to share their values and lessons with the rest of the organization and $33 \%$ of participants were in strong agreement that the approach creates effective communication within the project team, improves overall communication and coordination and enhances team ownership and motivation.

For services projects, $100 \%$ of respondents strongly agreed that the AgileStage-Gate approach encourages the team to share their values and lessons with the rest of the organization (Figure 51). The project type filter revealed that NPD projects have the best impact on team communication and coordination when integrated with the approach. We can thus conclude that companies are more familiar with the approach when managing NPD Projects.

\section{Agile-Stage-Gate Tools}

Respondents $61 \%$ (Figure 52) of the time strongly agreed that if the crossfunctional teams cannot be present in one place, a virtual meeting tool can be used in lieu of daily in-person stand-ups and $\mathbf{4 5 \%}$ of participants strongly agreed that the project team has a daily scrum meeting, 53\% strongly agreed that the Scrum Task Board is still used and $\mathbf{4 2 \%}$ strongly agreed that the Sprint Review meeting is still implemented so that the team can demonstrate the completed features and receive stakeholder feedback.

\section{Agile-Stage-Gate Tools (based on Product Type)}

When developing software products, $100 \%$ of respondents (Figure 53) strongly agreed that a virtual meeting tool can be used in place of daily in-person stand-ups if the cross-functional teams cannot be present in one place, while just $50 \%$ strongly agreed that the project team has a daily scrum meeting and that the Sprint Review meeting is still applied. For hardware products, $50 \%$ of respondents (Figure 54) strongly agreed that a virtual meeting tool can be used instead of holding daily in-person stand-ups if the cross-functional teams are not present and 50\% strongly agreed that the Scrum Task Board is still applied in the Agile-Stage-Gate approach. For combination products, $50 \%$ of respondents (Figure 55) strongly agreed that if the cross-functional teams cannot be present in one place, a virtual meeting tool can be used instead.

Most of the Agile-Scrum tools, such as the Sprint Review meeting and Daily Scrum Meeting, are still applied in the Agile-Stage-Gate approach. However, some modifications do take place, like the possibility of holding a virtual meeting instead of an in-person meeting. It seems that these tools are more applicable when developing software and combination products with respondents indicating a very strong agreement that the project team is not isolated from the rest of the organization during software product development. In contrast, the results show that the project team is somewhat more isolated from the rest of the organization for other types of product development. Isolation may therefore decrease if 
companies dedicate more focus and attention to the project team when using the approach for hardware and combination products.

\section{Agile-Stage-Gate Tools (based on Project Type)}

In the case of NPD projects, $71 \%$ of respondents (Figure 56) strongly agreed that a virtual meeting tool can be used instead of holding daily in-person stand-ups and $64 \%$ of participants strongly agreed that the project team has a daily scrum meeting.

For R\&D projects, $17 \%$ (Figure 57) strongly agreed that a virtual meeting tool can be used in lieu of daily in-person stand-ups if the cross-functional teams are not present in one place and 50\% strongly agreed that the Scrum Task Board is still used in the Agile-Stage-Gate approach. When analyzing services projects, 0\% (Figure 58) strongly agreed that a virtual meeting tool can be used instead of daily in-person stand-ups as well as $0 \%$ strongly agreed that the project team has a daily scrum meeting. When managing different projects, it is essential to identify what kind of communication tools are most effective within the Agile-Stage-Gate approach. The survey results revealed that Agile-Stage-Gate tools (such as the virtual meeting, daily scrum meeting, Scrum Task Board, and Sprint Review meeting) were used extensively for new product development projects.

\section{Organizational Strategy when Adapting the Agile-Stage-Gate Approach}

The fifth research question (RQ5) aimed to identify factors that encourage companies to adopt this relatively new Agile-Stage-Gate approach and how this adoption integrates into their overall company strategy. 53\% (Figure 59) strongly agreed that the approach allows the company to better deal with uncertain situations and effectively manage complex projects and $\mathbf{5 8 \%}$ strongly agreed that this approach allows senior management to be more involved with all stakeholders.

Organizational Strategy in the Agile-Stage-Gate Approach (based on Product Type)

In the case of software products, 100\% (Figure 60) strongly agreed that the Agile-Stage-Gate approach allows the company to better deal with uncertain situations and effectively manage complex projects, $50 \%$ strongly agreed that this approach allows senior management to be more involved with all stakeholders and $100 \%$ strongly agreed that this approach more effectively integrates the voice and needs of the customer throughout every step of the process.

In the case of hardware products, only $25 \%$ (Figure 61) strongly agreed with most of the statements in this section while $\mathbf{7 5 \%}$ strongly agreed that AgileStage-Gate is an efficient approach that allows companies to more quickly respond to the increasing demand for new and innovative products. In contrast, 57\% (Figure 62) strongly agreed that the approach allows the company to deal with uncertain situations and effectively manage complex projects for products with a combination component and $\mathbf{4 3 \%}$ strongly agreed that this model allows senior management to be more involved with all stakeholders. 
It can be concluded that the Agile-Stage-Gate approach is markedly beneficial in terms of allowing senior management to be more involved with all stakeholders and helping companies to retain control over projects on both the strategic and executive levels. The hybrid model also seems to enable companies to respond quickly to market changes and align the projects with the company strategy.

Most participants strongly agreed that companies can achieve excellent results on very critical goals using the hybrid approach, such as handling uncertain situations and managing complex projects effectively. In the case of software and combination products, participants also strongly agreed that this new approach enables companies to respond quickly to market changes and gives them the ability to align projects with the company strategy. It can therefore be concluded that companies managing software products have an excellent chance to achieve results in line with their long-term strategy by adopting the Agile-Stage-Gate approach.

Organizational Strategy in the Agile-Stage-Gate Approach (based on Project Type)

In the case of NPD, $\mathbf{5 0 \%}$ of respondents (Figure 63) strongly agreed that the Agile-Stage-Gate approach allows the company to better handle uncertain situations, effectively manage complex projects and allows the senior management group to be more involved with all stakeholders. 57\% strongly agreed it helps companies overcome the challenges of developing smart and connected products at a lower price point and $\mathbf{7 1 \%}$ strongly agreed that this approach provides the company with the ability to align the projects with the company's strategy.

For R\&D projects findings reveal that the level of agreement on each question related to organizational strategy is less extreme and most responses were at or under $50 \%$ (Figure 64) when compared to the results of the NPD section. For example, $50 \%$ of participants strongly agreed that the Agile-Stage-Gate approach allows senior management to be more involved with all stakeholders.

When it comes to Services projects, it was strongly agreed (Figure 65) that the new approach is more efficient and allows companies to respond more quickly to the increasing demand for new and innovative products. Based on the project type analysis, the Agile-Stage-Gate approach has promising results when it comes to improving the company's strategic goals with $71 \%$ of the participants citing the goals of aligning projects with the company's strategy during new product development projects.

\section{Agile-Stage-Gate Performance Rate}

To measure the overall achievement when implementing the Agile-StageGate approach, criteria such as productivity, prioritization and reduced time-tomarket were used to measure the effectiveness of this approach based on participant's experience. 63\% of respondents (Figure 66) strongly agreed that the approach enables companies to reduce time-to-market and improve the prioritization process and $\mathbf{7 1 \%}$ strongly agreed the approach improves product quality and productivity, with $\mathbf{5 8 \%}$ agreeing that profitability increases. 
Agile-Stage-Gate Performance Rate (based on Product Type)

In the case of Software products, $\mathbf{1 0 0 \%}$ (Figure 67) strongly agreed that the Agile-Stage-Gate approach enables companies to reduce time-to-market, improve the prioritization process and productivity as seen in. In addition, 50\% strongly agreed that product quality improves and profitability increases. For the hardware products, 50\% of the respondents (Figure 68) strongly agreed that the approach enables companies to reduce time-to-market and $\mathbf{5 0 \%}$ strongly agreed the approach improves product quality and overall productivity. In the case of combination products, 50\% (Figure 69) strongly agreed that the Agile-Stage-Gate approach enables companies to reduce time-to-market, while $\mathbf{7 1 \%}$ agreed the model improves product quality and productivity.

The survey results reveal that the Agile-Stage-Gate approach has beneficial results when it comes to improving the prioritization process, product quality and overall productivity. However, these results are more substantial when the hybrid model is applied to software and combination product development, rather than hardware products when comparing Figures 67 and 69 to Figure 68. It is obvious from the survey findings that the approach has a positive influence on the IT/Software industry and may be a result of this industry implementing the hybrid approach first (before combination and hardware products) and therefore has had more time to test the effectiveness of the hybrid model. These promising results will likely encourage companies to apply the hybrid approach on the hardware products in the future (Kempeneers 2019).

\section{Agile-Stage-Gate Performance Rate (based on Project Type)}

In the case of NPD, 64\% of participants (Figure 70) strongly agreed that the Agile-Stage-Gate approach enables companies to reduce time-to-market and $\mathbf{8 6 \%}$ agreed it improves product quality, while $\mathbf{7 1 \%}$ agreed the model improves productivity and $\mathbf{7 9 \%}$ agreed the approach increases profitability.

In the case of R\&D projects, $67 \%$ of respondents (Figure 71) strongly agreed that the Agile-Stage-Gate approach enables companies to reduce time-tomarket, improve product quality and productivity while $\mathbf{5 0 \%}$ of participants agreed the model improves the prioritization process and increases profitability. In stark contrast, $0 \%$ of participants (Figure 72) strongly agreed on the items listed when evaluating service projects.

After examining the results of the Agile-Stage-Gate, it is clear that the approach has a significant impact on improving product quality, productivity, and increasing profitability when firms adopt the approach to manage NPD and R\&D projects as seen in Figures 70 and 71 . In contrast, the new approach has a lower percentage when it comes to services projects.

\section{Conclusions}

An overview of the standard structure, roles, and responsibilities in the AgileStage-Gate approach in which most participants strongly agreed, patterns emerged from the study results and that those consistent patterns improve productivity and efficiency within the team. Table 1 presents all the structures, roles, and 
responsibilities of the Agile-Stage-Gate approach that emerge for each product and project type and also provides the total percentage for each category that the participants strongly agreed on. The percentages greater than $50 \%$ were highlighted to identify the most common features when implementing the Agile-Stage-Gate approach. The purpose of this table is to identify the differences and similarities of the Agile-Stage-Gate approach when it is implemented to manage different product and project types. By studying these results, manufacturing firms can learn how this approach is performing in each category, what problems it best solves and what areas of the hybrid approach still need to be improved.

Table 1. Total Percentage of the Main Survey's Areas

\begin{tabular}{|l|c|c|c|c|c|c|}
\hline \multirow{2}{*}{ Task group } & \multicolumn{2}{|c|}{ Product type - \% Strongly agree } & \multicolumn{2}{|c|}{ Project type $\%$ Strongly agree } \\
\cline { 2 - 7 } & Software & Hardware & Combination & $\begin{array}{c}\text { New Product } \\
\text { Development }\end{array}$ & R\&D & Services \\
\hline $\begin{array}{l}\text { Q7- For what type of projects does } \\
\text { your company use the Agile-Stage- } \\
\text { Gate approach? }\end{array}$ & & & & $70 \%$ & $25 \%$ & $5 \%$ \\
\hline $\begin{array}{l}\text { Q8- For what type of products does } \\
\text { your company use the Agile-Stage- } \\
\text { Gate approach? }\end{array}$ & $10 \%$ & $20 \%$ & $70 \%$ & & & \\
\hline $\begin{array}{l}\text { B. Common Structure and Features } \\
\text { of the Agile-Stage-Gate Model }\end{array}$ & $83 \%$ & $25 \%$ & $42 \%$ & $48 \%$ & $31 \%$ & $0 \%$ \\
\hline $\begin{array}{l}\text { C. Project team roles within the } \\
\text { Agile-Stage-Gate model }\end{array}$ & $60 \%$ & $17 \%$ & $47 \%$ & $56 \%$ & $19 \%$ & $7 \%$ \\
\hline $\begin{array}{l}\text { D. Responsibilities in the Agile- } \\
\text { Stage-Gate model }\end{array}$ & $64 \%$ & $43 \%$ & $49 \%$ & $56 \%$ & $40 \%$ & $14 \%$ \\
\hline $\begin{array}{l}\text { E. Communication and teamwork } \\
\text { performance in the Agile-Stage-Gate } \\
\text { model }\end{array}$ & $75 \%$ & $22 \%$ & $44 \%$ & $51 \%$ & $25 \%$ & $0 \%$ \\
\hline $\begin{array}{l}\text { F. Organization strategy of adapting } \\
\text { Agile-Stage-Gate model and } \\
\text { changes }\end{array}$ & $77 \%$ & $20 \%$ & $44 \%$ & $50 \%$ & $29 \%$ & $18 \%$ \\
\hline G. Agile-Stage-Gate rate & $80 \%$ & $40 \%$ & $61 \%$ & $70 \%$ & $60 \%$ & $0 \%$ \\
\hline $\begin{array}{l}\text { Q67-The Agile-Stage-Gate approach } \\
\text { improves product quality. }\end{array}$ & $50 \%$ & $50 \%$ & $71 \%$ & $86 \%$ & $67 \%$ & $0 \%$ \\
\hline $\begin{array}{l}\text { Q68-The Agile-Stage-Gate approach } \\
\text { improves productivity. }\end{array}$ & $100 \%$ & $50 \%$ & $71 \%$ & $71 \%$ & $67 \%$ & $0 \%$ \\
\hline $\begin{array}{l}\text { Q69-The Agile-Stage-Gate approach } \\
\text { improves the prioritization process. }\end{array}$ & $100 \%$ & $25 \%$ & $57 \%$ & $50 \%$ & $50 \%$ & $0 \%$ \\
\hline $\begin{array}{l}\text { Q70-The Agile-Stage-Gate approach } \\
\text { increases profitability. }\end{array}$ & $50 \%$ & $25 \%$ & $57 \%$ & $79 \%$ & $50 \%$ & $0 \%$ \\
\hline $\begin{array}{l}\text { Q71-The Agile-Stage-Gate approach } \\
\text { enables companies to reduce time- } \\
\text { to-market. }\end{array}$ & $100 \%$ & $50 \%$ & $50 \%$ & $64 \%$ & $67 \%$ & $0 \%$ \\
\hline
\end{tabular}

The result of this research provides strong evidence that the hybrid approach is a promising model when it comes to managing combination products. These findings support most of the research outcomes that were outlined in the literature review. The study also reveals that the hybrid approach can improve the management of Product Development projects as well. This is a very promising result for manufacturing firms that are willing to adopt this hybrid approach for combination products and Product Development projects.

One of the most important findings that has emerged from this study is that highest benefit that comes from integrating of the Agile-Scrum model is not 
limited to a specific stage, from initiation to the final stage. Instead, manufacturing firms can apply this model throughout all different stages of the Stage-Gate model. In addition, the study shows that most of the Agile-Scrum features and Stage-Gate processes are not only effectively applied when the Agile and Stage-Gate models are combined, but also improve overall performance. Although some companies prefer to keep some of the traditional roles like Project Manager when they adopt the new approach, the study reveals that the roles in the hybrid approach can be slotted into existing roles as needed and that companies do not need to hire new employees for these positions.

My initial assumption nine months ago before diving deeply into this research was that the hybrid approach would have the greatest impact when managing products that have a combination component (software and hardware). However, the study has revealed that the Agile-Stage-Gate approach also greatly improves the efficiency and productivity of software products as well, even though the benefits of applying this approach are clear based on the survey results, surprisingly only $10 \%$ of manufacturing companies use the hybrid approach to manage software products. Perhaps in the future, there will be a higher percentage of companies that apply the hybrid approach as they will see the direct benefits to their team communication and market response time.

The hybrid approach has also been proven to positively impact many aspects of the management process, such as increasing productivity and reducing time-tomarket (specifically in the case of software products). Companies currently use this approach most often for combination products and new product development projects, according to $70 \%$ of participants, as seen in Table 1 . There is also a positive impact on product quality, productivity and profitability when dealing with combination products and managing new product development projects when operating within this hybrid model. Overall, the study's results indicate that the early adopters are still attempting to find the best combination of both the StageGate and Agile-Scrum models. This result also highlights how much room there is for improvement and clarification when it comes to companies adjusting and modifying the hybrid approach during implementation. The maturity of the hybrid model has not yet been reached; therefore its full potential is still unknown. It is clear from the results of this research that the Agile-Stage-Gate approach does not work for every kind of products and projects. More detailed studies should be conducted to examine the application of the new approach on each type of product and project that is mentioned in this study.

The focus of this study was on the participants who strongly agree on the survey questions to best identify patterns that emerge. However, there were still a significant number of respondents selected "somewhat agree" and these answers should be considered in future studies as well. In the future, more studies should be conducted to investigate why the hybrid approach does not work for projects that provide service to customers and what should be adjusted in this hybrid approach in order for it to be the most effective option for companies to manage services projects.

The Agile-Stage-Gate approach was initially created to find a better solution for complex combination products. This study confirms that the hybrid approach is 
in fact the best option for combination products, but that there is also much improvement to be gained when applied to software products as well. In conclusion, defining the consistent structure, roles, and responsibilities of this new approach is what led to these findings, and the results provide a roadmap for future companies that want improved productivity, efficiency and communication within manufacturing production.

\section{References}

Cooper RG (1990) Stage-gate systems: a new tool for managing new products. Business Horizons 33(3): 44-54.

Cooper RG (2006) Managing technology development projects. Research-Technology Management 49(6): 23-31.

Cooper RG (2010) The stage-gate idea to launch system. Wiley International Encyclopedia of Marketing.

Cooper RG (2011) Winning at new products: creating value through innovation. $4^{\text {th }}$ Edition. New York: Basic Books.

Cooper RG (2015) The latest view: the Stage-Gate ${ }^{\circledR}$ system for new product development. Product Development Institute Inc. Retrieved from: http://bobcooper.ca/images/files/ articles/2/2-2-The-Latest-View-on-Stage-Gate.pdf. [Accessed 6 October 2017]

Cooper RG, Sommer AF (2016a) Agile-Stage-Gate: new idea-to-launch method for manufactured new products is faster, more responsive. Industrial Marketing Management 59(Nov): 167-180.

Cooper RG, Sommer AF (2016b) The Agile-Stage-Gate hybrid model: a promising new approach and a new research opportunity. Journal of Product Innovation Management 33(5): 513-526.

Karlström D, Runeson P (2005) Combining agile methods with stage-gate project management. IEEE Software 22(3): 43-49.

Karlström D, Runeson P (2006) Integrating agile software development into stage-gate managed product development. Empirical Software Engineering 11(2): 203-225.

Kempeneers J (2019) Scaled agile. Personal Interview, November 2019.

Schwaber K (2004) Agile project management with Scrum. Microsoft Press.

Schwaber K, Sutherland J (2017) The scrum guide. The definitive guide to scrum: the rules of the game. Retrieved from:_ https://www.scrumguides.org/docs/scrumguide/ v2017/2017-Scrum-Guide-US.pdf\#zoom=100. [Accessed 6 May 2019]

Scrum Alliance (2015) The 2015 state of Scrum report. Westminster, CO: Scrum Alliance.

Sliger M (2011) Agile project management with Scrum. Paper Presented at PMI® Global Congress 2011-North America, Dallas, TX. Newtown Square, PA: Project Management Institute.

Sommer AF, Hedegaard C, Dukovska-Popovska I, Steger-Jensen K (2015) Improved product development performance through Agile/Stage-Gate hybrids: the nextgeneration Stage-Gate process. Research-Technology Management 58(1): 34-45.

Vedsmand T, Kielgast S, Cooper RG (2016) Integrating agile with Stage-Gate ${ }^{\circledR}-$ How new Agile-Scrum methods lead to faster and better innovation. Innovation management. SE. Retrieved from: http://www.innovationmanagement.se/2016/08/ 09/integrating-agile-with-stage-gate/. [Accessed 6 May 2019]

White KRJ (2008) Agile project management: a mandate for the changing business environment. Paper Presented at PMI® Global Congress 2008-North America, Denver, CO. Newtown Square, PA: Project Management Institute. 


\section{Appendix}

Figures 10-15 were not used.

Figure 17. Agile-Stage-Gate Structure within Companies that have Implemented Stage-Gate First

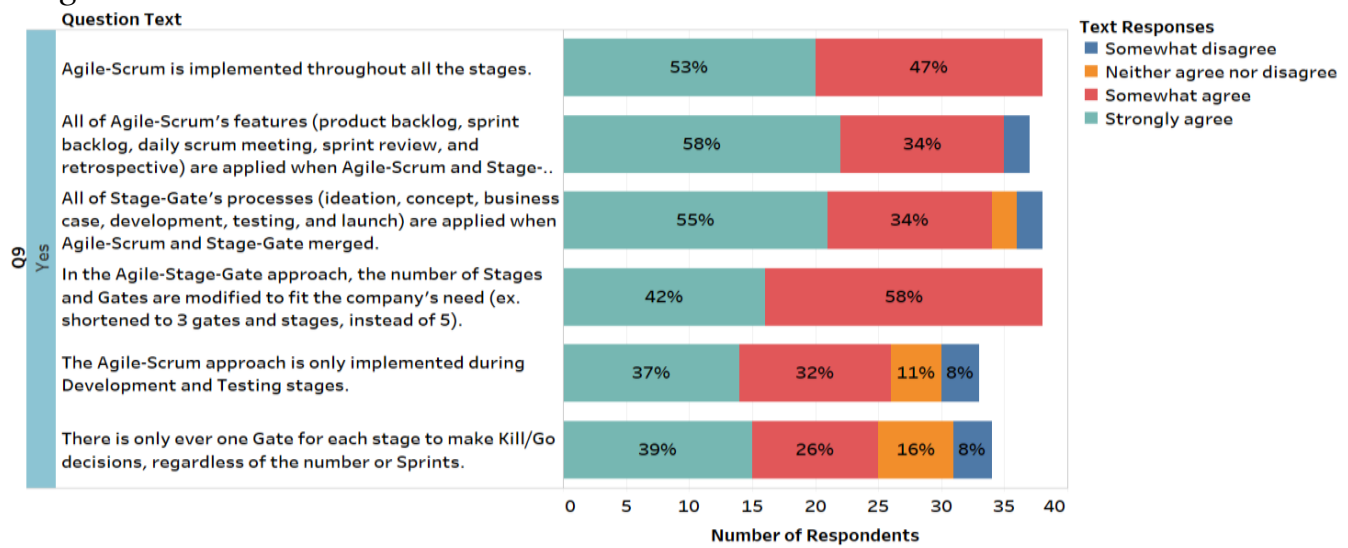

Figure 18. Participants Describe the Agile-Stage-Gate Structure for a Software Product
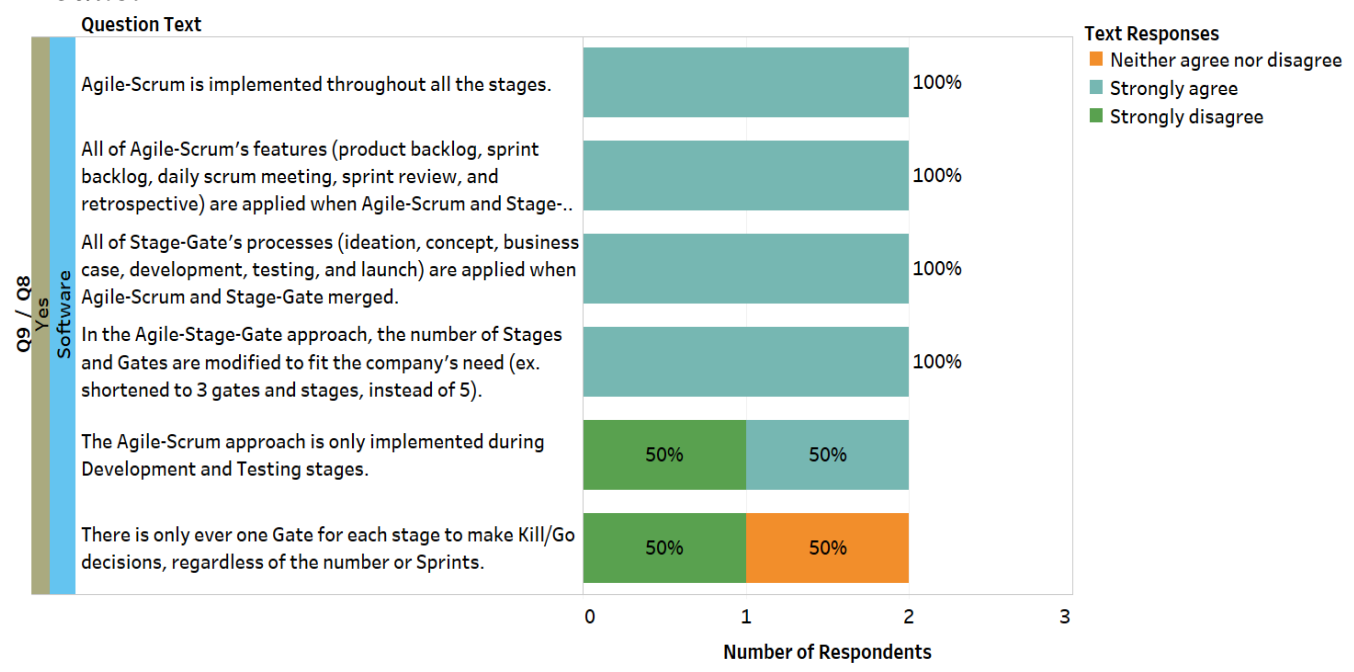

Figure 19. Agile-Stage-Gate Structure for Hardware Products

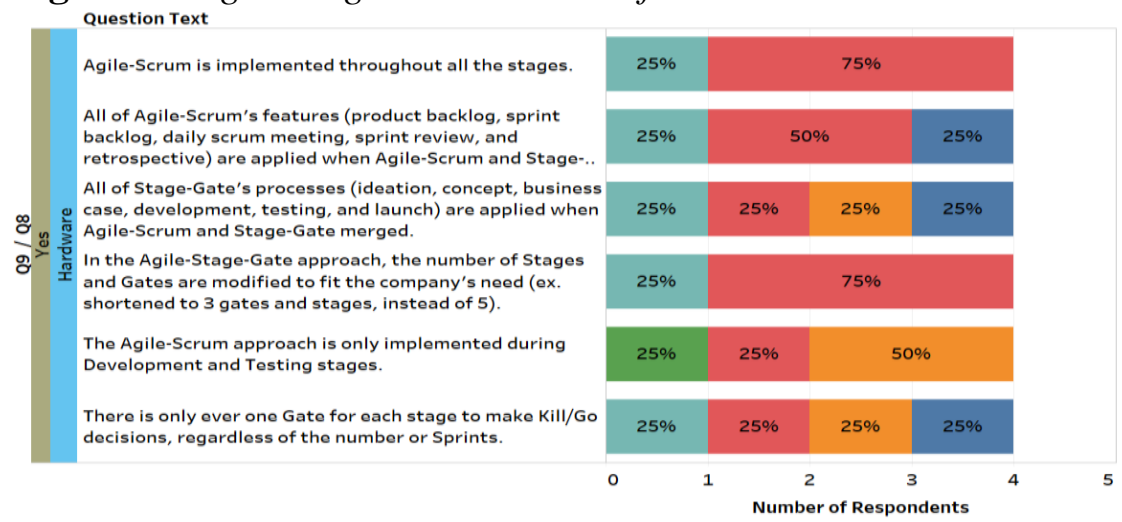


Figure 20. Agile-Stage-Gate Structure for Combination Products

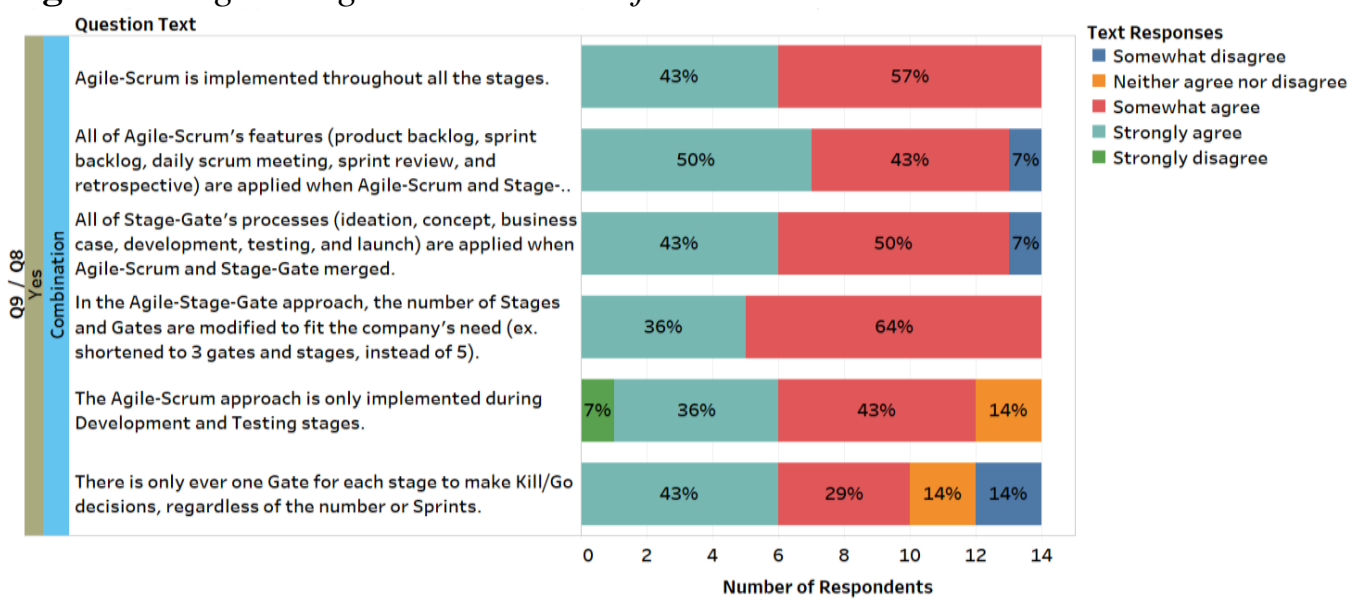

Figure 21. The Agile-Stage-Gate Structure is Filtered by Project Type

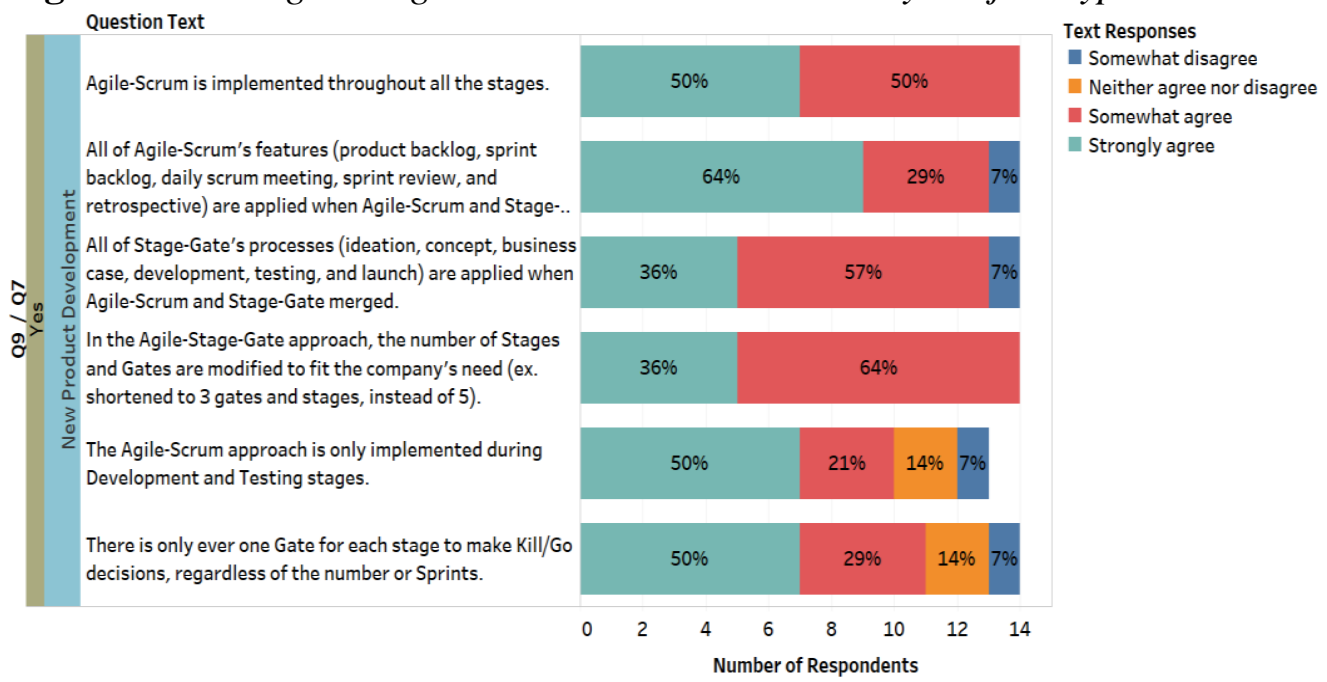

Figure 22. Agile-Stage-Gate Structure for R\&D Projects

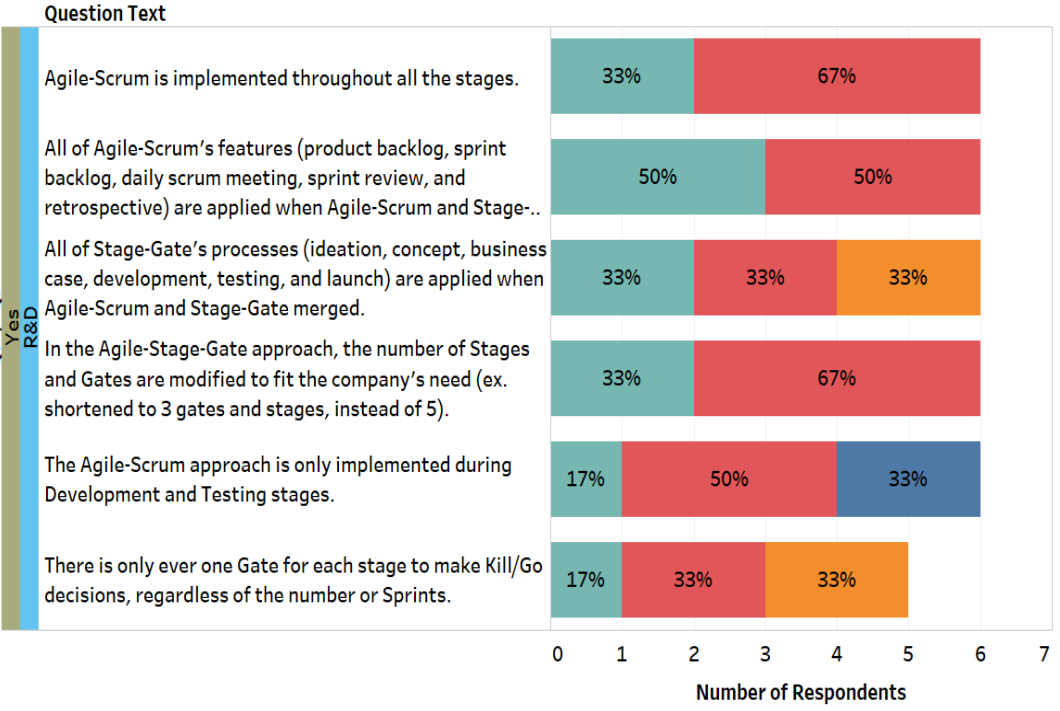

Text Responses

- Somewhat disagree

Neither agree nor disagree

- Somewhat agree

- Strongly agree 
Figure 23. Agile-Stage-Gate Structure for Service Projects

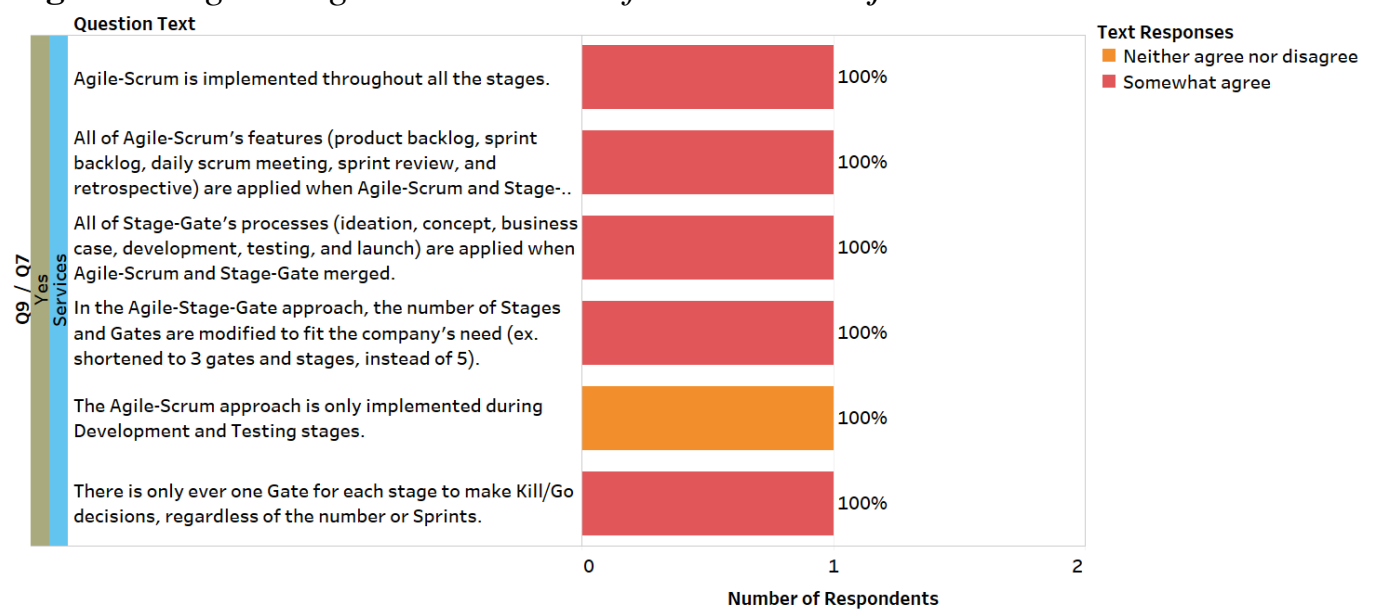

Figure 24. Project Team Composition and Characteristics in the Agile-Stage-

\section{Gate Model}

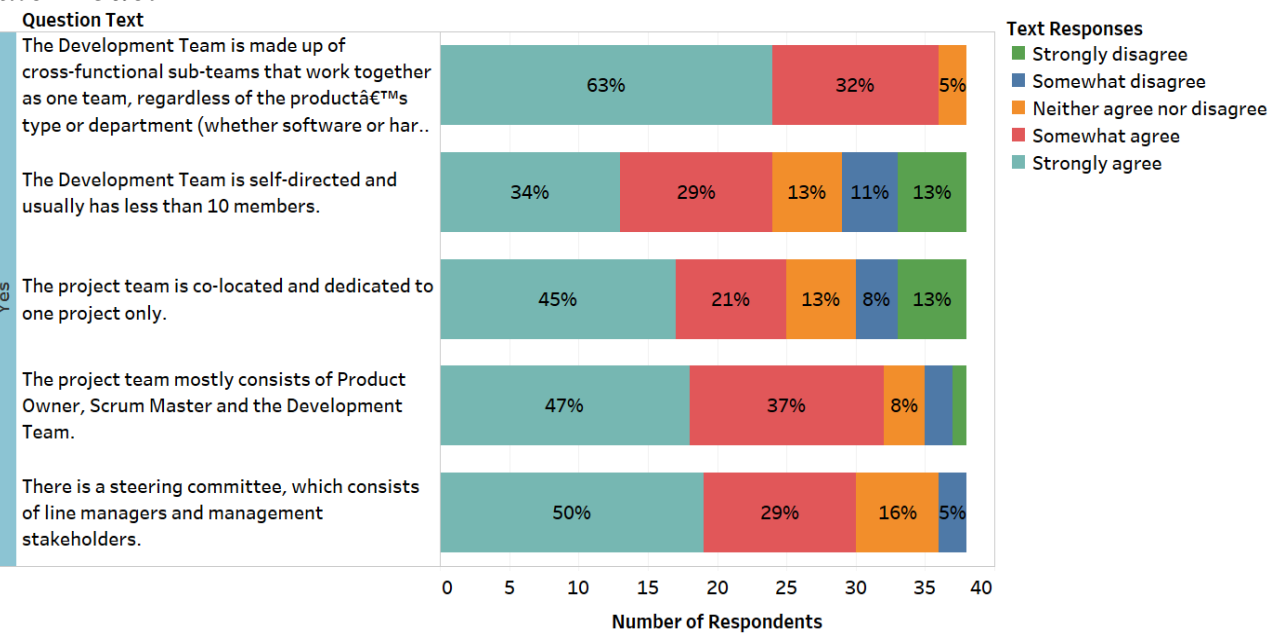

Figure 25. Project Team Roles in the Agile-Stage-Gate Approach

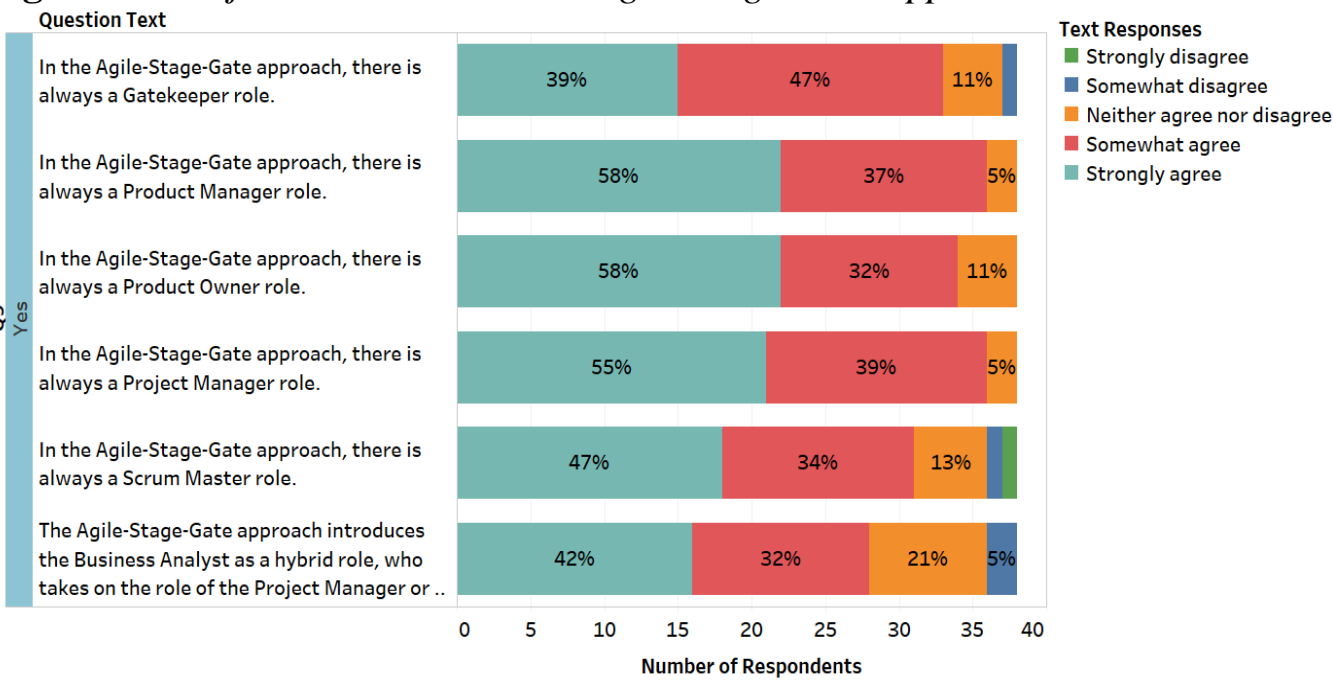


Figure 26. Project Team Roles in the Agile-Stage-Gate Model for a Software

Product

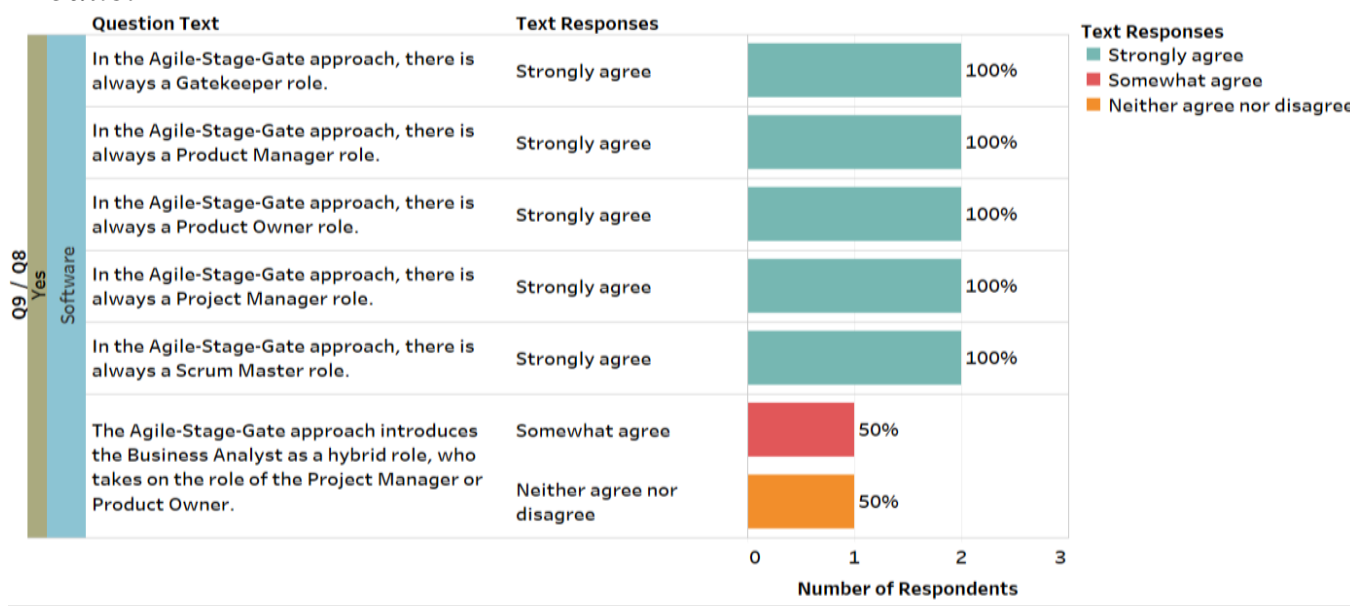

Figure 27. Project Team Roles in the Agile-Stage-Gate Model when Developing Hardware Products

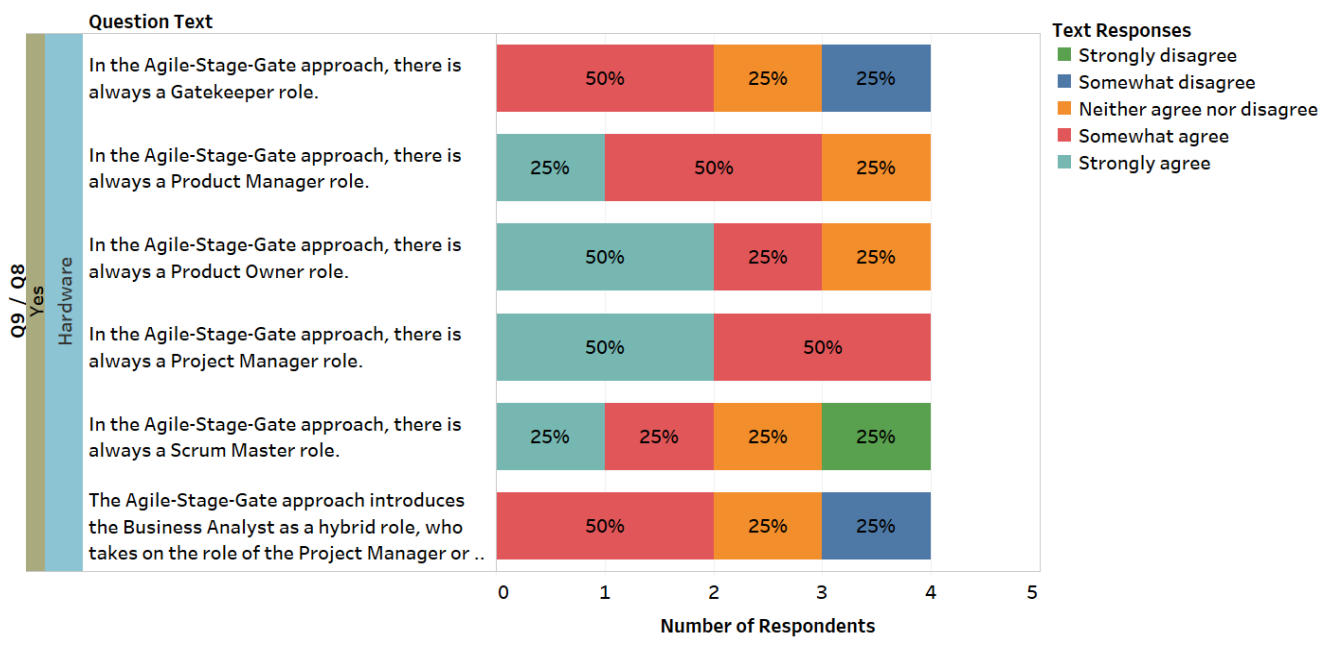

Figure 28. Project Team Roles in the Agile-Stage-Gate Model when Developing Combination Products

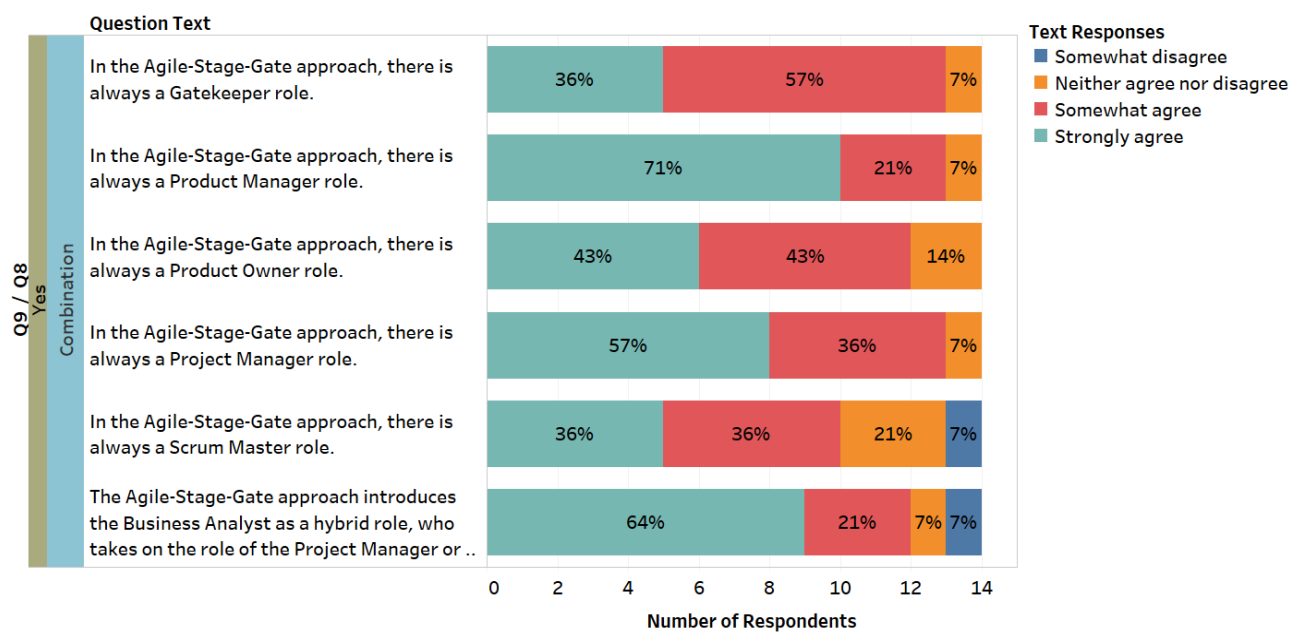


Figure 29. Project Team Roles for New Product Development

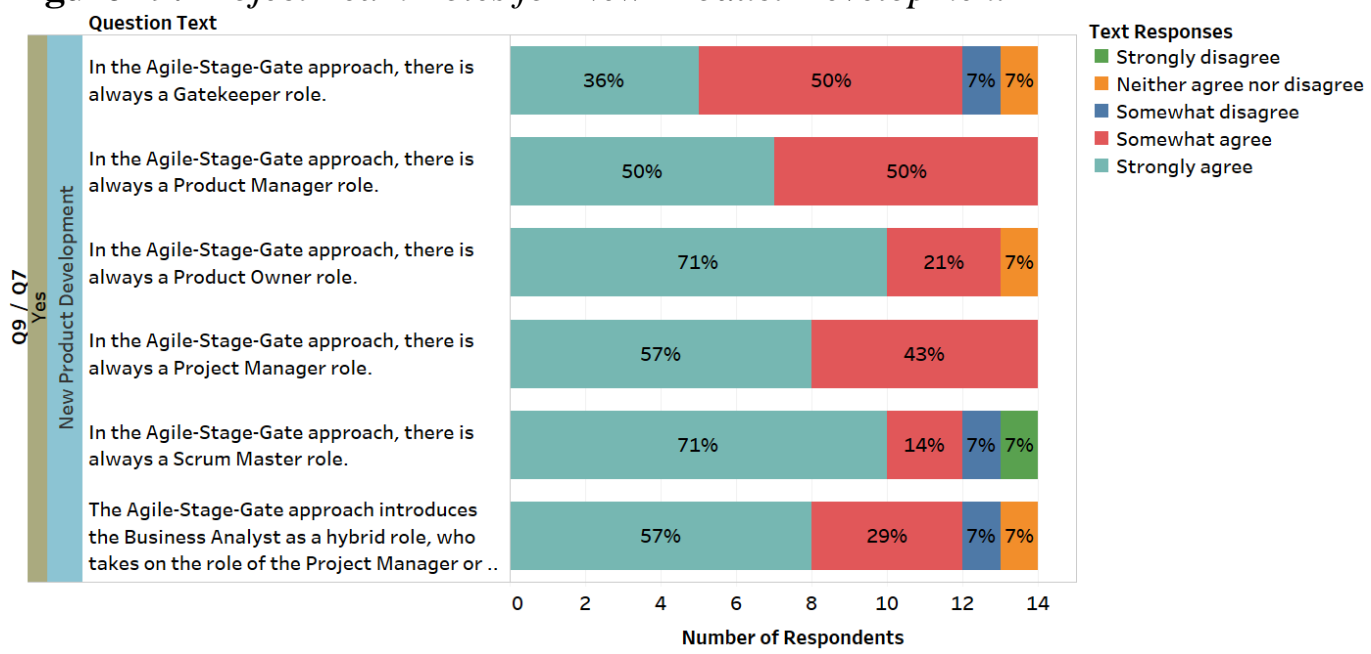

Figure 30. Project Team Roles in the Agile-Stage-Gate Model for R\&D Projects

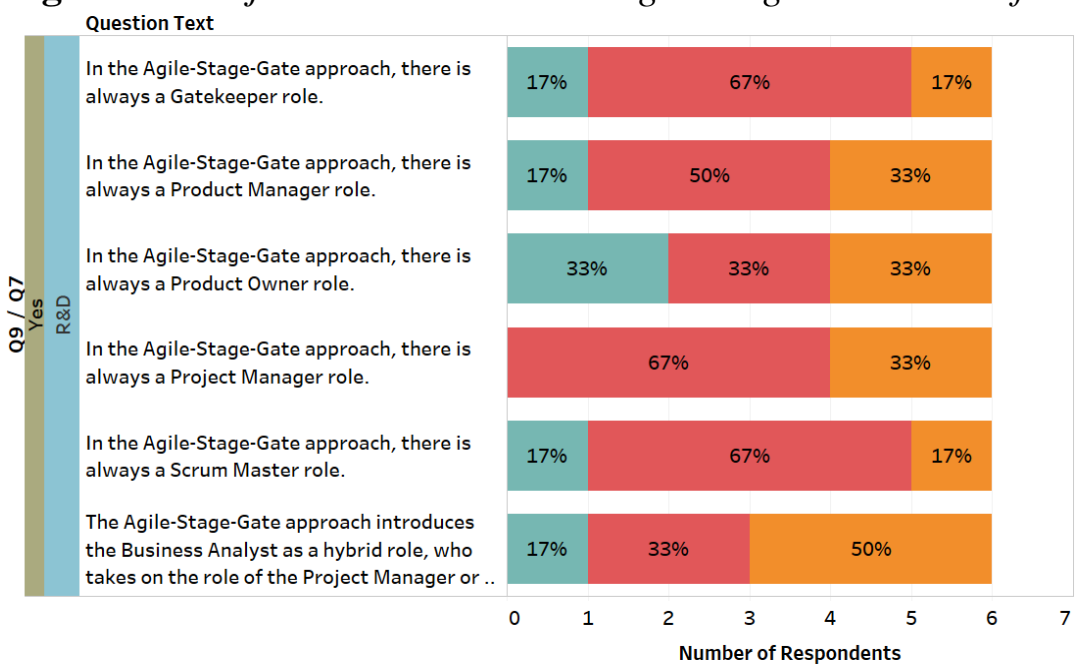

Figure 31. Project Team Roles in the Agile-Stage-Gate Model for Services Projects

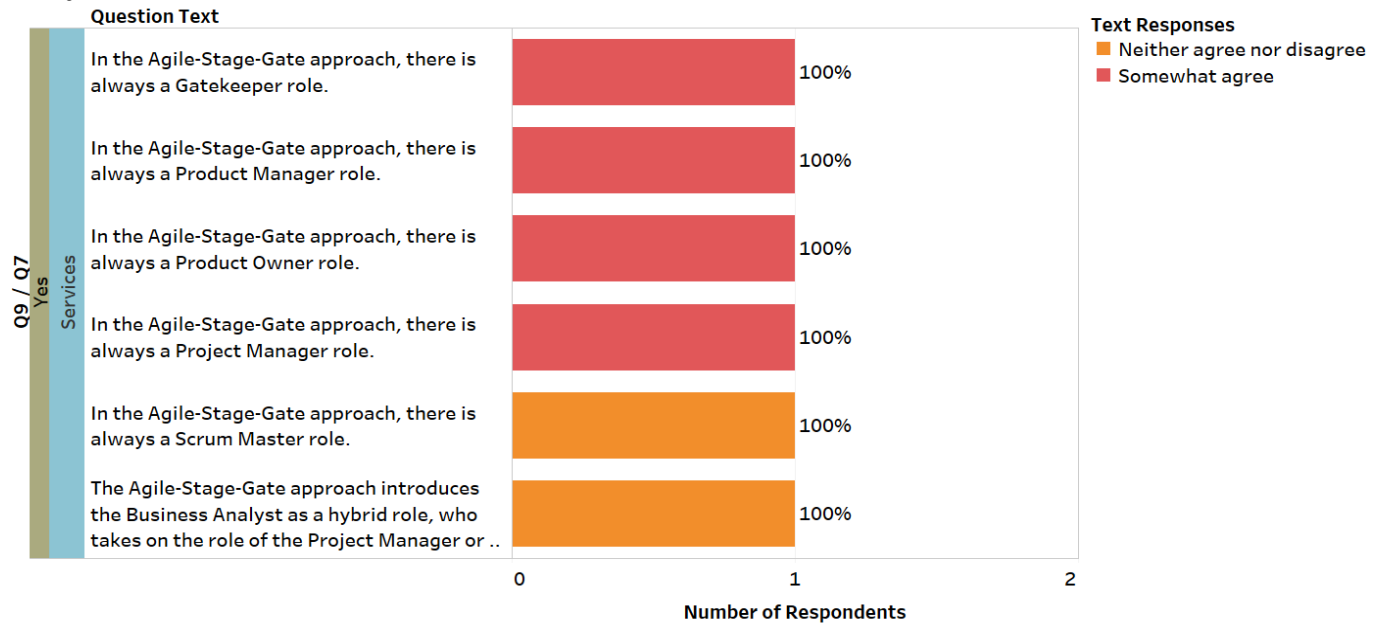


Figure 32. Project Team Roles for Software Products

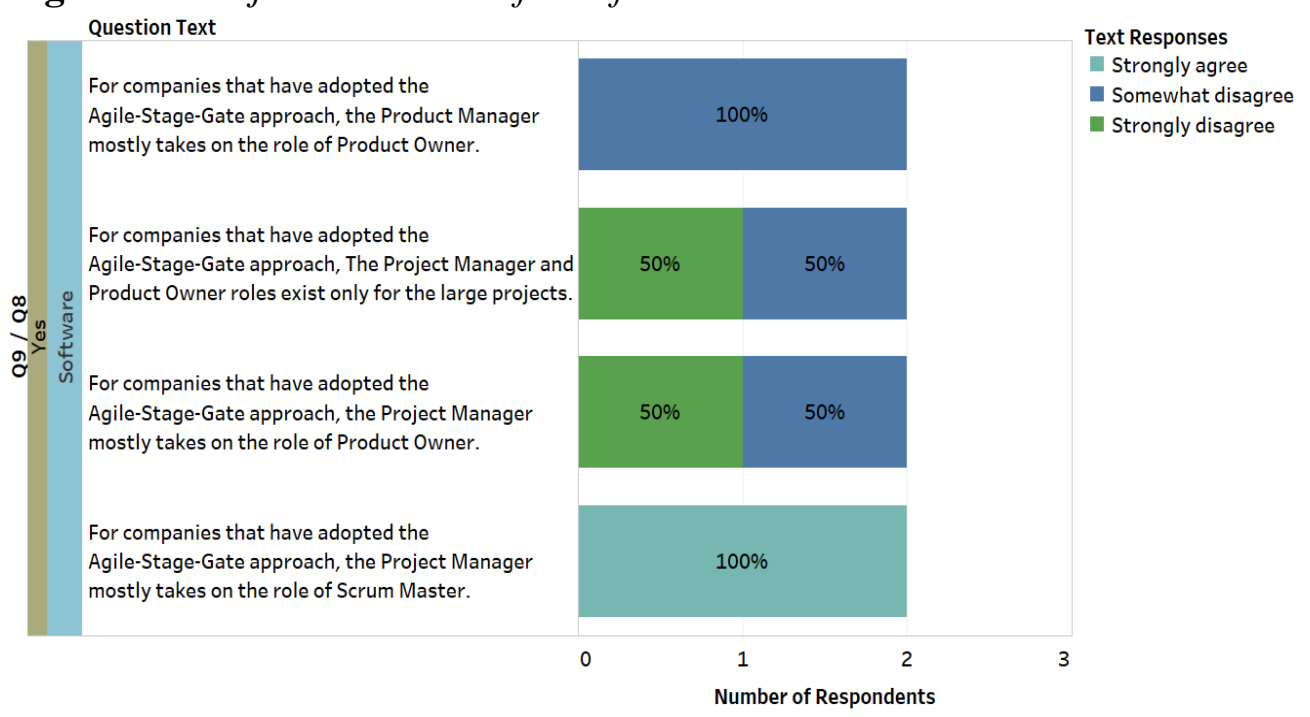

Figure 33. Project Team Roles after Adopting the Agile-Stage-Gate Model for Hardware Products

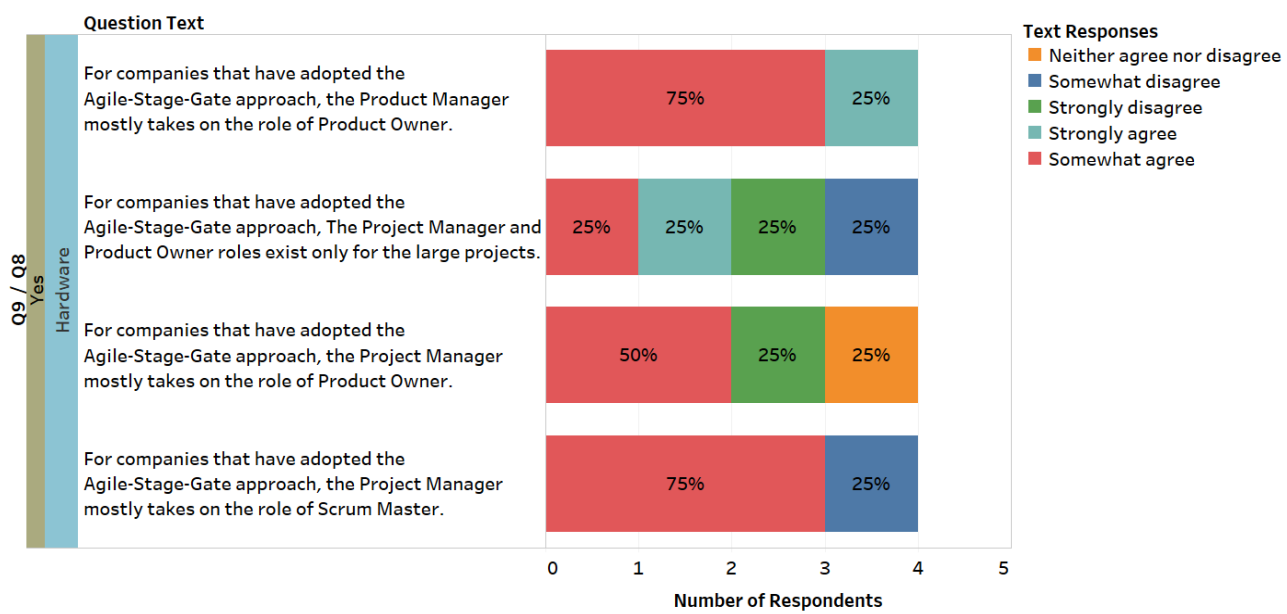

Figure 34. Project Team Roles after Adopting the Agile-Stage-Gate Model for Combination Products

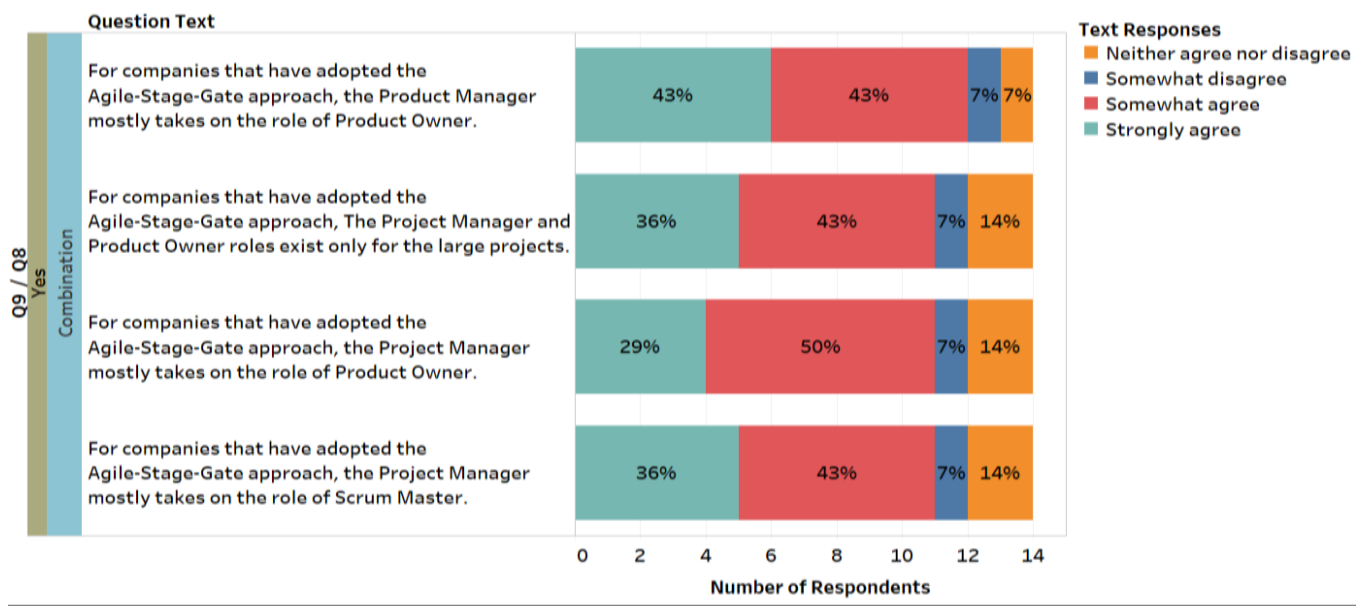


Figure 35. Adjusted Project Team Roles for New Product Development

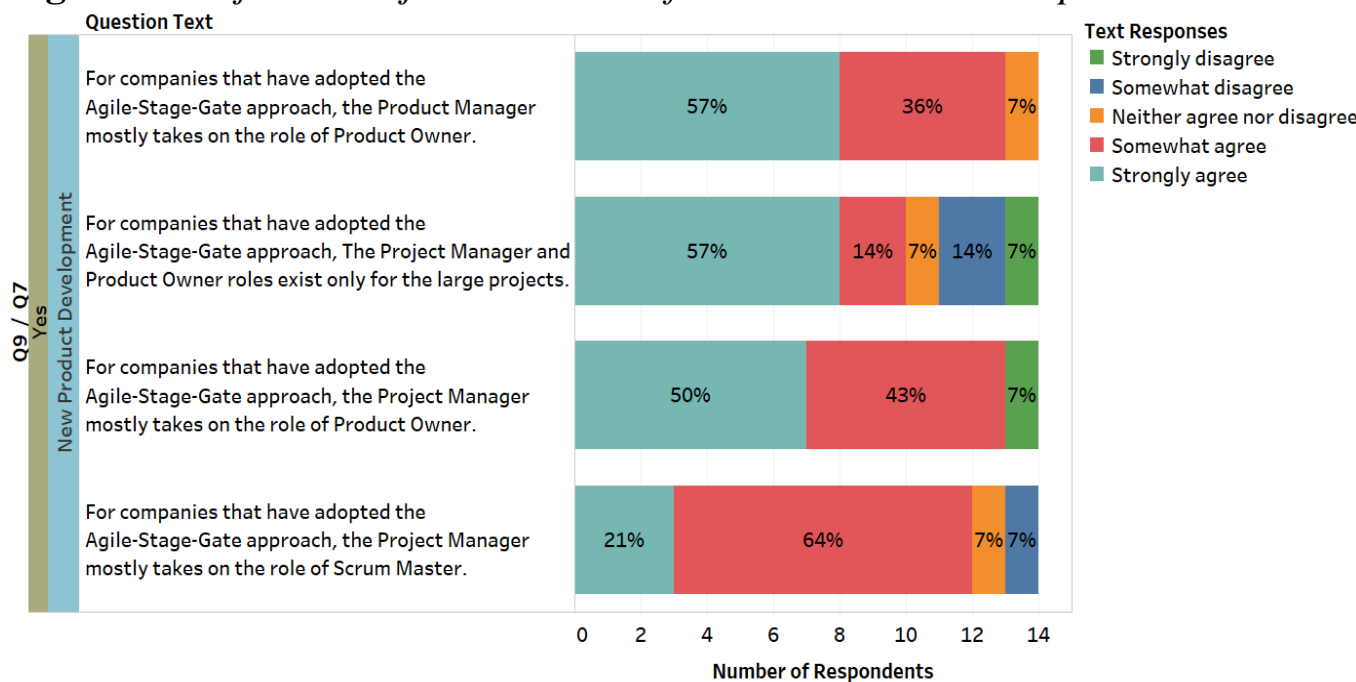

Figure 36. Project Team Roles after Adopting the Agile-Stage-Gate Model for $R \& D$ Projects

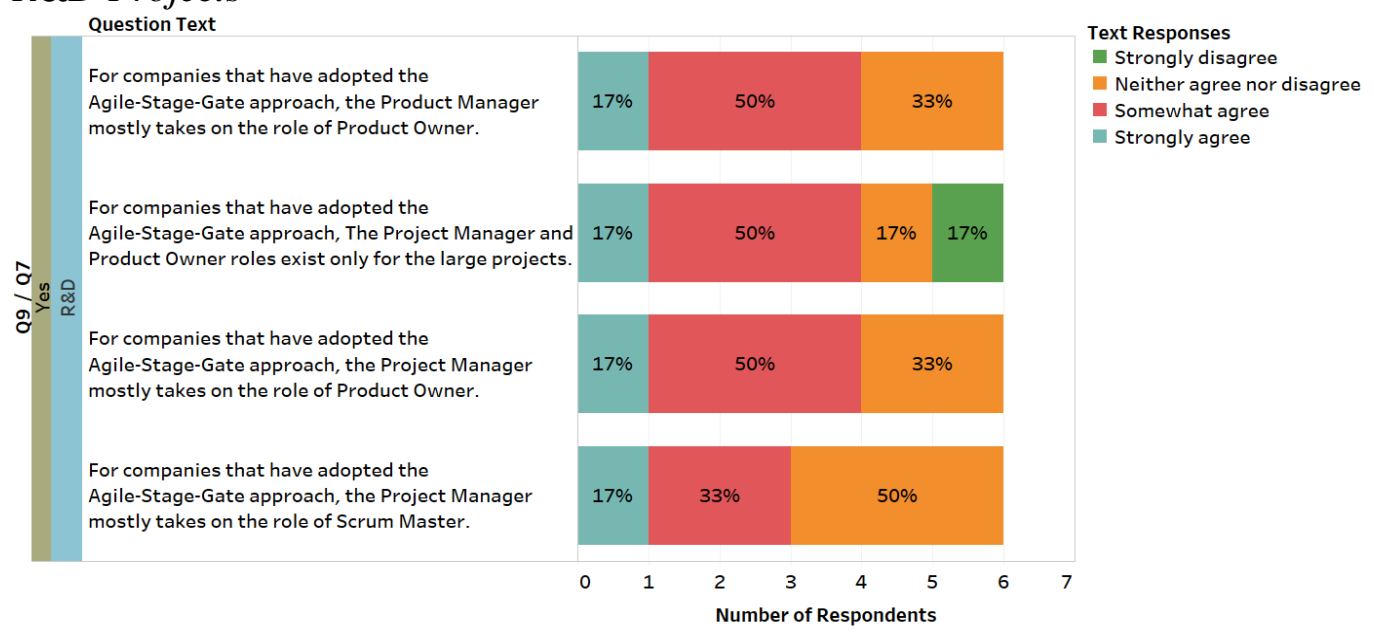

Figure 37. Project Team Roles after Adopting the Agile-Stage-Gate Model for Services Projects

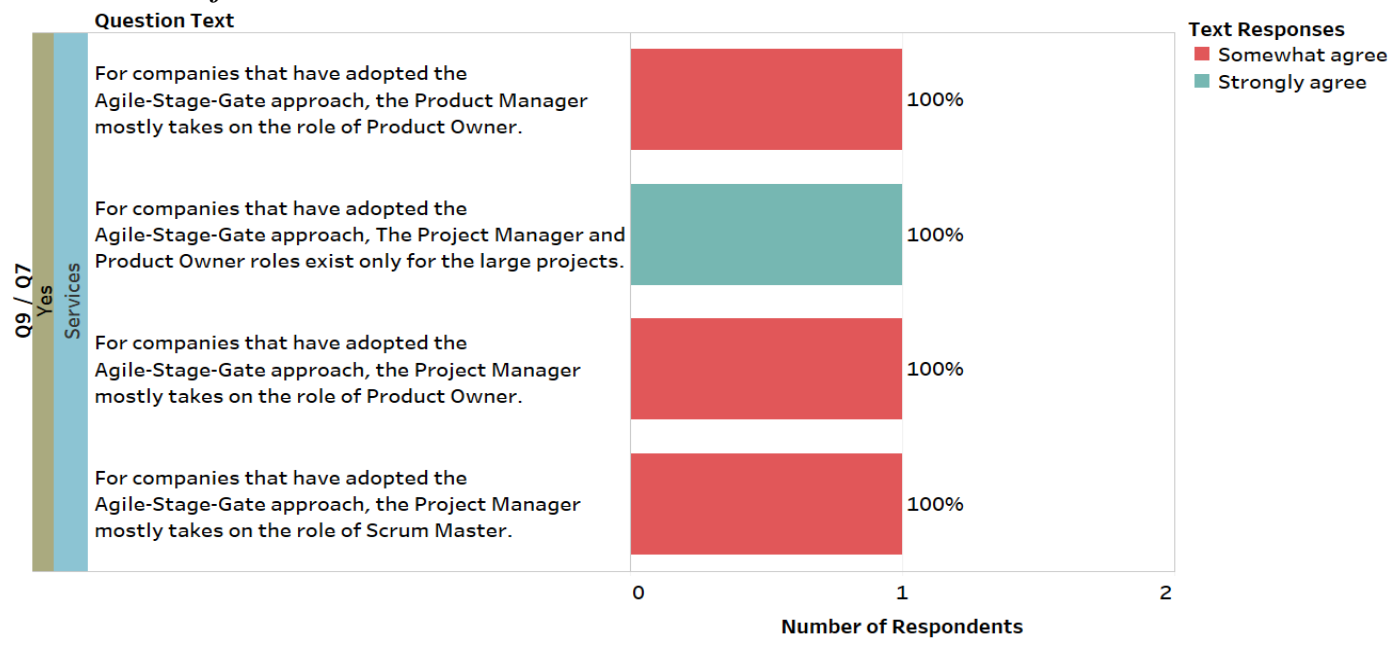


Figure 38. Project Team Responsibilities within the Agile-Stage-Gate Approach

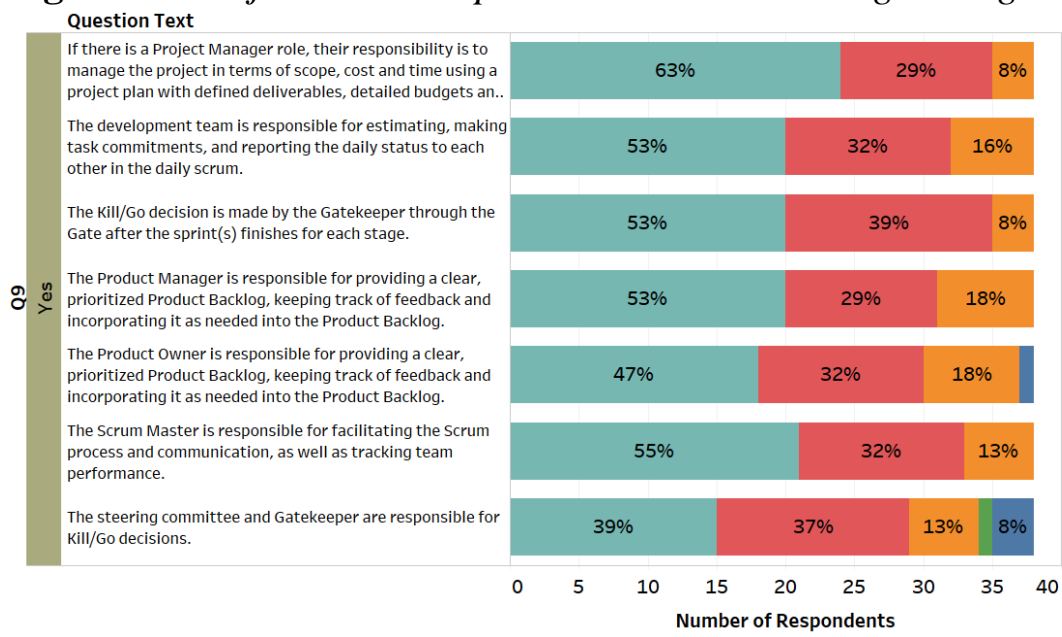

Text Responses

Somewhat disagree

Strongly disagree

Neither agree nor disagree

Somewhat agree

Strongly agree

Figure 39. Project Team Responsibilities for Software Products

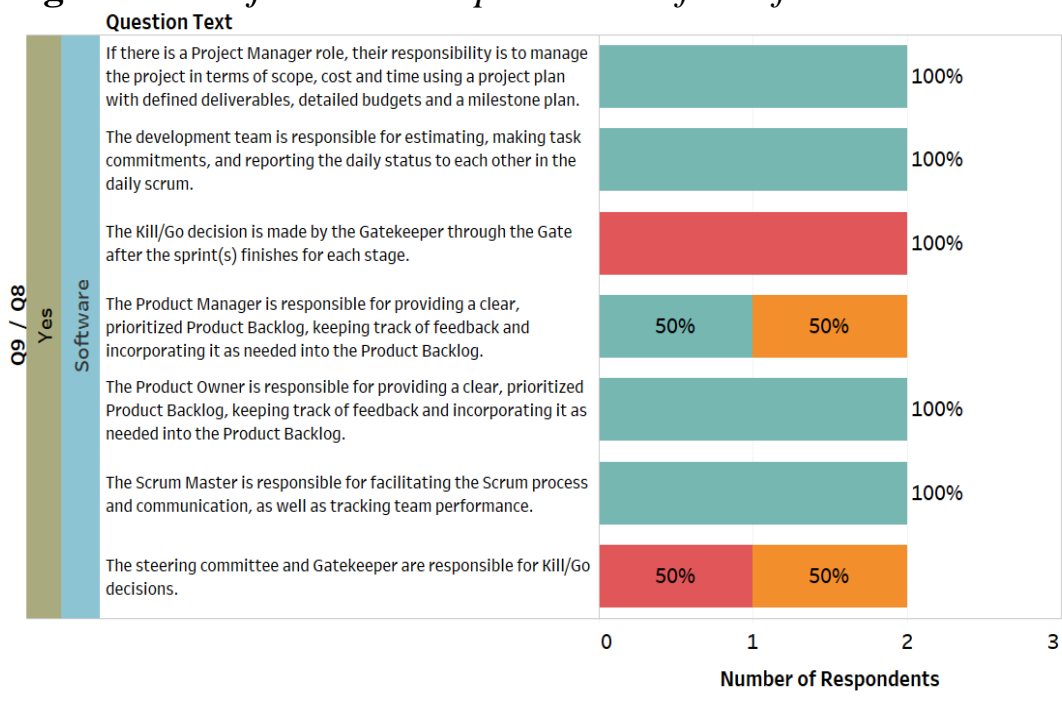

Text Responses

Neither agree nor disagree

- Somewhat agree

Strongly agree

Figure 40. Project Team Responsibilities in the Agile-Stage-Gate Approach for Hardware Products

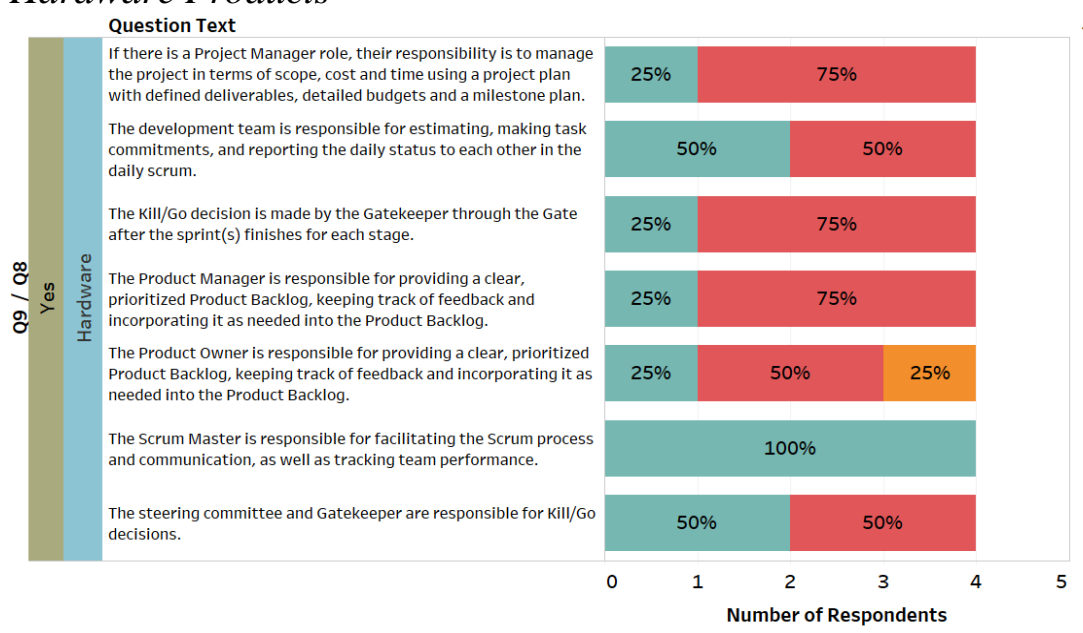

Text Responses

Neither agree nor disagree

- Somewhat agree

- Strongly agree 
Figure 41. Project Team Responsibilities in the Agile-Stage-Gate Approach for Combination Products

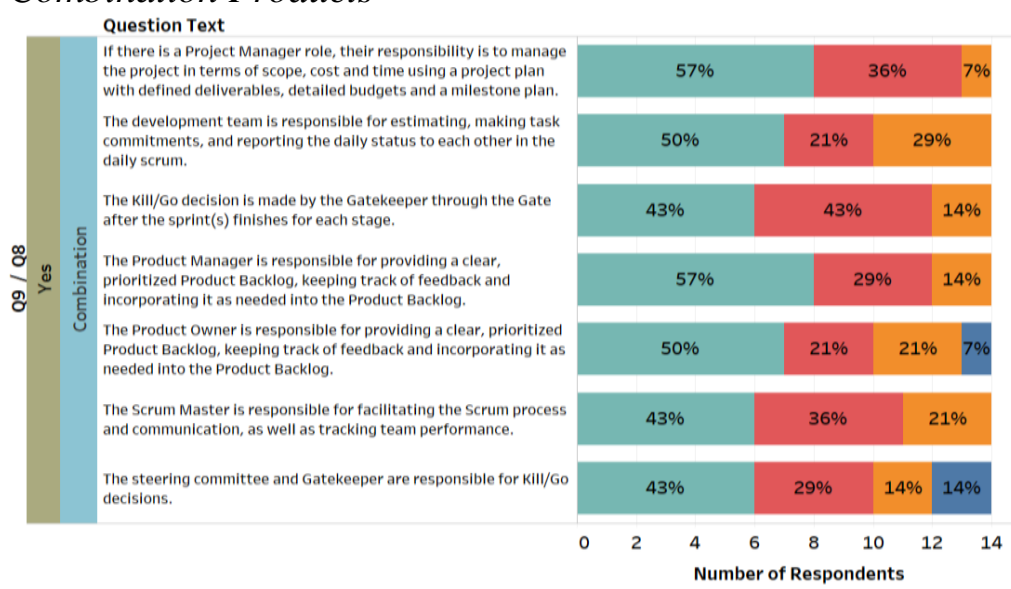

Text Responses

Tomewhat disagree

Neither agree nor disagree

- Somewhat agree

- Strongly agree

Figure 42. Project Team Responsibilities for New Product Development

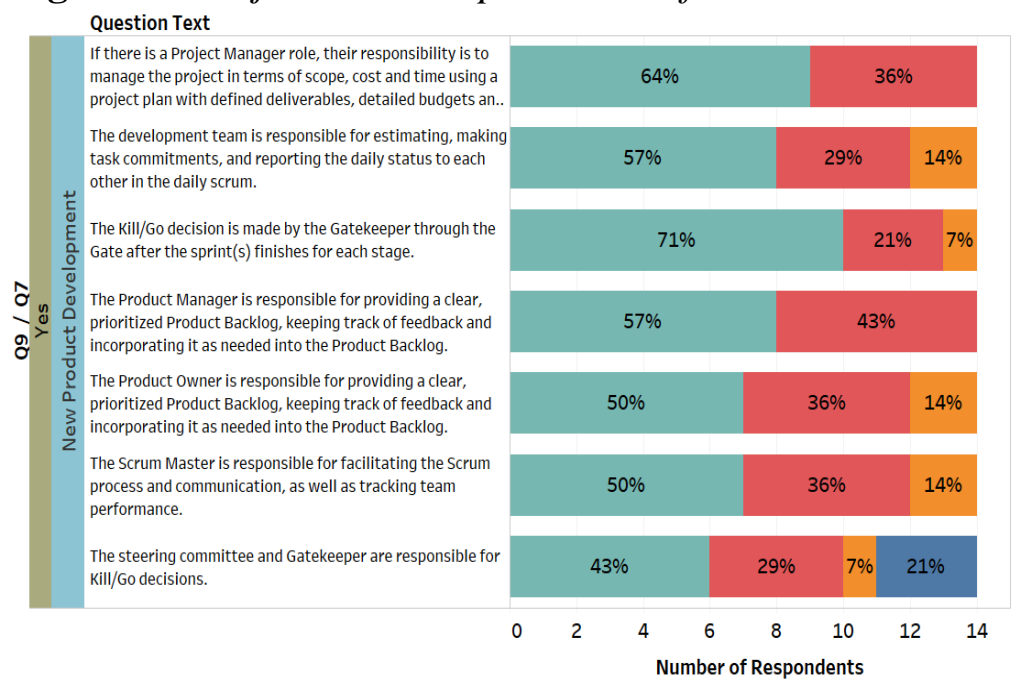

Text Responses

Somewhat disagree

Neither agree nor disagree

- Somewhat agree

Strongly agree

Figure 43. Project Team Responsibilities in the Agile-Stage-Gate Approach for $R \& D$ Projects

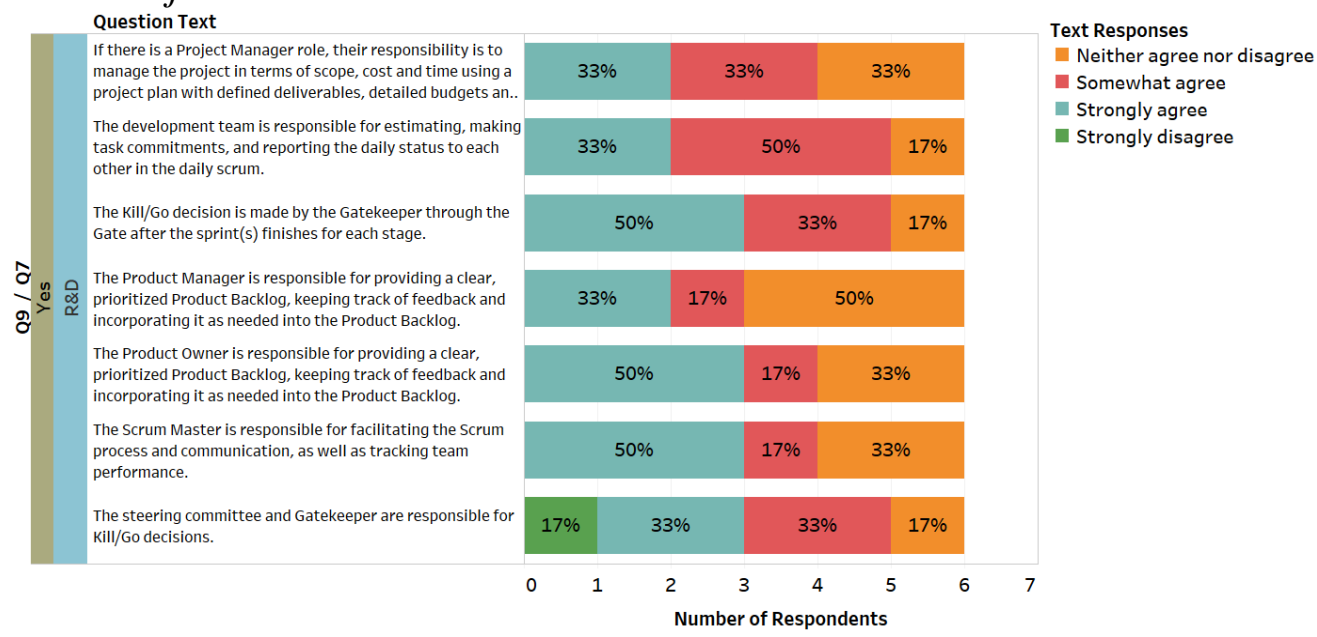


Figure 44. Project Team Responsibilities in the Agile-Stage-Gate Approach for Services Projects

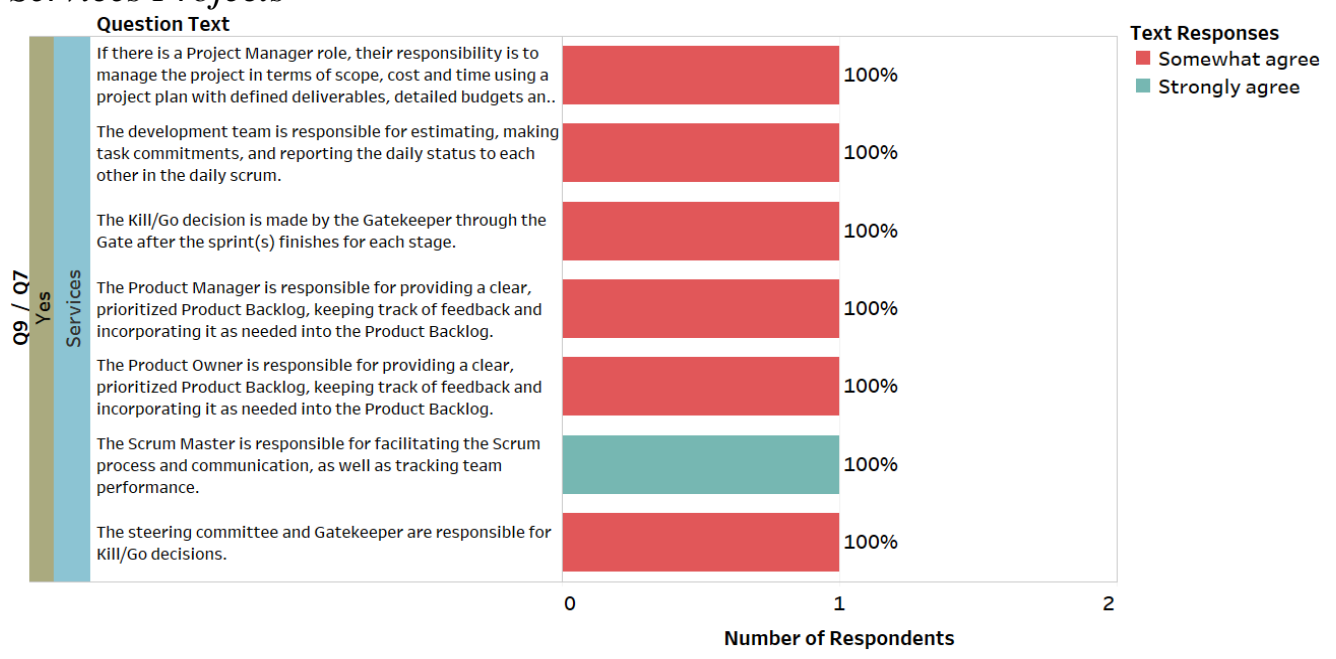

Figure 45. Project Team Communication and Coordination

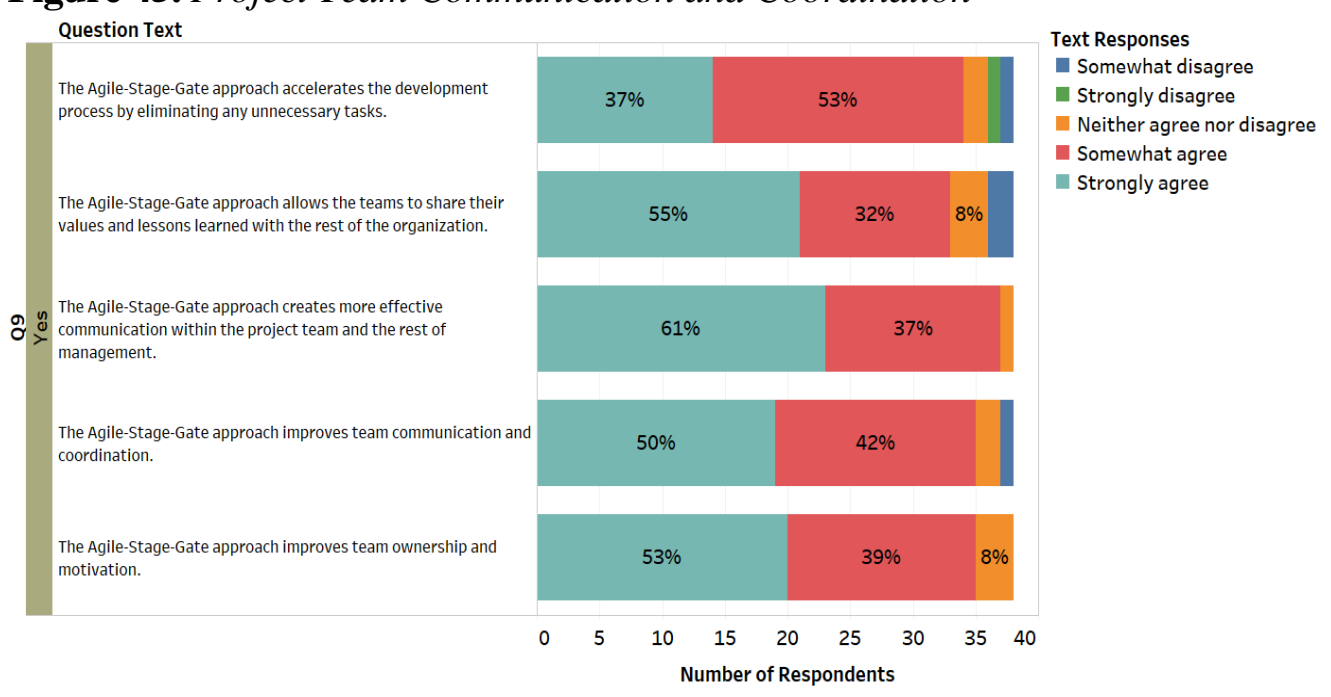

Figure 46. Project Team Communication and Coordination for Software Products

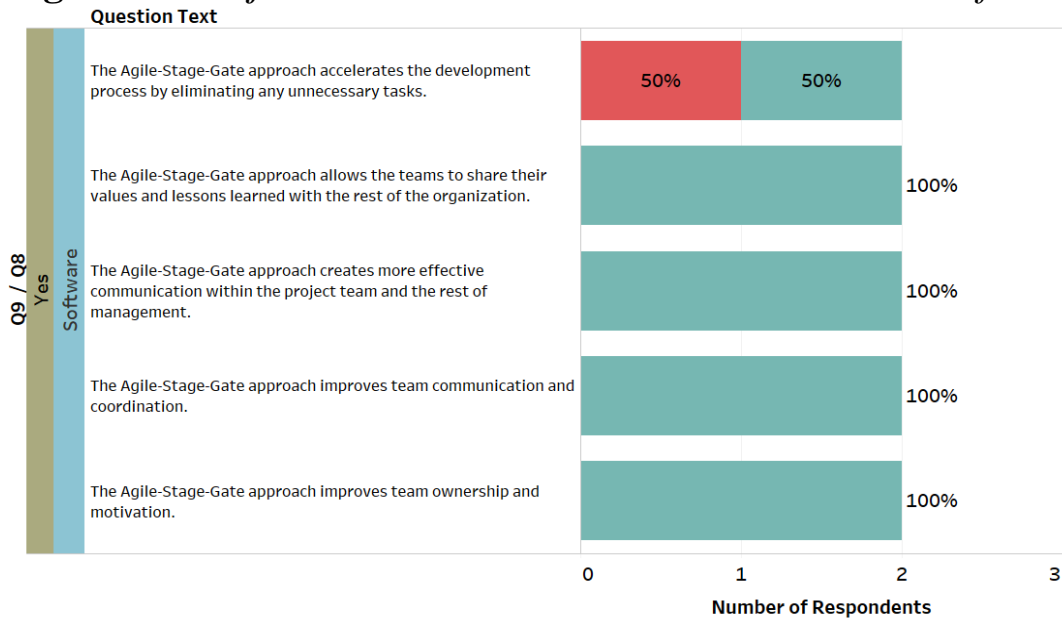

Text Responses

Strongly agree

Somewhat agree 
Figure 47. Project Team Communication and Coordination in the Agile-StageGate Approach for Hardware Products

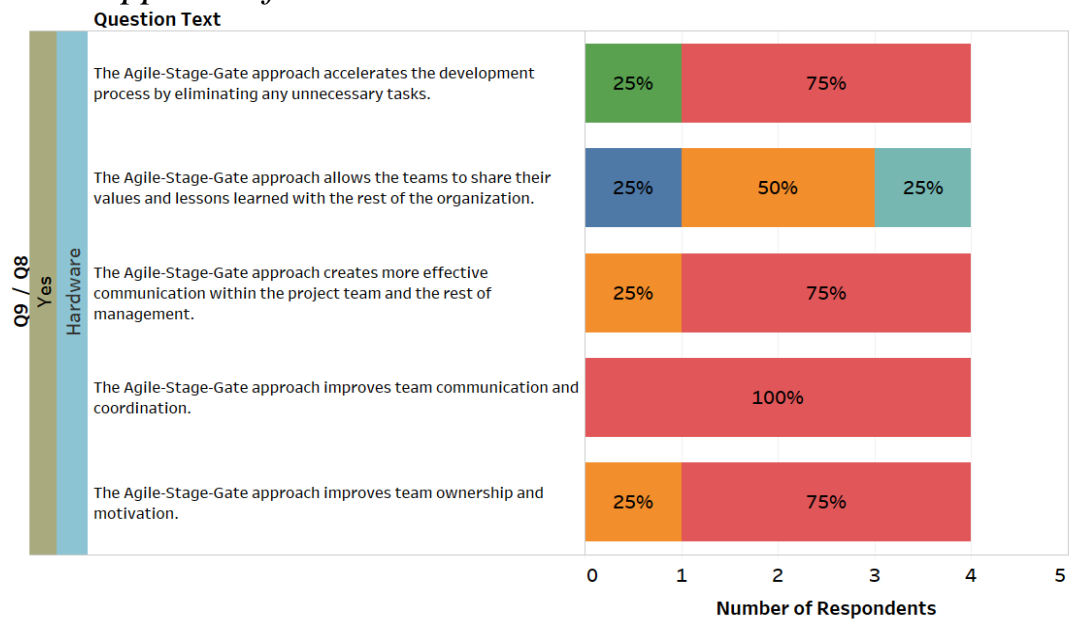

Text Responses

Strongly agree

Somewhat agree

Neither agree nor disagree

- Somewhat disagree

Strongly disagree

Figure 48. Project Team Communication and Coordination in the Agile-StageGate Approach for Combination Products

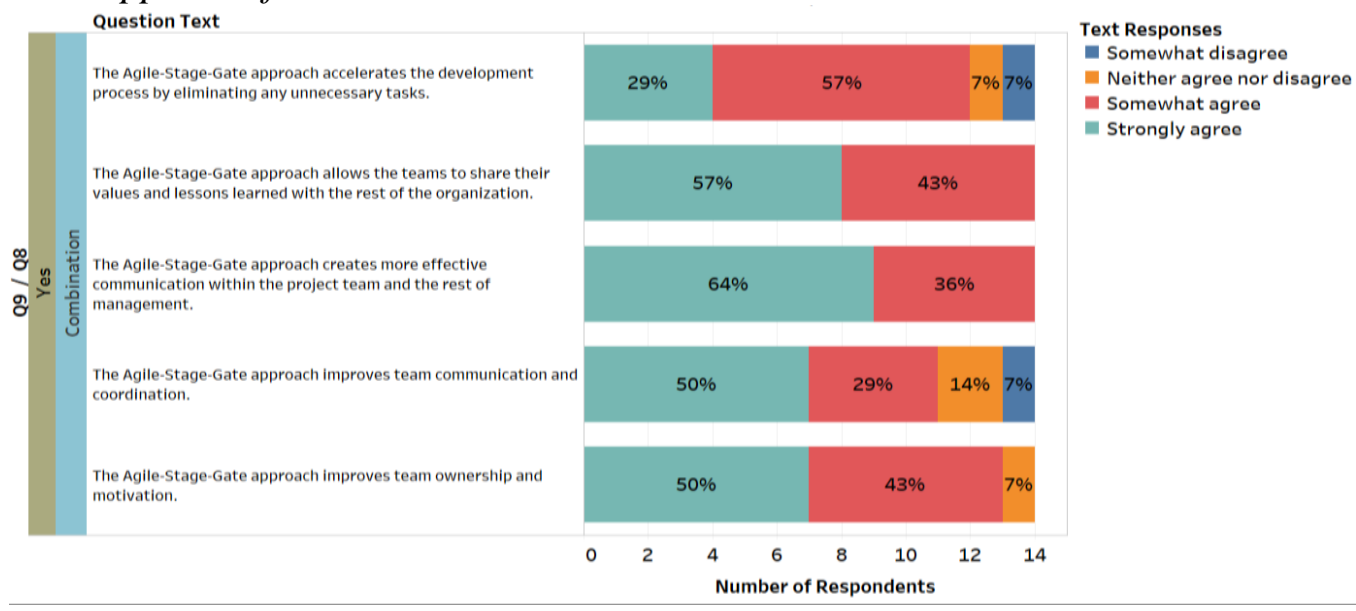

Figure 49. Project Team Communication and Coordination for New Development Products

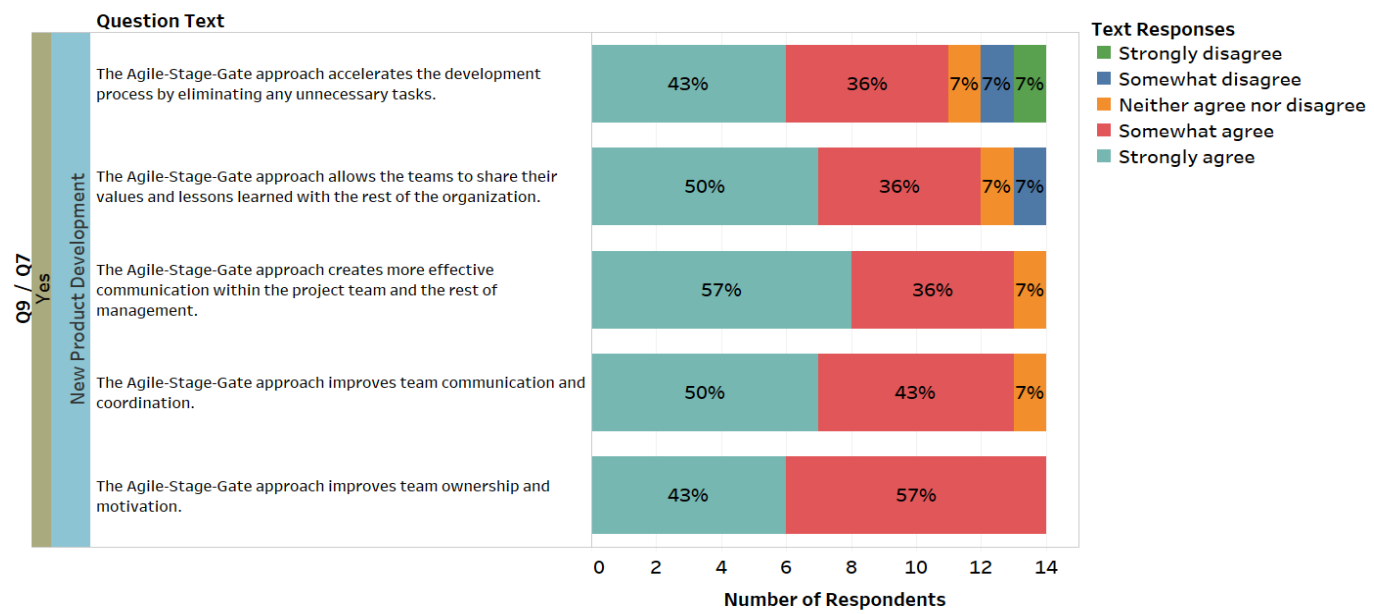


Figure 50. Project Team Communication and Coordination in the Agile-StageGate Approach for $R \& D$ Projects

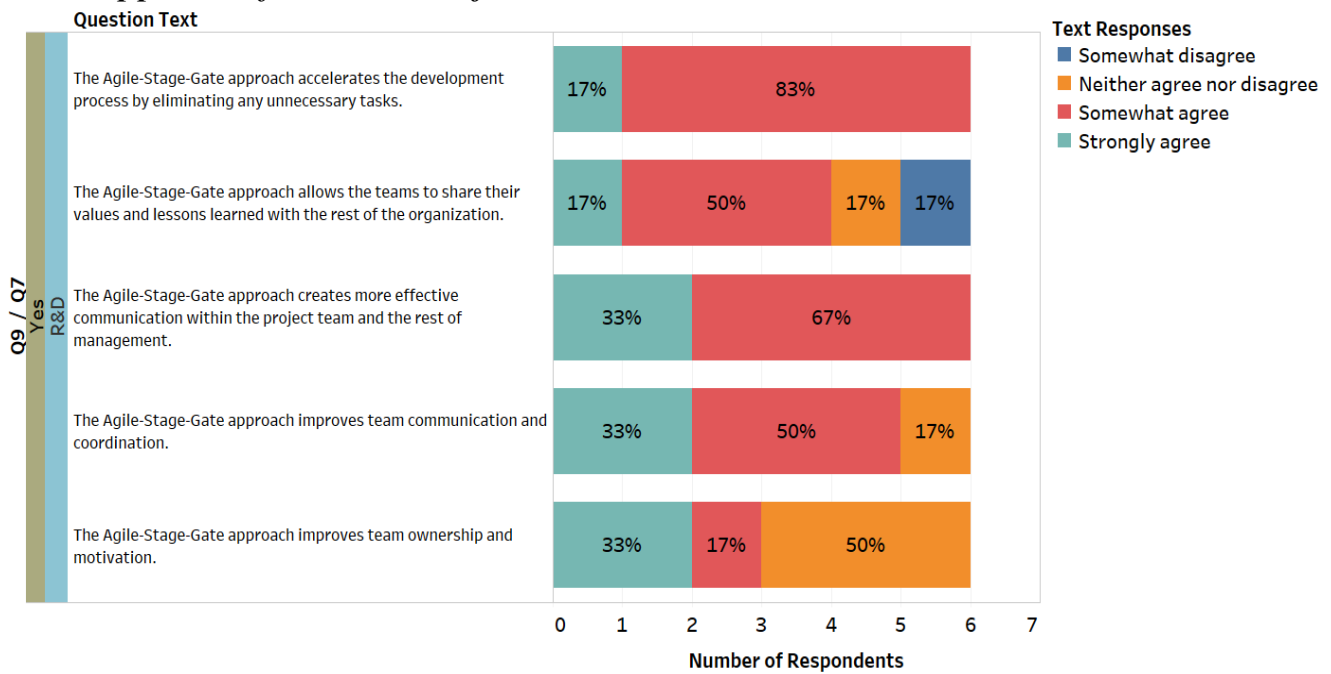

Figure 51. Project Team Communication and Coordination in the Agile-StageGate Model for Services Projects

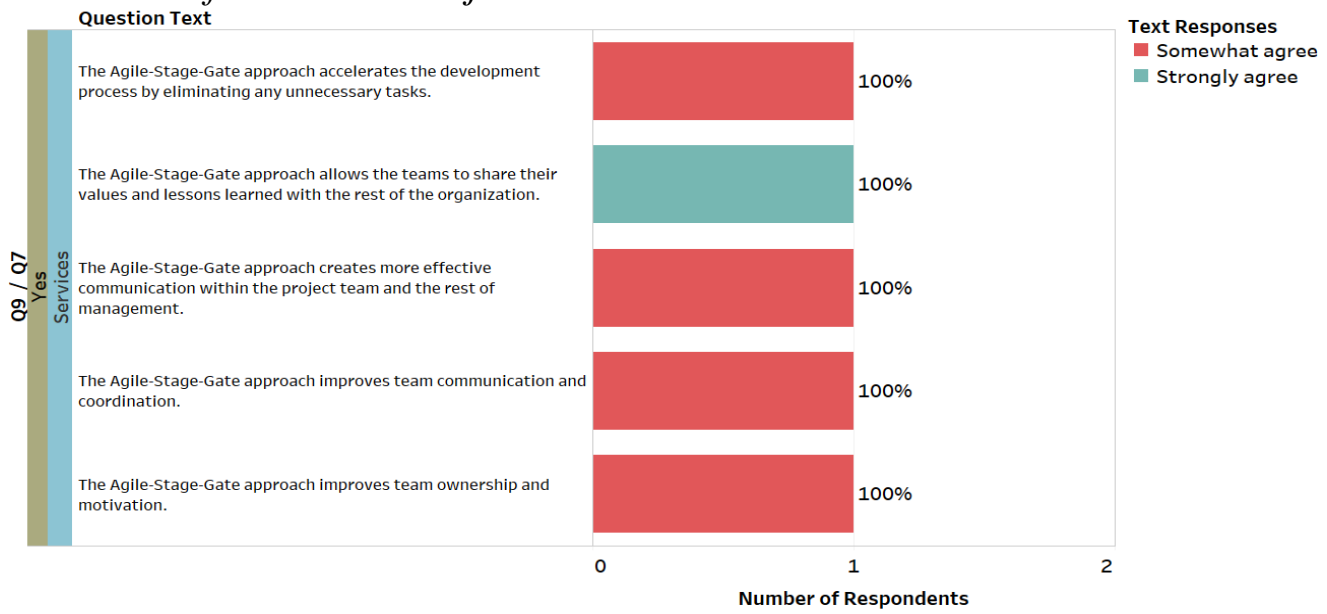

Figure 52. Implemented Tools in the Agile-Stage-Gate Approach

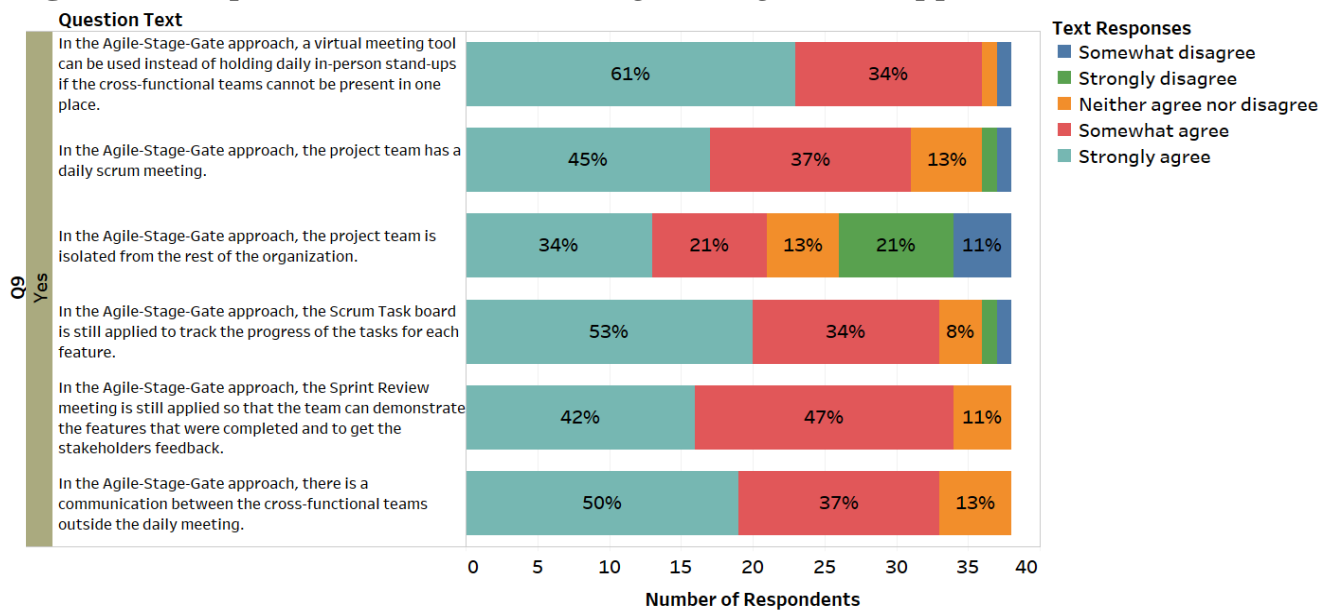


Figure 53. Agile-Stage-Gate Tools for Software Products

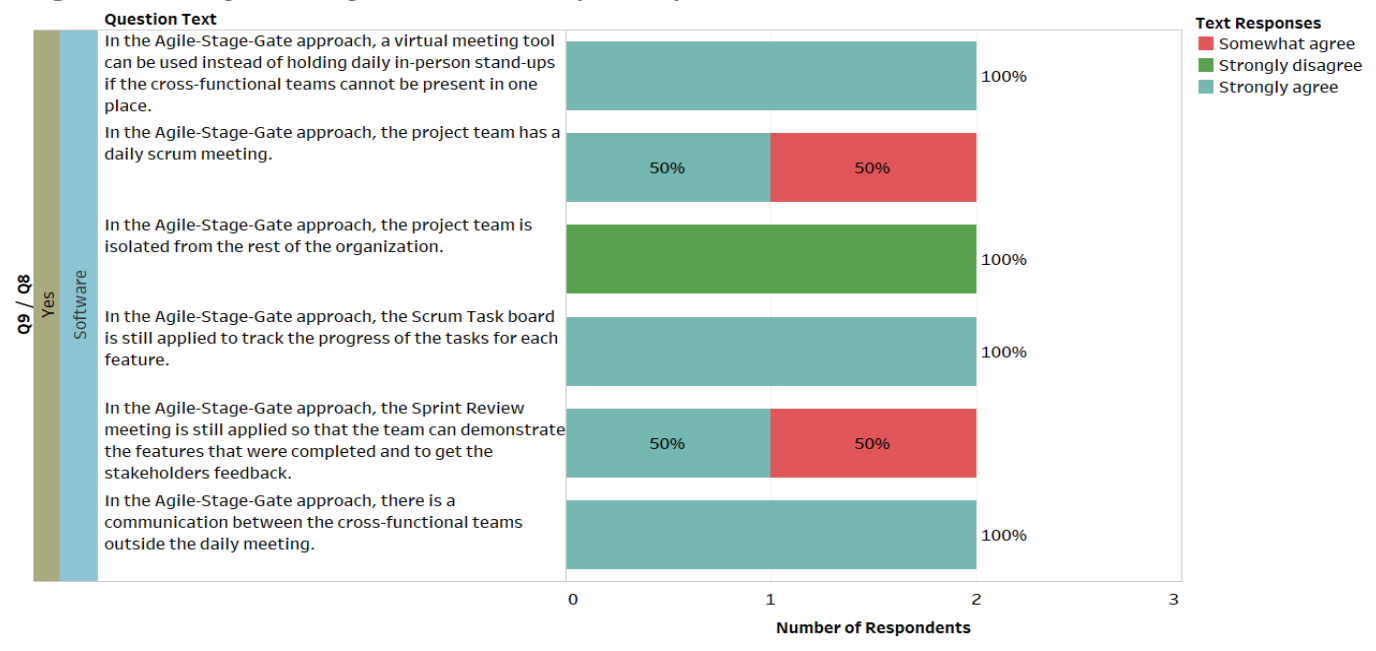

Figure 54. Agile-Stage-Gate Tools for Hardware Products

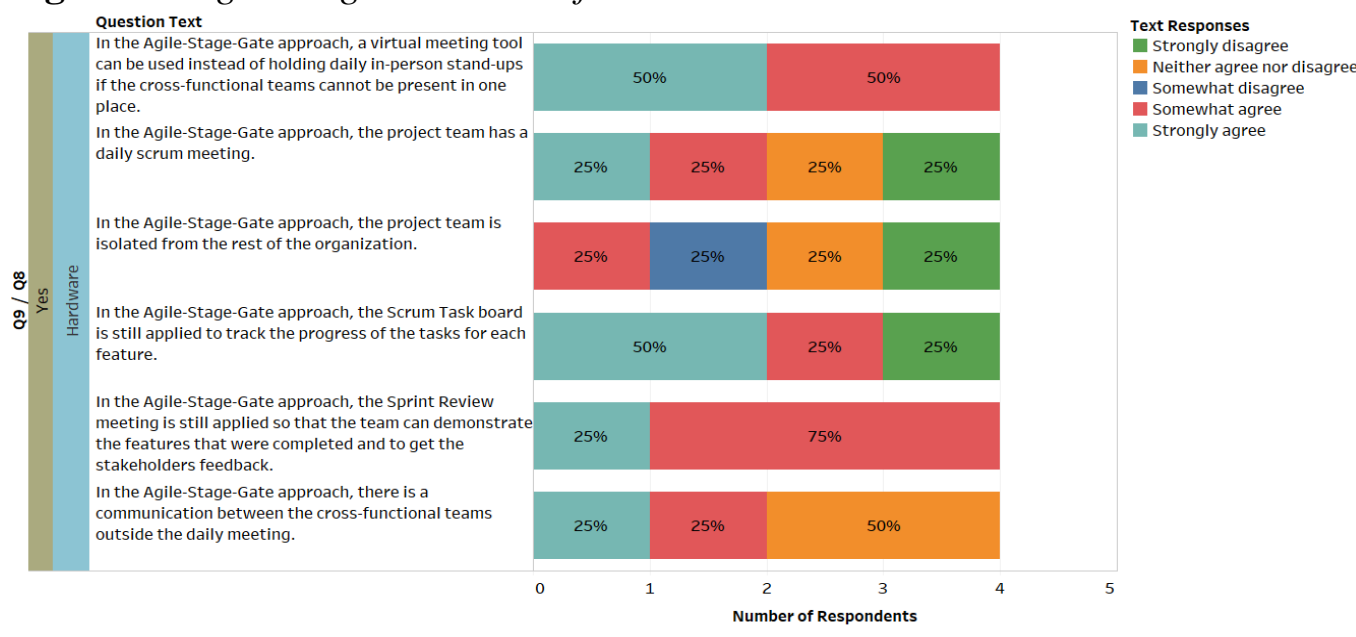

Figure 55. Agile-Stage-Gate Tools for Combination Products

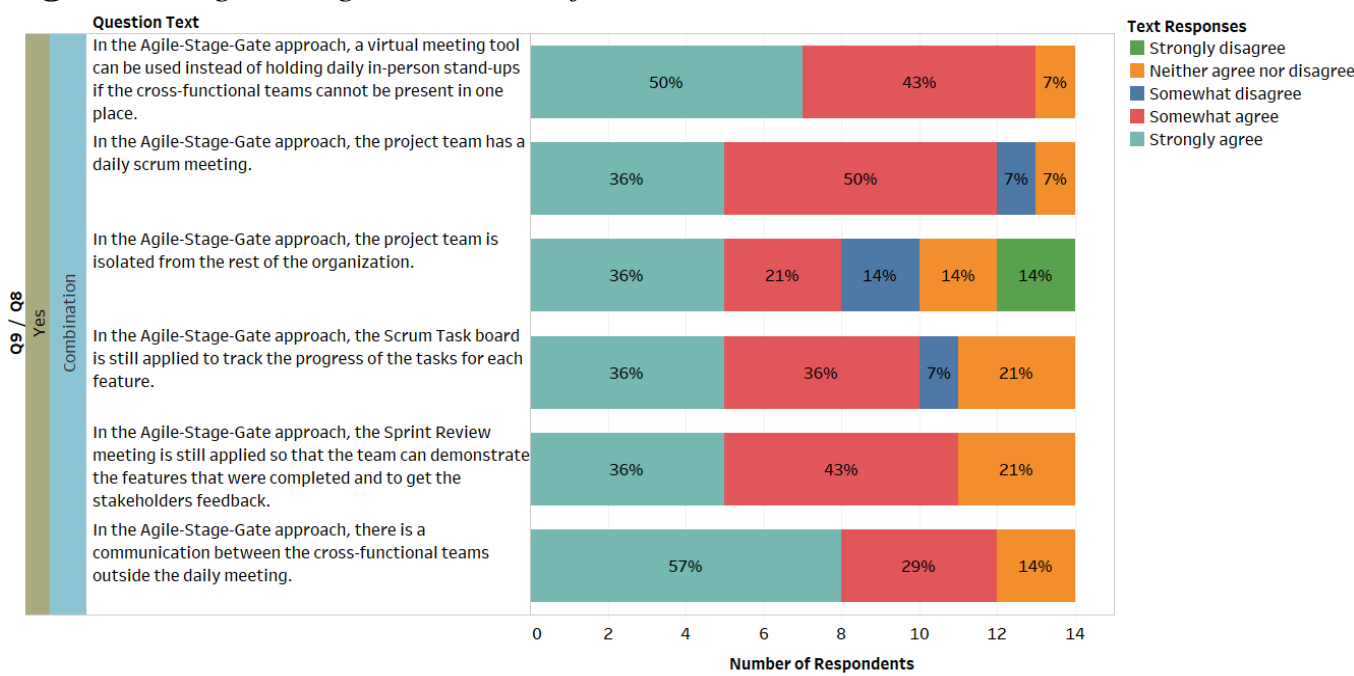


Figure 56. Agile-Stage-Gate Tools for New Product Development

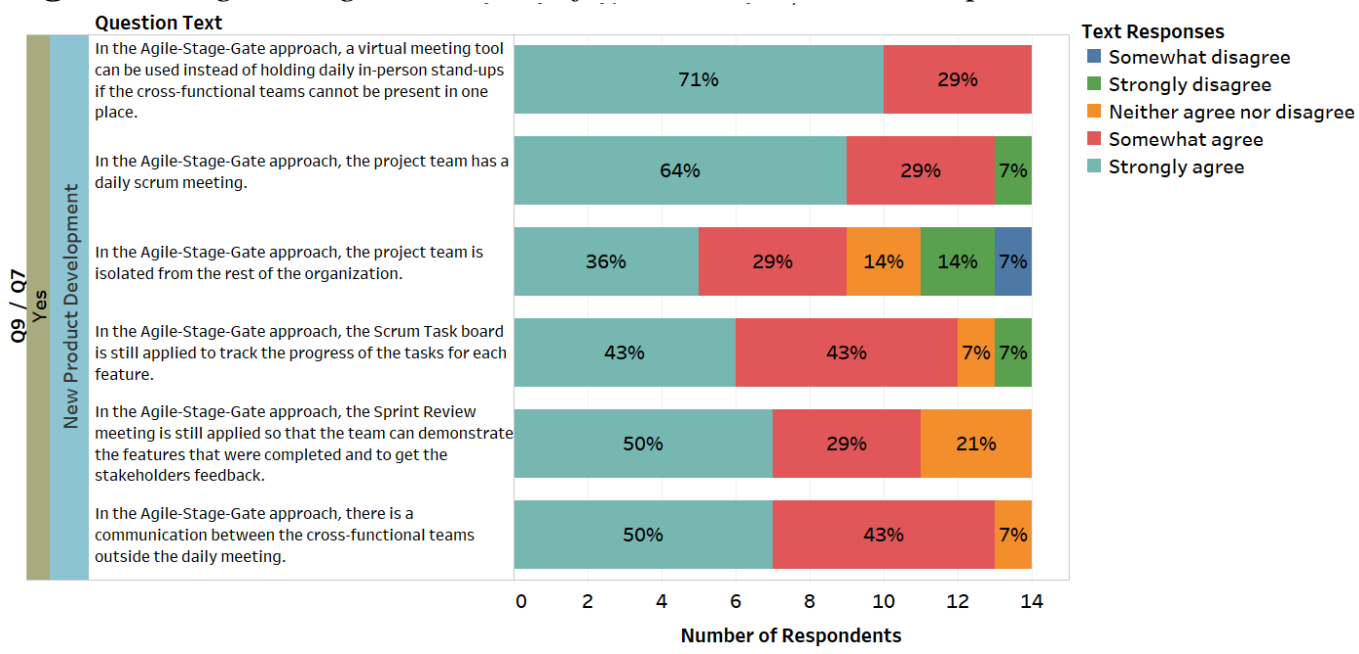

Figure 57. Agile-Stage-Gate Tools for R\&D Projects

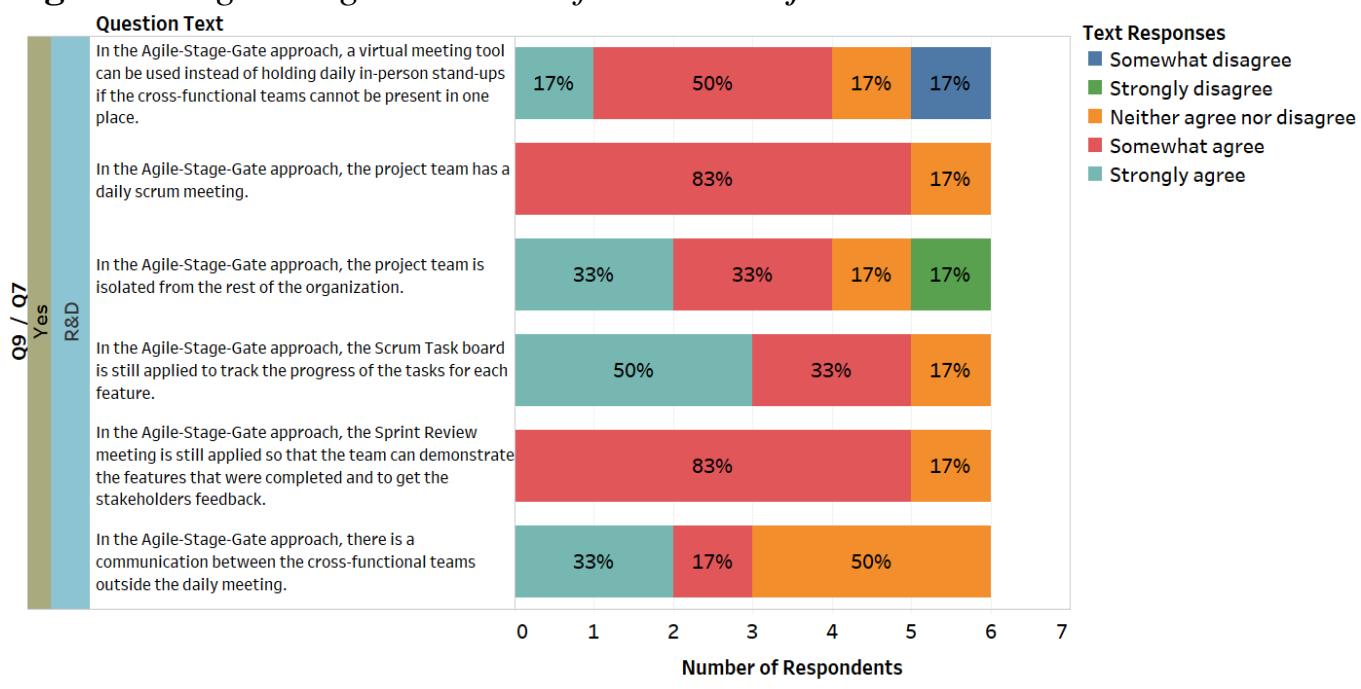

Figure 58. Agile-Stage-Gate Tools for Service Projects

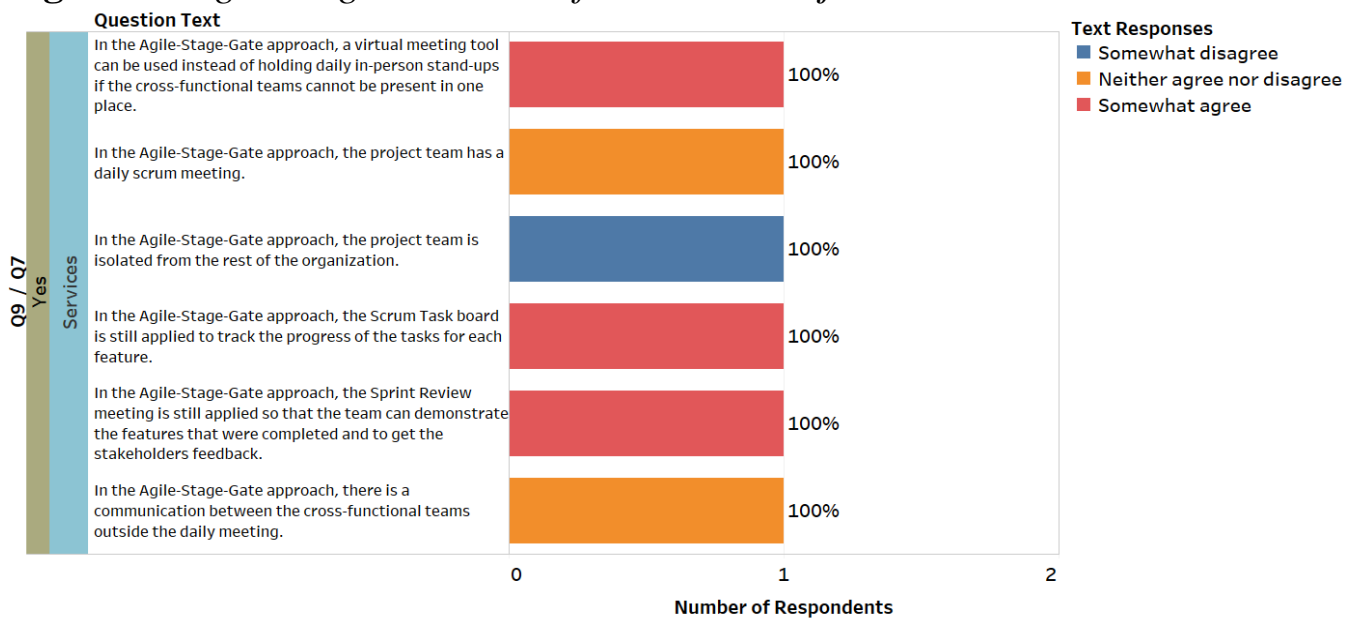


Figure 59. Organizational Strategy when Adopting the Agile-Stage-Gate Approach

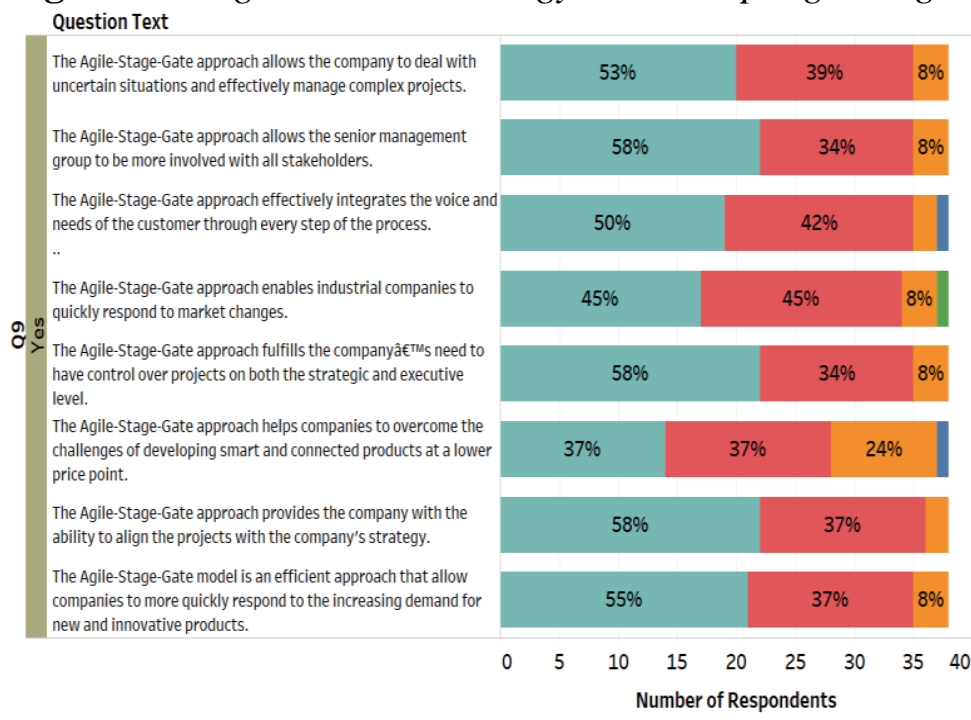

ext Responses

- Somewhat disagree

- Strongly disagree

Neither agree nor disagree

- Somewhat agree

Strongly agree

Figure 60. Organizational Strategy Using the Agile-Stage-Gate Approach for Software Products

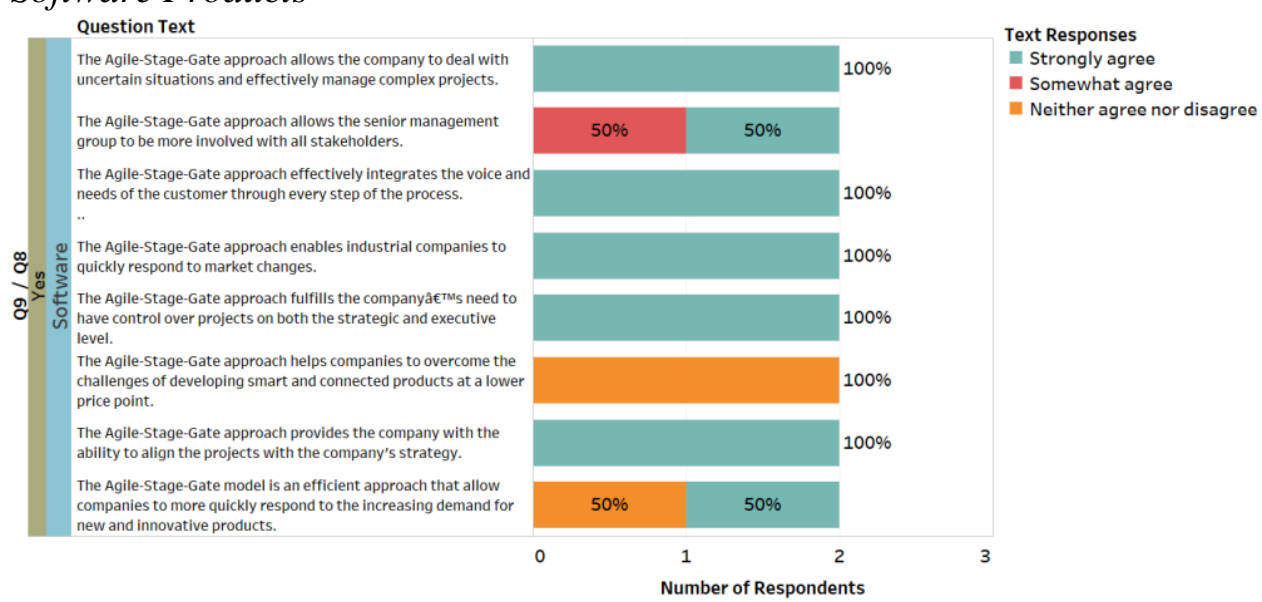

Figure 61. Company Strategy for Agile-Stage-Gate Approach for Hardware Products

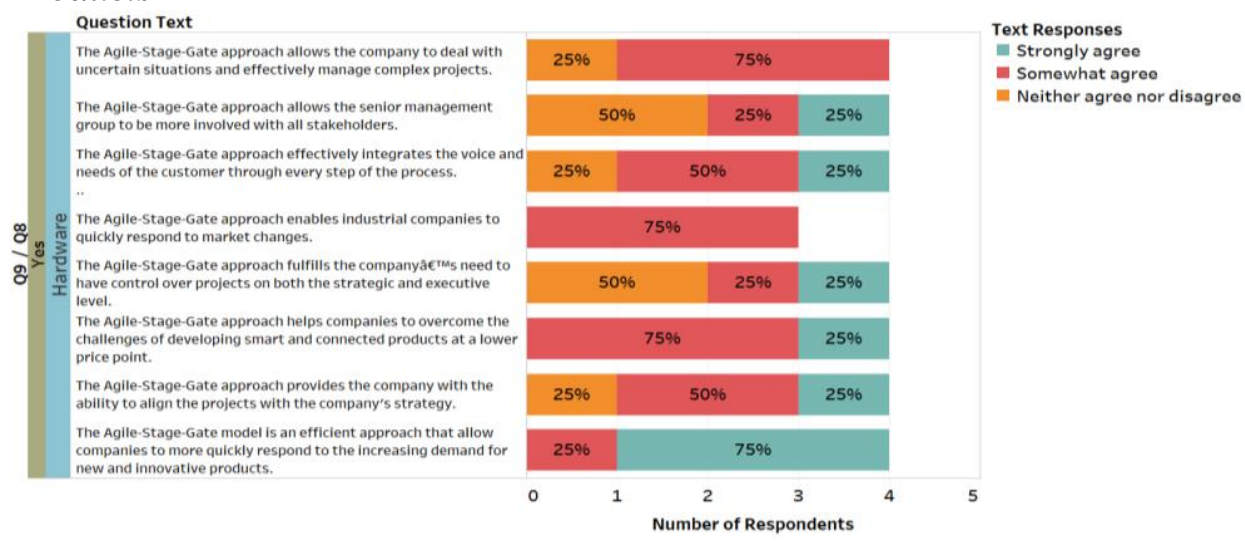


Figure 62. Company Strategy for Agile-Stage-Gate Approach for Combination Products

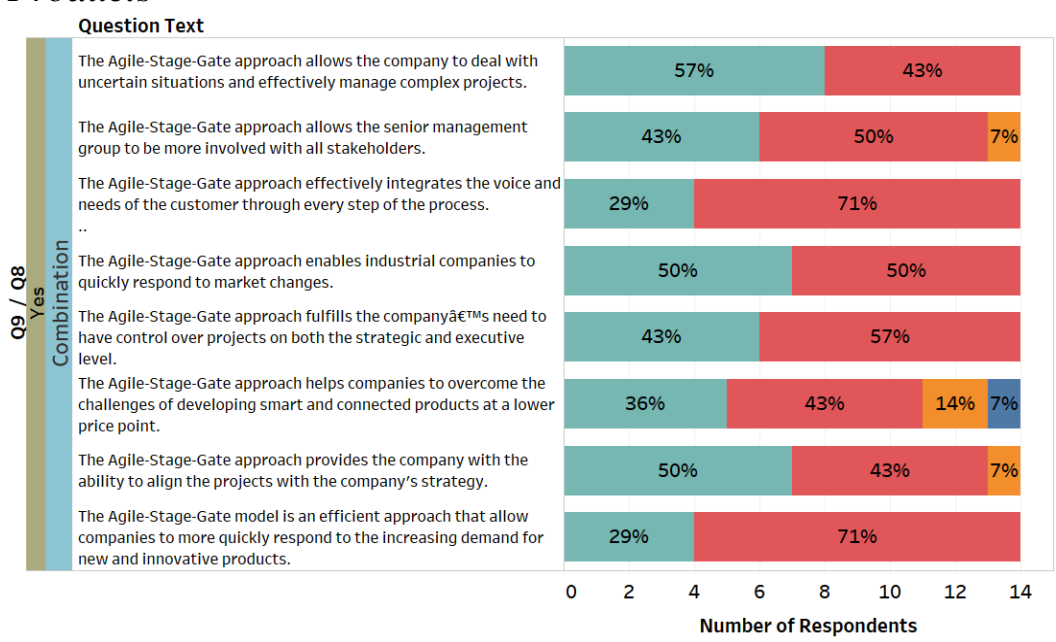

Text Responses

- Somewhat disagree

Neither agree nor disagree

- Somewhat agree

Strongly agree

Figure 63. Organizational Strategy Using the Agile-Stage-Gate Approach for New Product Development

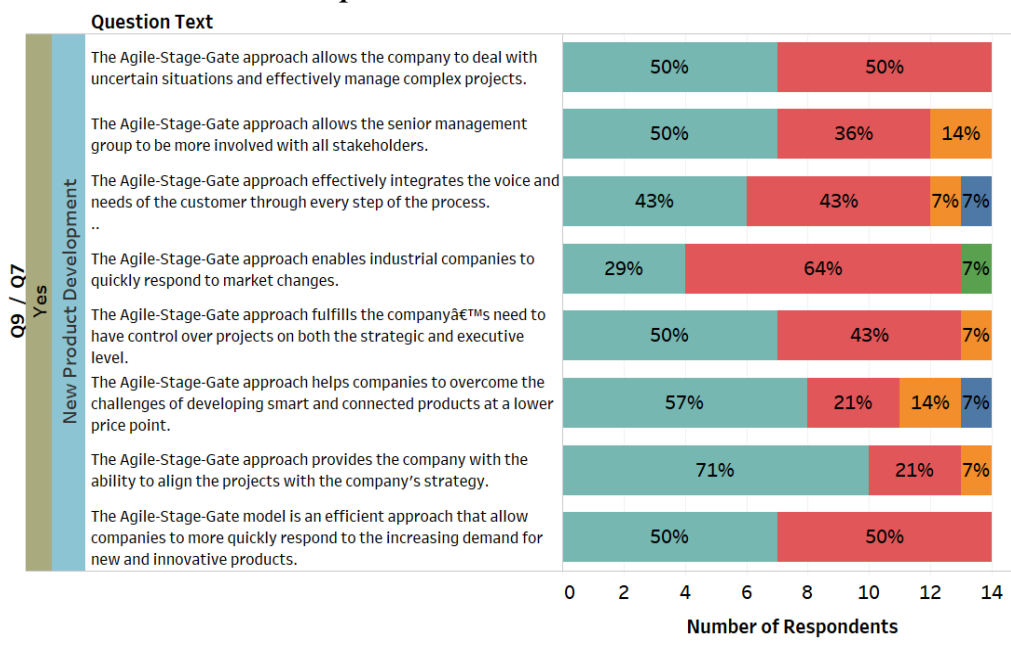

Text Responses

- Somewhat disagree

- Strongly disagree

Neither agree nor disagree

- Somewhat agreo

Strongly agree

Figure 64. Company Strategy for Agile-Stage-Gate Approach for $R \& D$ Projects

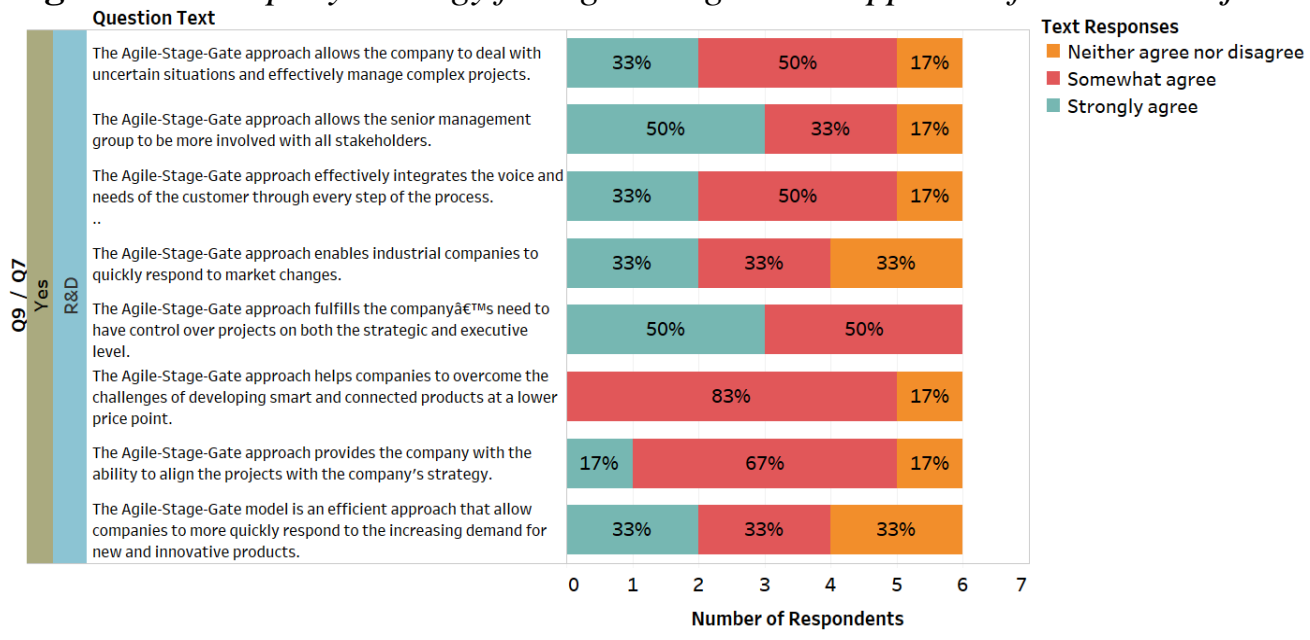


Figure 65. Company Strategy for Agile-Stage-Gate Approach for Services Projects

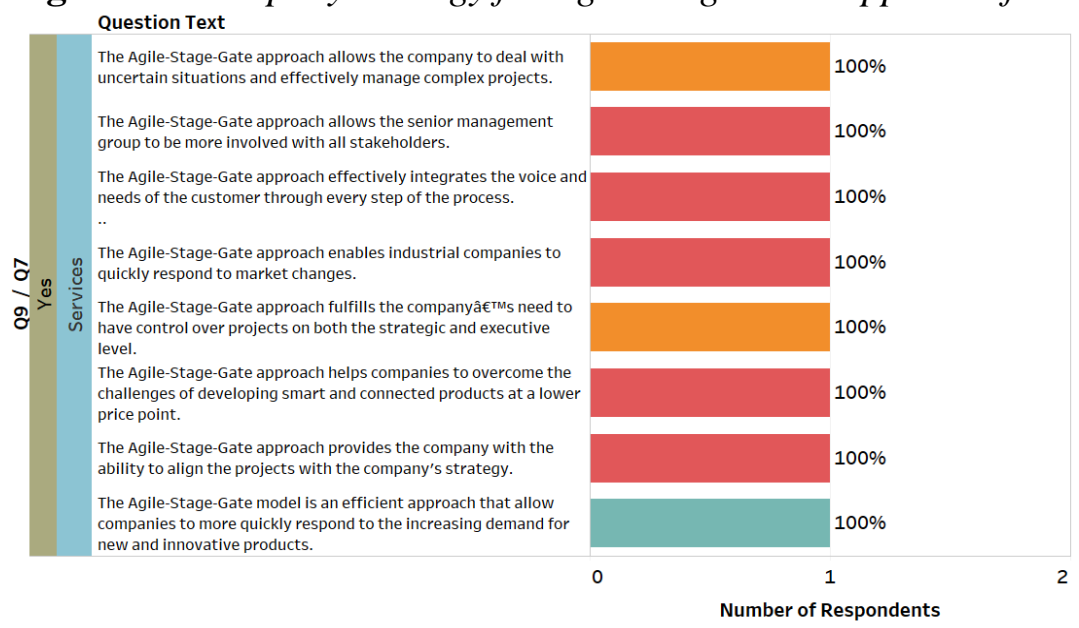

Text Responses

Neither agree nor disagree

- Somewhat agree

Strongly agree

Figure 66. Agile-Stage-Gate Performance Rate

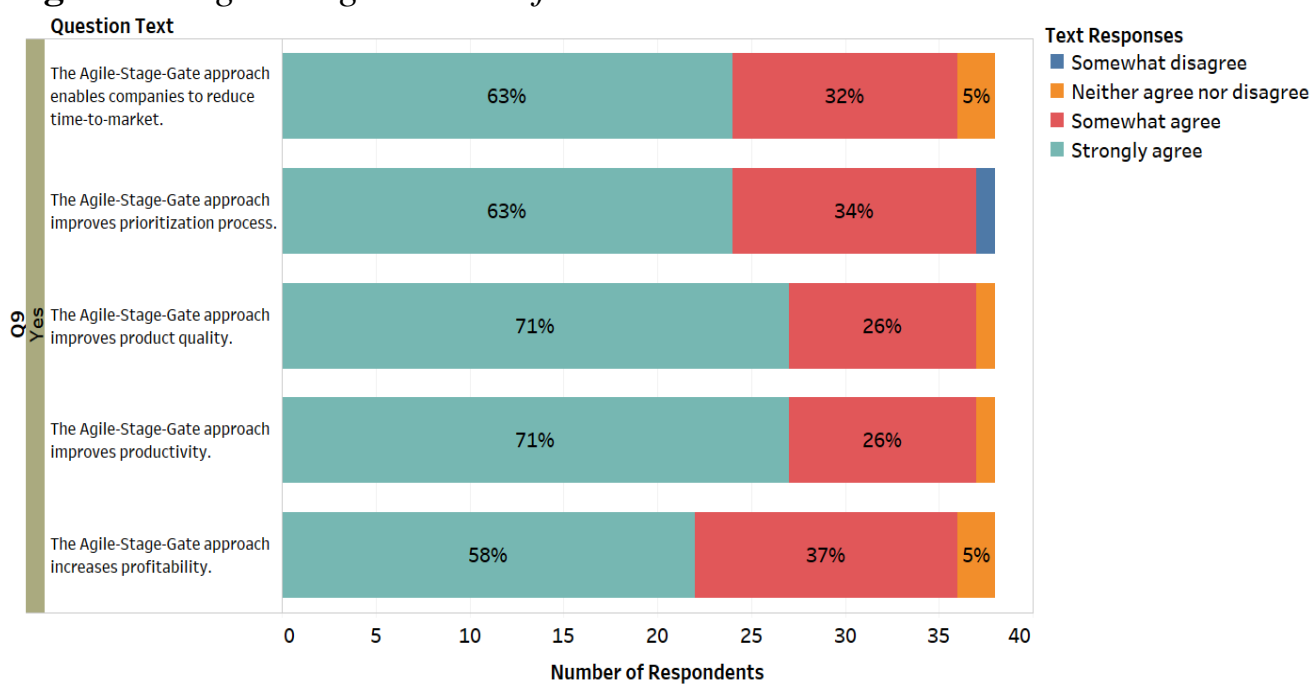

Figure 67. Agile-Stage-Gate Performance rate for Software Products

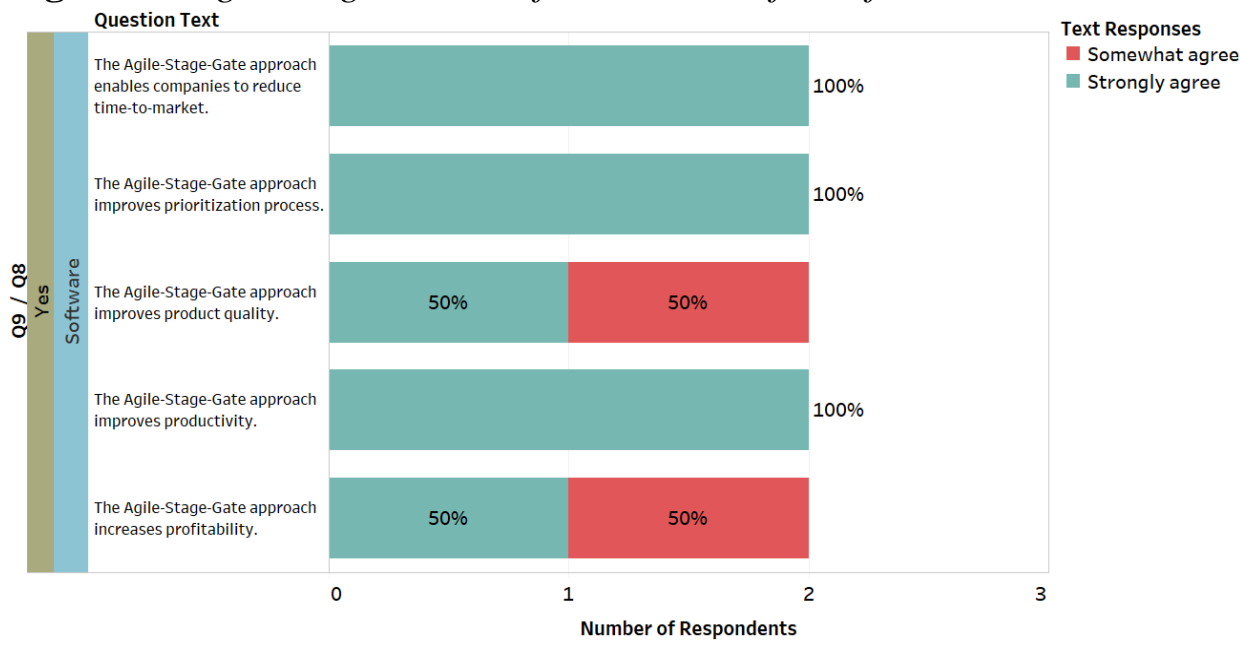


Figure 68. Agile-Stage-Gate Performance Rate for Hardware Products

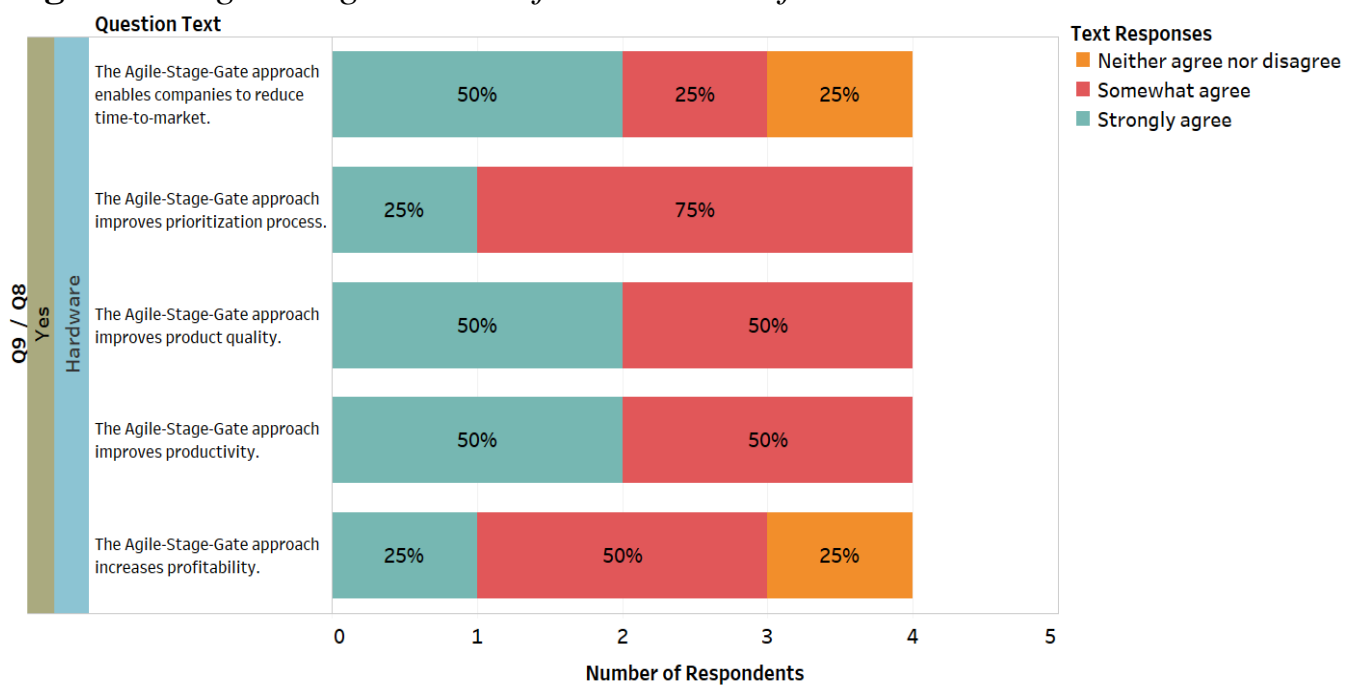

Figure 69. Agile-Stage-Gate Performance Rate for Combination Products

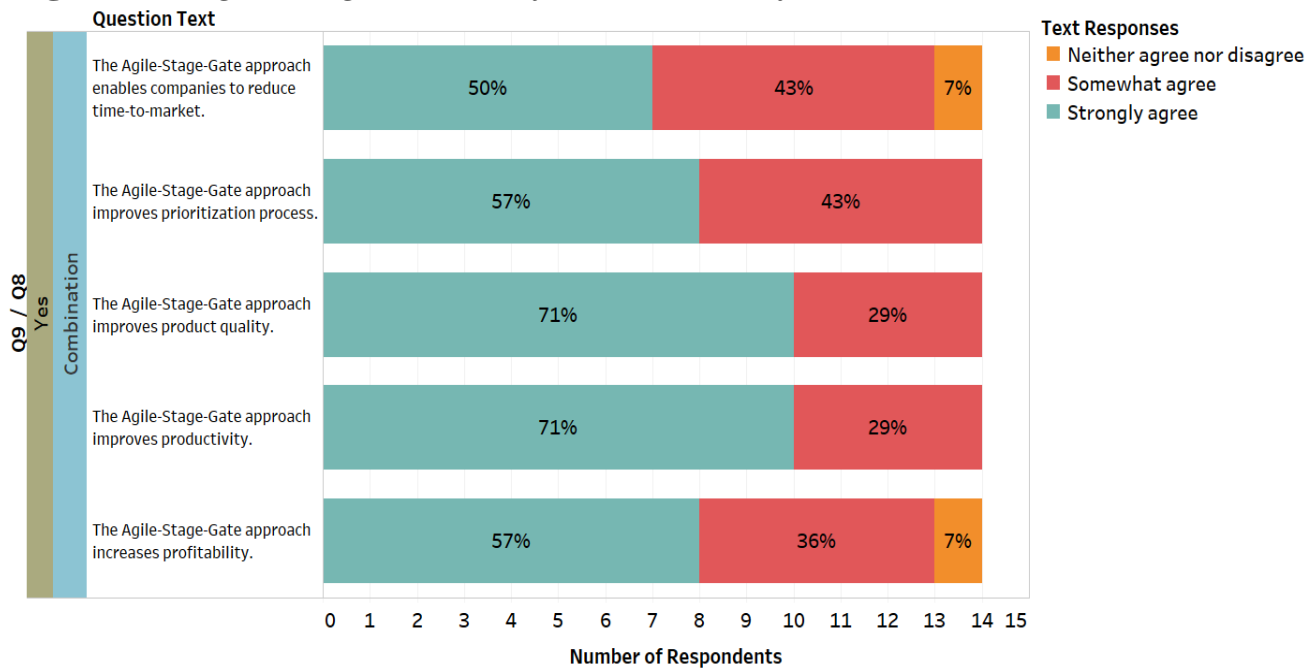

Figure 70. Agile-Stage-Gate Performance Rate for New Product Development

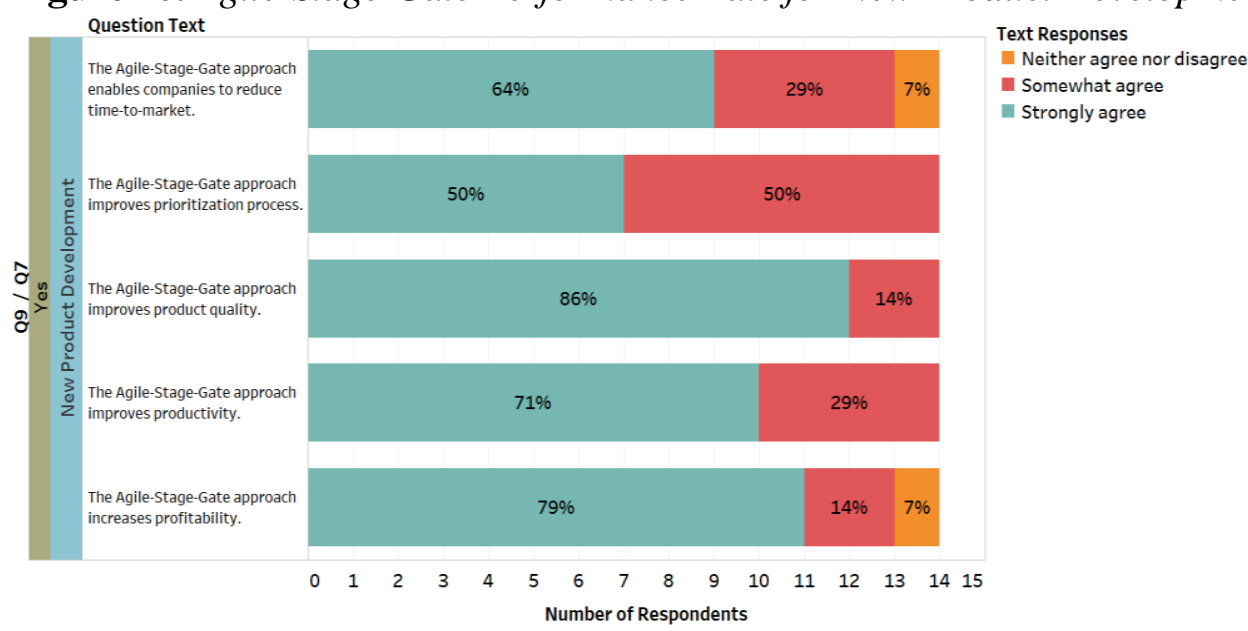


Figure 71. Agile-Stage-Gate Performance Rate for R\&D Projects

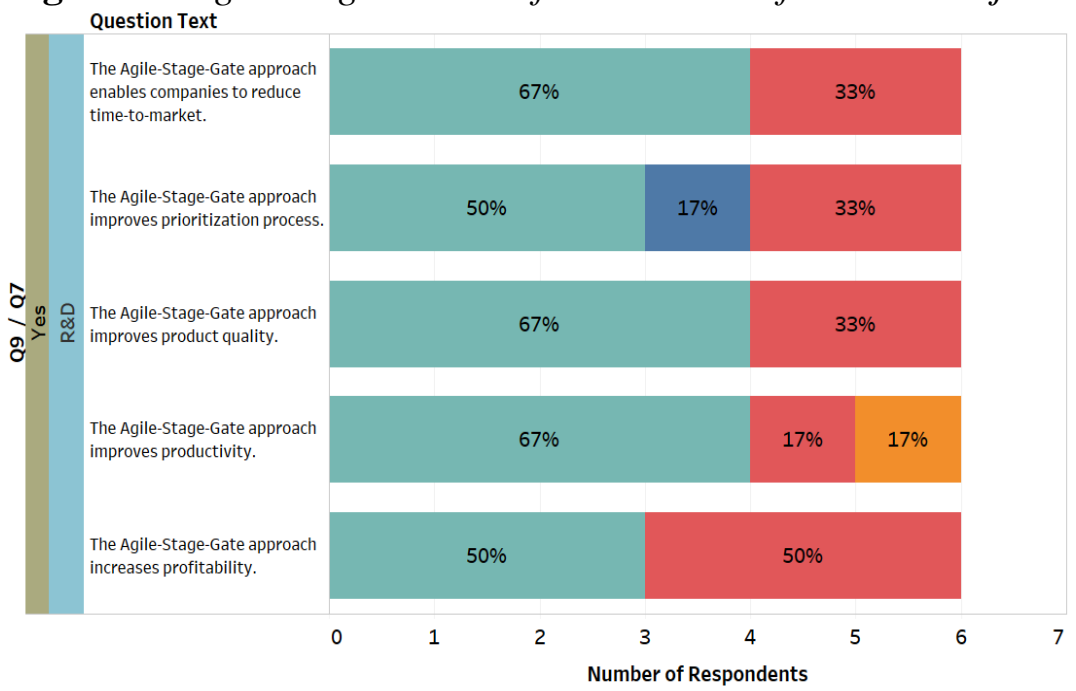

Text Responses

Neither agree nor disagree

- Somewhat agree

Somewhat disagree

Strongly agree

Figure 72. Agile-Stage-Gate Performance Rate for Services Projects

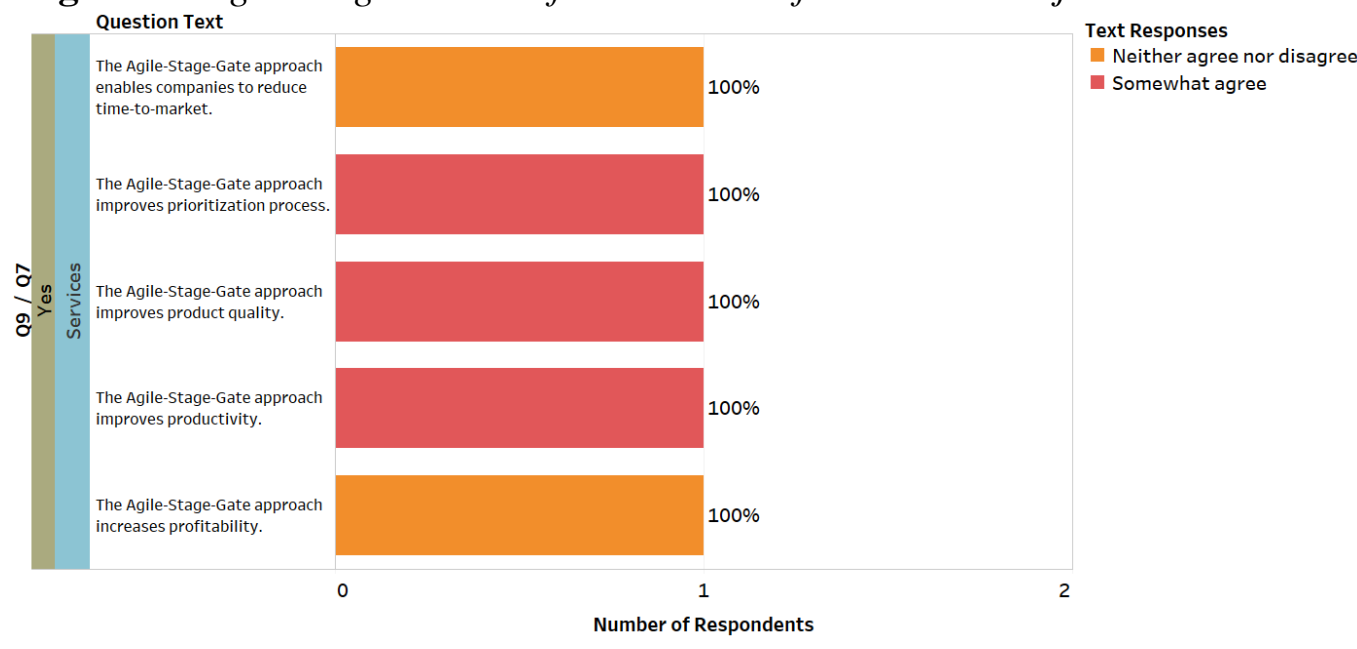


